\title{
PROCESS DEVELOPMENT FOR BIOMASS DELIGNIFICATION USING A DEEP EUTECTIC SOLVENT
}

Dion Smink 



\title{
PROCESS DEVELOPMENT FOR BIOMASS DELIGNIFICATION USING A DEEP EUTECTIC SOLVENT
}

\author{
PROEFSCHRIFT
}

ter verkrijging van

de graad van doctor aan de Universiteit Twente, op gezag van de rector magnificus,

Prof.dr. T.T.M. Palstra, volgens besluit van het College voor Promoties in het openbaar te verdedigen vrijdag 3 juli 2020 om 12.45 uur

door

\section{Dion Smink}

Geboren op 4 mei 1993

te Doetinchem, Nederland 
Dit proefschrift is goedgekeurd door:

Promotors

prof. dr. ir. B. Schuur

prof. dr. S.R.A. Kersten

Cover design: $\quad$ Gildeprint

Printed by: Gildeprint

Lay-out: Dion Smink

ISBN: 978-90-365-5029-1

DOI: $\quad 10.3990 / 1.9789036550291$

This project received funding from the Bio-Based Industries Joint Undertaking under the European Union's Horizon 2020 research and innovation programme under grant agreement Provides No. 668970 and was co-funded by TKI E\&I with the supplementary grant 'TKI-Toeslag' for Topconsortia for Knowledge and Innovation (TKI's) of the Ministry of Economic Affairs and Climate Policy.

(c) 2020 Dion Smink, The Netherlands. All rights reserved. No parts of this thesis may be reproduced, stored in a retrieval system or transmitted in any form or by any means without permission of the author. Alle rechten voorbehouden. Niets uit deze uitgave mag worden vermenigvuldigd, in enige vorm of op enige wijze, zonder voorafgaande schriftelijke toestemming van de auteur. 


\section{PROMOTIECOMMISSIE:}

Voorzitter

Promotors

Leden prof. dr. J.L. Herek

prof. dr. ir. B. Schuur

prof. dr. S.R.A. Kersten

prof. dr. A.J.D. Silvestre

prof. dr. ir. E. Zondervan

prof. dr. ir. W. de Jong

prof. dr. ir. J. Huskens

prof. dr. H.J.M. Bouwmeester 


\section{Samenvatting}

Lignocellulose biomassa is de meest beschikbare, hernieuwbare grondstof op deze aarde. Het vervangen van fossiele grondstoffen, zoals olie, steenkool en aardgas, in de chemische industrie zal een grote reductie van de $\mathrm{CO}_{2}$ uitstoot van de chemische industrie opleveren. Echter, de beschikbaarheid van biomassa is beperkt. Daarom is het van groot belang om deze grondstof zo efficiënt mogelijk te gebruiken. Op dit moment is het meest gebruikte proces om biomassa te verwerken het kraft proces. Hierin wordt de lignine uit biomassa verwijderd met een oplossing van natriumhydroxide en natriumsulfide. De geproduceerde cellulosepulp wordt voornamelijk gebruikt voor de productie van papier. Helaas wordt maar de helft van de grondstof gebruikt om papier van te maken. De andere helft wordt verbrand om warmte te genereren en natriumsulfide terug te winnen. Processen die meerdere producten uit hout kunnen maken, waaronder naast cellulosepulp ook lignine en/of furanen zijn noodzakelijk om de wereldwijde $\mathrm{CO}_{2}$ uitstoot te verminderen.

Diepe eutectische oplosmiddelen (DES) zijn samengestelde oplosmiddelen die diep eutectisch gedrag vertonen bij het mengen. Deze oplosmiddelen hebben veel potentie om te worden toegepast voor delignificatie en kunnen niet alleen cellulosepulp, maar ook andere waardevolle bijproducten uit biomassa maken, zoals lignine en furanen. Daarom kunnen processen die gebruikmaken van deze DES efficiënter gebruikmaken van de biomassa grondstof dan het kraft proces. Er zijn echter een aantal kwesties die moeten worden verholpen voordat deze processen op grote schaal kunnen worden toegepast. Allereerst zijn de voordelen van de DES samenstellingen nog relatief onbekend. Ook zijn de methodes die beschikbaar zijn voor de terugwinning van lignine uit DES voornamelijk toepasbaar op laboratoriumschaal. Procedures voor in het laboratorium zijn niet altijd toepasbaar op industriële schaal en meer onderzoek is nodig om het pulpproces beter te begrijpen, net als de terugwinning van het oplosmiddel. In dit proefschrift worden deze kwesties behandeld, waarna een conceptueel proces wordt voorgesteld waarin lignine wordt verwijderd uit Eucalyptus globulus met een DES bestaande uit choline chloride en melkzuur.

In hoofdstuk 2 wordt een studie naar de rol van choline chloride op de delignificatie van biomassa met DESsen die melkzuur bevatten beschreven. Hiervoor zijn pulpexperimenten uitgevoerd met $E$. globulus op $120^{\circ} \mathrm{C}$ met een duur van 8 uur een DES tot biomassa ratio van 20:1. Verschillende experimenten zijn uitgevoerd waarbij de invloed van choline chloride op de lignine oplosbaarheid, afbraakreacties en massatransport is onderzocht om tot een beter begrip te komen van de gemeten pulpresultaten. Hieruit is geconcludeerd dat het chloride anion het actieve bestandsdeel is van choline chloride is waardoor de delignificatiesnelheid wordt vergroot. Het veel goedkopere $\mathrm{NaCl}$, oftewel keukenzout, 
werkte wat dat betreft net zo goed. Verder is choline chloride al effectief in een molratio van 1:250 ten opzicht van melkzuur. Uit studies op gemalen hout lignine is vastgesteld dat choline chloride het breken van de $\beta-0-4$ bindingen in lignine versnelt en daardoor de delignificatiesnelheid van biomassa verhoogt. Ook verlaagde choline chloride de oplosbaarheid van lignine in de DES en verlaagde het de geschatte massatransport coëfficiënt door een verhoging van de viscositeit. Een model is toegepast om de kraaksnelheid van lignine te bepalen. Deze kraaksnelheid nam $90 \%$ toe met de toevoeging van choline chloride aan melkzuur. Kort samengevat wordt de delignificatiesnelheid van eucalyptus door melkzuur verhoogd door toevoeging van halogeniden.

In hoofdstuk $\mathbf{3}$ is een nieuwe methode ontwikkeld om lignine terug te winnen uit DES. In het laboratorium wordt de DES aan een grote hoeveelheid water toegevoegd, waardoor de lignine precipiteert. Wanneer deze methode op industriële schaal wordt toegepast moet het water vervolgens weer uit de DES worden verdampt, wat zeer veel energie kost. Daarom is er een alternatieve methode ontwikkeld die gebruikt maakt van vloeistof-vloeistof extractie (LLX). De terugwinning van lignine uit DES met deze methode was onderzocht voor verschillende melkzuur tot choline chloride ratio's. Hiervoor zijn eerst zes oplosmiddelen gescreend, waaruit 2-methyltetrahydrofuran (2-MTHF) is geselecteerd als meest geschikte oplosmiddel voor vervolgstudies. Het fase evenwicht tussen 2-MTHF en de DES is bepaald op 25,50 en $75^{\circ} \mathrm{C}$. Er is op evenwicht ten minste $30 \%$ choline chloride in de DES nodig om twee fases te vormen. Het toevoegen van meer choline chloride verlaagd de wederzijdse oplosbaarheid van 2-MTHF en melkzuur. De evenwichtsverdeling van lignine tussen de DES en 2-MTHF veranderde nauwelijks met veranderende DES composities, maar de evenwichtsverdeling was sterk afhankelijk van de molecuulmassa van de lignine. De ligninefractie met een lage molecuulmassa had een verdelingscoëfficiënt van 1 , terwijl de ligninefractie met een hoge molecuulmassa een verdelingscoëfficiënt van 0,1 had. De toevoeging van een beetje water veranderde het systeem drastisch, waardoor met name de extractie van de ligninefractie met een hoge molecuulmassa sterk verbeterde. Wanneer er $25 \%$ water in de DES aanwezig is stijgt de verdelingscoëfficiënt van elke ligninefractie tot boven de 4, wat een efficiënte extractie van lignine uit DES met 2-MTHF mogelijk maakt.

In hoofdstuk 4 is de terugwinbaarheid van lignine uit DES middels LLX en precipitatie in koud water onderzocht dieper onderzocht, inclusief extracties in meerdere stappen en analyses op de geëxtraheerde lignine fracties. Opgeloste lignine in de DES is niet homogeen, wat betekent dat het bestaat uit verschillende fracties met verschillende molecuulmassa's en mogelijk ook verschillende dichtheden van functionele groepen. Daarom is een vergelijking tussen de terugwinbaarheid middels LLX en precipitatie erg belangrijk. Hiervoor is de terugwinning van lignine uit een DES bestaande uit 30\% choline chloride en $70 \%$ melkzuur onderzocht door drie dwarsstroomextracties met 2-MTHF. Hiermee kon 95\% van de lignine met een molecuulmassa rond de $2.000 \mathrm{~g} / \mathrm{mol}$ en $85 \%$ van de lignine met een molecuulmassa 
rond de $10.000 \mathrm{~g} / \mathrm{mol}$ worden geëxtraheerd. In de resterende ligninefractie in de DES zijn geen inter-aromatische etherbindingen gevonden met heteronucleaire, enkelvoudige kwantum-coherentie spectroscopie (HSQC). Dit duidt erop dat de ligninefractie die in de DES achterblijft een sterk gecondenseerd is. Middels precipitatie in koud water kon alle lignine met een molecuulmassa van meer dan $4.000 \mathrm{~g} / \mathrm{mol}$ worden geëxtraheerd door toevoeging van $3,5 \mathrm{~kg}$ water per $\mathrm{kg}$ DES. Echter, van de fractie met een molecuulmassa rond $1.000 \mathrm{~g} / \mathrm{mol}$ kon met deze methode slechts de helft van de lignine worden teruggewonnen. Kort gezegd is LLX geschikter voor de terugwinning van ligninefracties met een lage molecuulmassa, terwijl precipitatie in koud water geschikter is voor de terugwinning van de ligninefracties met een hoge molecuulmassa. Voor industriële toepassingen zal een combinatie van beide technieken noodzakelijk zijn om de lignine volledig terug te winnen uit de DES.

In hoofdstuk $\mathbf{5}$ is een conceptueel ontwerp gemaakt voor de delignificatie van E. globulus middels een DES bestaande uit 30\% choline chloride en $70 \%$ melkzuur. In dit ontwerp worden lignine en afbraakproducten van hemicellulose teruggewonnen uit de DES middels LLX met 2-MTHF als oplosmiddel. Er zijn materiaal- en energiebalansen voor dit proces opgesteld en het proces is geoptimaliseerd op het energieverbruik middels aanvullende experimenten. De hoeveelheid DES die benodigd is voor het proces kon worden verminderd tot de hoeveelheid die nodig is om de poriën in de biomassa te vullen (5 kg DES per kg biomassa), zonder dat dit sterk ten koste ging van de celluloseopbrengst of delignificatiegraad. Het direct terugvoeren van lignine-in-DES mengsels, zonder terugwinning van lignine, kan extra energiebesparingen opleveren, maar dit weegt niet op tegen de extra verhoging de molecuulmassa van de lignine die dit tot gevolg heeft. Hierdoor zal de waarde van de lignine verminderen en het moeilijker zijn om de lignine terug te winnen middels LLX. Na de energie optimalisatie was het totale warmteverbruik van het voorgestelde proces $8,4 \mathrm{GJ}$ per ton cellulosepulp, wat $24 \%$ minder is dan het kraft proces. Een bijkomend voordeel van dit proces is de mogelijkheid tot het winnen van andere bijproducten, zoals lignine en furanen die worden gevormd uit hemicellulose. 


\section{Summary}

Lignocellulosic biomass is the most abundantly available sustainable raw material on earth. Replacing fossil feedstocks for the chemical industry, such as oil, coal and natural gas by biomass can reduce the $\mathrm{CO}_{2}$ emissions of the chemical industry. However, the availability of lignocellulosic biomass is limited. Therefore, it is key to use this feedstock as efficiently as possible. The current benchmark process in biomass fractionation is the kraft process. In this process, biomass is delignified using a solution of sodium hydroxide and sodium sulfide and the produced cellulose pulp is mostly used for papermaking. However, only half of the raw material is converted into cellulose pulp, the rest of the material is combusted for the generation of heat and for the recovery of sodium sulfide. Processes that can convert biomass in multiple products, including next to cellulose, also lignin and/or furans, are required to reduce global $\mathrm{CO}_{2}$ emissions.

Deep eutectic solvents (DES) are composite solvents that exhibit deep eutectic behavior upon mixing. These solvents have shown great potential for biomass delignification and have the potential to produce not only cellulose pulp, but also other valuable byproducts, such as lignin and furans. Therefore, DES based processes can make more efficient use of the biomass feedstock than the kraft process. However, there are a couple of issues that need to be resolved before DES delignification processes can be applied on a large scale. First, the advantages of the combination of DES constituents are poorly understood. Second, the known methods for the recovery of lignin from DES are mostly applicable for laboratory purposes. Laboratory unit operations are not always applicable on industrial scale, and research is needed to better understand the pulping process, as well as solvent recovery operations. These issues are addressed in this thesis, after which a conceptual process is designed for the delignification of Eucalyptus globulus using a DES comprised of lactic acid and choline chloride.

In chapter 2, a study on the role of choline chloride in biomass delignification by the DES containing lactic acid is described. Pulping experiments using $E$. globulus were performed at $120^{\circ} \mathrm{C}$ for 8 hours with a DES to wood ratio of 20:1. Various experiments were performed to study the influence of choline chloride on lignin solubility, cleaving reactions and mass transfer in order to gain understanding of the observed pulping results. It was found that the chloride anion is the active component of choline chloride, enhancing the rate of the delignification. In fact, the inexpensive salt $\mathrm{NaCl}$ performed as well as choline chloride in that respect. Furthermore, choline chloride it is already effective in a 1:250 molar ratio to lactic acid. It was found by studies on milled wood lignin (MWL) that choline chloride increases the cleavage rate of $\beta-0-4$, and thereby increases the delignification rate of biomass. Furthermore, choline chloride slightly decreased the solubility of lignin in DES, and 
due to an increase in viscosity the estimated mass transfer coefficient is also reduced. A model was applied to fit the lignin cleaving rate, which increased by $90 \%$ upon the addition of choline chloride to lactic acid. Overall, the delignification rate of eucalyptus by lactic acid increased by the addition of halide salts.

In chapter 3, a new method was developed for the regeneration of lignin from DESs. Laboratory routine has been to precipitate lignin by addition of cold water, however large amounts of water are required, resulting in energy intensive operations to remove the water from the DES afterwards. Therefore, liquid-liquid extraction (LLX) was proposed as alternative method for industrial applications. The recovery of lignin from a DES consisting of lactic acid and choline chloride was studied for various DES ratios. Six solvents were investigated for this purpose, from which 2-methyl tetrahydrofuran (2-MTHF) was selected for further studies. The phase equilibria between the DES and 2-MTHF were determined at 25,50 and $75^{\circ} \mathrm{C}$. Addition of more choline chloride decreases the mutual solubility of 2MTHF and lactic acid. The overall equilibrium lignin distribution between DES and solvent did not change much with varying DES compositions, but the distribution was dependent on the molar mass of lignin. The low molar weight fractions showed a distribution coefficient around 1, while for the heavy fractions the distribution coefficient was below 0.1 . Addition of water changes the system greatly, and extraction of high molar mass lignin is tremendously enhanced. At 25 wt \% water in the DES, the distribution coefficient was for all molar weights at least 4, allowing effective extraction of lignin from DES by 2-MTHF.

In chapter 4 , the recoverability of lignin from DES using LLX and cold-water precipitation was studied more in-depth, including multi-stage extractions and analysis of the extracted lignin. Lignin that is dissolved in DES from biomass fractionation is inhomogeneous, meaning it has various fractions with different molar weights and possibly variations in functional group densities. Therefore, it is important to compare recoverability of every lignin fraction by LLX with cold-water precipitation. In this work, the recovery of lignin from a DES comprised of $30 \mathrm{wt} \%$ choline chloride and $70 \mathrm{wt} \%$ lactic acid was studied. Three crosscurrent extractions were performed using 2-MTHF. This method allowed to recover $95 \%$ of the lignin molar weight fractions around $2,000 \mathrm{~g} / \mathrm{mol}$ and $85 \%$ of the lignin molar weight fractions around $10,000 \mathrm{~g} / \mathrm{mol}$. No inter-aromatic ether bonds were found in the lignin remaining in the DES raffinate by heteronuclear single quantum coherence spectroscopy (HSQC), indicating the remaining lignin in the DES is has a highly condensed nature. Cold water precipitation could fully recover the lignin fractions above $4,000 \mathrm{~g} / \mathrm{mol}$ using $3.5 \mathrm{~kg}$ water per kg DES. However, only half of the lignin fraction of $1,000 \mathrm{~g} / \mathrm{mol}$ was recovered. Briefly, LLX is more suitable for the recovery of low molar weight fractions, while cold water precipitation is more suitable for the heavy molar weight fractions. For industrial applications, a combination of both approaches appears essential for full lignin recovery. 
In chapter 5, a conceptual process design for the delignification of E. globulus using a DES comprised of $30 \mathrm{wt} \%$ choline chloride and $70 \mathrm{wt} \%$ lactic acid was made. In this design, the lignin and hemicellulose by-products are recovered by LLX using 2-MTHF as solvent. Material and energy balances were made and the energy usage of the process was optimized with additional experiments. The amount of DES was reduced to the minimal amount required to fill the porous biomass ( $5 \mathrm{~kg}$ per $\mathrm{kg}$ wood), with minor influences on the yield and delignification. Direct recycling of lignin-in-DES mixtures without lignin removal by LLX to the delignification stage may save energy, but increased repolymerization increases the lignin's molar weight, which decreases its value and makes recovery by LLX more difficult. After optimization, the total energy usage of the proposed process is $8.4 \mathrm{GJ} / \mathrm{t}$ pulp, which is $24 \%$ lower than the kraft process. An additional benefit of DES based delignification processes is the possible valorization of byproducts, such as lignin and furans from hemicellulose. 


\section{Table of contents}

1 Introduction

2 Understanding the role of choline chloride in deep eutectic solvents used for biomass delignification extraction precipitation for improvement of lignin recovery from deep eutectic solvents

$5 \quad$ Process development for biomass delignification using deep eutectic solvents. Conceptual design supported by experiments

6 Conclusions and outlook

List of abbreviations

Publications

Acknowledgements 


\title{
Chapter 1
}

\author{
Introduction
}




\section{Research context}

The consumption of fossil feedstocks, such as oil coal and gas, has an enormous contribution to the current standard of living. They are not only used for transport, power and heating, but also as feedstock for the production of numerous chemicals. Examples include, but are not limited to plastics, fertilizers, textiles, detergents, adhesives and paints. The fossil feedstocks used for the production of these materials are not only used as an energy source in the production process, but are also used as material feedstock. The molecules in these products are physically derived from the fossil feedstocks. In the chemical industry, roughly half of the fossil feedstocks are used as energy source, and the other half as feedstock [1]. In 2017, the fossil material demands of the chemical industry were $760 \mathrm{Mt}$ (excluding demands for energy), as estimated using data from the International Energy Agency [1].

The combustion of fossil feedstocks produces $\mathrm{CO}_{2}$, which is emitted to the atmosphere, where it accumulates. This has caused an increase in the $\mathrm{CO}_{2}$ concentration in the atmosphere from 316 to 413 ppm from 1960 to 2020 [2]. As a result, more radiation is absorbed by the atmosphere, which has caused an increase in global temperatures. The effects of this temperature increase include rising sea levels, more extreme weather and threats to crop yields. Therefore, deep cuts in $\mathrm{CO}_{2}$ emissions are required [3].

It is expected that alternative energy sources, such as solar, wind and geothermal energy are able to replace fossil energy sources. However, for the chemical industry, not only the energy source must be replaced, but also the material source. The number of sustainable carbon sources is limited to two: $\mathrm{CO}_{2}$ from the air, or carbon from biomass. Direct $\mathrm{CO}_{2}$ capture from air seems very challenging. One Olympic-sized swimming pool filled with air only contains $750 \mathrm{~g}$ carbon, ${ }^{1}$ meaning enormous air flows are required for the recovery of small amounts of carbon. Therefore, it is desirable to use biomass as carbon feedstock for the chemical industry. However, extending the use of biomass also has its limitations. Grow cycles in forestry are very long, typically 15 to $50 \mathrm{y}$ [4] and increasing the amount of land used for forestry will compete with land use for living, agriculture and nature. Therefore, in view of the author, it is key to use this feedstock as efficiently as possible and find technologies that can convert biomass into a spectrum of products, rather than one single product. This principle is called a biorefinery. 


\section{Chapter 1}

There are two main types of biomass, animal and plant based biomass. This thesis is limited to the latter type, and more specifically to lignocellulosic biomass. This type can be further divided in two categories: wood that is harvested from forestry, and agricultural residues. Agricultural residues, such as straw, corncob or sugar beet pulp, are mainly used as feed and bedding for cattle, but are also used for the production of chemicals, such as ethanol [5] or furfural [6]. The use of wood can roughly be divided in two groups: fuel wood and industrial wood. The first accounts for almost half of the total wood usage and covers 12$13 \%$ of the global energy usage. Fuel wood is almost entirely used in developing countries for heating or cooking. Despite the low energy efficiency and associated health risks, this is the sole access to energy carriers for more than 2 billion people [7].

Most of the industrial wood consists of sawlogs, which are further processes to sawnwood, railway sleepers and veneer. Not only are these the most valuable, the material losses in the production of these products in only limited to the losses during sawing. Around $30 \%$ of the industrial wood is used as pulpwood for the production of cellulose pulp, as summarized in fig. 1.1 [8].

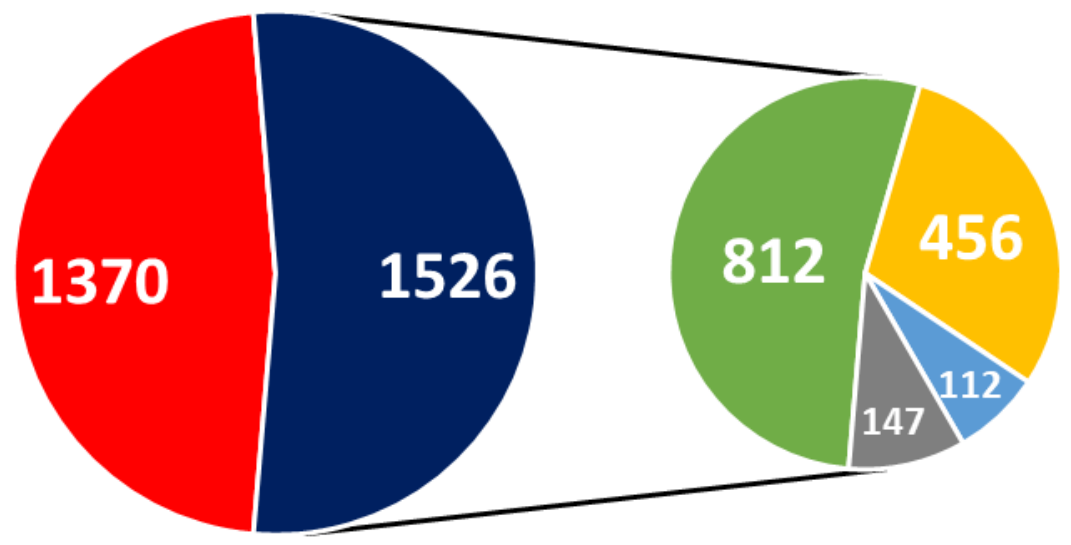

Fuel

Pulpwood $\approx$ Others
- Industrial $\square$ Sawlogs Residues

Fig. 1.1. Global use of wood resources. A division is made between fuel and industrial wood. Industrial wood is further split out in sawlogs, pulpwood, others and residues. All values are in $\mathrm{Mt} /$ year and the data is used from [8].

In 2017, 456 Mt pulpwood was used to produce $184 \mathrm{Mt}$ of cellulose pulp [8]. This means that $272 \mathrm{Mt}$ of byproducts are produced, mainly consisting of lignin and sawdust. These high 
losses are mainly due to the way pulpwood is processed to produce cellulose fibers. Most cellulose fibers are produced using the kraft process. This process removes lignin from wood by a nucleophilic substitution reaction using sulfur. As a result, the lignin produced by the kraft process contains high amounts of covalently bound sulfur, as can be seen in fig. 1.2. This makes the valorization of kraft lignin challenging since sulfur is an established catalyst poison [9]. In the kraft process, the lignin is combusted to recover the sulfur and to produce the required heat for the process.<smiles>[R]c1ccc(OC(CO)C(O)c2ccc(O)c(OC)c2)c(OC)c1</smiles><smiles>COc1cc(C2SC2CO)ccc1O</smiles><smiles>CC(C)(C)C(C)(C)C</smiles><smiles>[R]c1ccc(O)c(OC)c1</smiles><smiles>CC(C)(C)C</smiles>
$\mathrm{H}_{2} \mathrm{O}$

Fig. 1.2. Reaction scheme for the cleavage of the $\beta-0-4$ bond in the kraft process [10].

Recently, deep eutectic solvents (DESs) have been proposed as solvents for biomass delignification [11-13]. DES based delignification processes can convert wood into cellulose suitable for papermaking and valuable lignin, because the mechanism of the delignification is different. This makes DES delignification processes attractive alternatives to the kraft process. Since there are many unknown aspects of DES-based delignification, and also on the recycling of these DESs, these aspects are interesting elements for scientific study. In the rest of the introduction, important aspects of DES-based delignification, including the concept of deep eutectic solvents and the structure of lignocellulosic biomass are briefly discussed. At last, a brief outline of the thesis is presented.

\section{Deep eutectic solvents}

Deep eutectic solvents (DESs) are a relatively new class of solvents, first named by Abbott et al. in 2004 [14]. DES are composite solvents that exhibit eutectic behavior upon mixing, attributed to the hydrogen bonding interactions between the constituents [15]. These solvents have raised wide attention in academia since 2004 and are often biocompatible, biodegradable [16] and can have a low toxicity [17]. Although it must be noted that these properties depened entirely on the constituents of a DES. Many applications have been proposed for these solvents, such as $\mathrm{CO}_{2}$ capture [18-20], air pollutant removal [21], 


\section{Chapter 1}

extractive distillation [22], metal extractions [23], desulfurization [24,25] and biomass delignification $[13,26,27]$. DESs are usually comprised of two compounds that are solids at room temperature. The melting point curve of a solid as function of composition can be calculated using a thermodynamic equation (1).

$\ln \left(x_{i} \gamma_{i}\right)=\frac{\Delta_{f u s} H}{R}\left(\frac{1}{T_{m}}-\frac{1}{T}\right)$

In this equation, $\mathrm{x}$ is the mole fraction and $\mathrm{y}$ the activity coefficient of compound $\mathrm{i}, \Delta_{\mathrm{fus}} \mathrm{H}$ the enthalpy of fusion, $R$ the ideal gas constant, $T_{m}$ the melting temperature of the pure compound and $T$ the melting point of the mixture. If it is assumed that the mixture is ideal $(\gamma=1)$, the melting temperature can be calculated as a function of the composition when the melting enthalpy and temperature are known for the pure compounds. When these curves are calculated for both compounds in a DES, they will cross at certain temperature, called the eutectic temperature. An example of two of these curves is shown in fig. 1.3.

From the application point of view, it might not seem very relevant whether a mixture can be called a DES or not. However, a proliferation of mixtures entitled as DESs that are actually not DESs will decrease the value of the term DES. In order to identify DESs, some considerations should be taken into account, among which the melting point of a mixture is one aspect, but certainly not governing. For instance, the eutectic point of the cubane and tetramethylbutane is $70^{\circ} \mathrm{C}$ lower than the melting point of tetramethylbutane (see fig. 1.3), as calculated assuming ideal behavior. Thus, this appears as a composite solvent that exhibits deep eutectic behavior upon mixing. However, is it unlikely that the use of this mixture will have any practical advantage over the use of $n$-octane or $\mathrm{i}$-octane. Thus only considering the melting behavior is not really satisfying. 

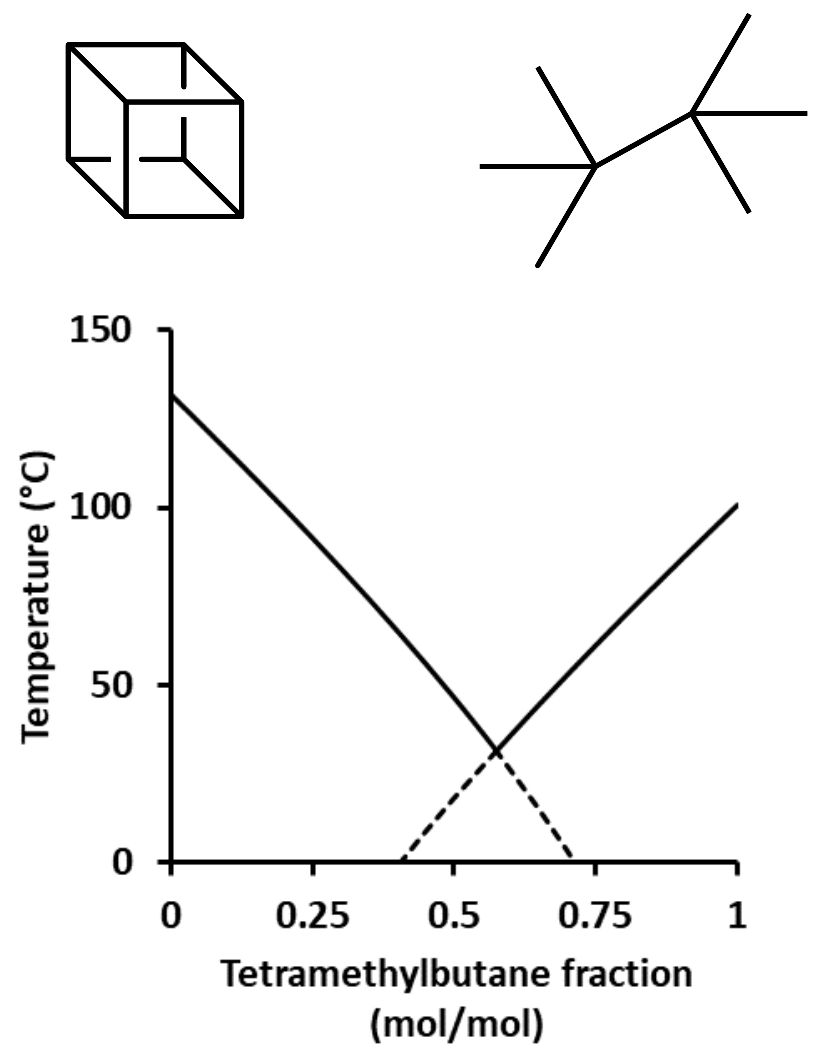

Fig. 1.3. Ideal solid-liquid phase diagram of tetramethylbutane (structure top right) with cubane (structure top left), as calculated according to equation (1).

A stricter definition of a DES is thus highly desirable. Some authors have proposed a stricter definition of a DES $[28,15,29-31]$. These are summarized in table 1.1.

The definitions proposed by Zhang [28] et al. and Paiva et al. [29] cover a very wide range of miscible systems, such as a mixture of $\mathrm{NaCl}$ and water. A salt in water mixture is generally not regarded as a DES, but does meet the definitions proposed by Zhang [28] et al. and Paiva et al. [29], hence, this definition does not seem very satisfactory, and an even more strict definition is required. The definition proposed by Smith [15] is clear and unambiguous, but according to this definition, any protic ionic liquid is a DES as well. Furthermore, it excludes many substances often used in DES, such as (poly)alcohols and sugars. 


\section{Chapter 1}

Table 1.1. overview of proposed DES definition.

\begin{tabular}{|l|l|l|}
\hline Author & Year & Definition \\
\hline $\begin{array}{l}\text { Zhang } \\
{[28]}\end{array}$ & 2012 & $\begin{array}{l}\text { A DES is a fluid generally composed of two or three cheap and safe } \\
\text { components that are capable of self-association, often through } \\
\text { hydrogen bond interactions, to form a eutectic mixture with a } \\
\text { melting point lower than that of each individual component. }\end{array}$ \\
\hline $\begin{array}{l}\text { Smith } \\
\text { [15] }\end{array}$ & 2014 & $\begin{array}{l}\text { DESs are systems formed from a eutectic mixture of Lewis or } \\
\text { Brønsted acids and bases which can contain a variety of anionic } \\
\text { and/or cationic species }\end{array}$ \\
\hline $\begin{array}{l}\text { Paiva } \\
{[29]}\end{array}$ & 2014 & $\begin{array}{l}\text { Deep eutectic solvents are defined as a mixture of two or more } \\
\text { components, which may be solid or liquid and that at a particular } \\
\text { composition present a high melting point depression becoming } \\
\text { liquids at room temperature. }\end{array}$ \\
\hline $\begin{array}{l}\text { Martins } \\
{[30]}\end{array}$ & 2018 & $\begin{array}{l}\text { In our view a 'deep eutectic solvent' is a mixture of two or more pure } \\
\text { compounds for which the eutectic point temperature is below that } \\
\text { of an ideal liquid mixture, presenting significant negative deviations } \\
\text { from ideality. Additionally, the temperature depression should be } \\
\text { such that the mixture is liquid at operating the temperature for a } \\
\text { certain composition range. }\end{array}$ \\
\hline $\begin{array}{l}\text { Schuur } \\
\text { [31] }\end{array}$ & 2019 & $\begin{array}{l}\text { DESs are composite solvents that exhibit deep eutectic behavior, } \\
\text { that is, upon mixing the constituents of these solvents, the mixtures' } \\
\text { melting points reduce considerably more (>50 }{ }^{\circ} \text { C) than would be the } \\
\text { case for ideal mixtures. }\end{array}$ \\
\hline
\end{tabular}

Martins [30] and Schuur [31] proposed definitions of a DES based on the melting point reductions compared to ideal behavior. It may seem cumbersome to compare the melting point reduction to the ideal reduction, rather than the reduction compared to the starting material(s). For the comparison with ideal behavior, experimental data is a pre-requisite, whereas an estimation of the eutectic temperature can be made simply from the heats of fusion and the melting points of the pure constituents, which will ease the screening of new DES very much. Furthermore, a relation between the ideality of a DES and potential applications is not always expected. For instance, a relation between the non-ideality of DES and a reaction rate in the DES seems unlikely. However, a dissimilarity between two molecules is required to obtain non-ideal behavior. Defining a DES based on the deviation from ideality therefore excludes most combinations between similar molecules (such as the example with cubane and tetramethylbutane mentioned earlier). Since it is unlikely that 
mixtures of two molecules with similar properties will have any advantages over the use of any of the pure substances, it has no benefits to define these mixtures as DESs. Therefore, defining a DES based on non-ideality is preferred, but does not come without its problems either. A mixture of water with DMSO for instance has a large negative deviation from ideality as well [32]. To the best of my knowledge, such a mixture was never proposed as $D E S$, but this is justified according to the definitions in the paragraph.

At this moment, there is no commonly agreed definition of a DES and is has proven to be very hard to come up with a definition that can describe most of the mixtures that are currently regarded as DES, while excluding mixtures that are not generally considered as DES. Although further discussions are essential to come to a generally accepted definition of a DES, but in view of the author it should at least:

1. Have a significant decrease in melting point upon mixing the constituents.

2. This melting point depression should be significantly more than expected from ideal behavior, there must be a dissimilarity between the constituents.

3. The combination of the DES constituents should have a clear benefit over the use of (solutions of) their constituents alone.

\section{Structure of lignocellulosic biomass}

Lignocellulosic biomass is used as a feedstock for the production of cellulose fibers. Lignocellulosic biomass is the most abundantly available organic raw material on earth and has a fibrous structure, which mainly consists of cellulose, hemicellulose and lignin.

\subsection{Cellulose}

Cellulose is a polymer of D-glucose. Cellulose is always formed by a condensation reaction of the hydroxyl groups between carbon 1 and carbon 4 of two different D-glucose units, called a glycosidic bond, as shown in fig. 1.4. In this structure, each consecutive unit is twisted $180^{\circ}$ over the 1-4 'axis'. This allows strong hydrogen bonds between adjacent glucose units in a cellulose molecule. This creates a stiff, linear polymer [4]. 

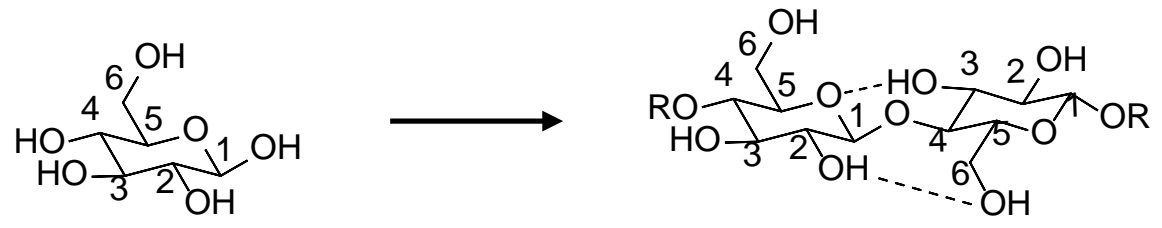

Fig. 1.4. Structural formula of D-glucose and one two monomers in a cellulose polymer with hydrogen bonds indicated by the dashed lines.

Multiple cellulose chains form sheets by strong hydrogen bonds between the cellulose chains, as shown in fig. 1.5. These sheets are stacked over each other and interact by van der Waals forces. Such a stack is called a fibril. Typically, the cellulose sheets are very long and narrow, making the fibrils very long and narrow. Cellulose chains may have a degree of polymerization of around 10,000, while a typical plant fibril contains around 36 cellulose chains [4].

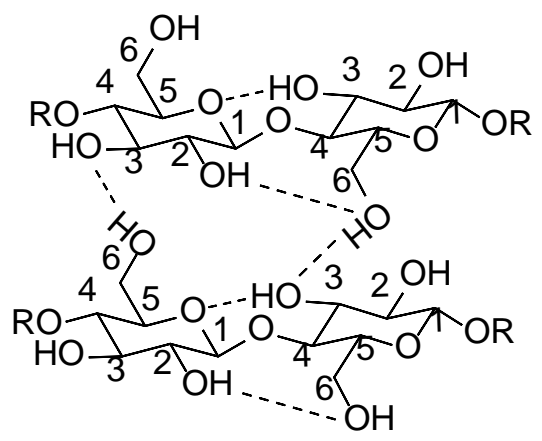

Fig 1.5. Two monomers of two cellulose chains with intra and inter molecular hydrogen bonds indicated by the dashed lines.

\subsection{Hemicellulose}

As opposed to cellulose, hemicelluloses are heterogeneous and slightly branched polymers. They consist of various pentose ( $D$-xylose and L-arabinose), hexose (D-glucose, D-mannose and D-galactose) and deoxyhexoses (L-rhamnose and L-fucose) sugars, as well as uronic acids and typically have a degree of polymerization up to 200 [4].

In lignocellulosic biomass, hemicelluloses are found between the cellulose fibrils in the cell walls. The types and amounts of hemicellulose found in lignocellulosic biomass depends greatly on the species, tissue type and growth stage and growth conditions. 


\subsection{Lignin}

Lignin is an aromatic and amorphous polymer. Lignin is mainly found between the cell walls of lignocellulosic biomass, where they 'glue' them together. This gives stiffness to the lignocellulosic biomass. It consists of three aromatic monomers ( $p$-Coumaryl alcohol, coniferyl alcohol and sinapyl alcohol, fig. 1.6), which form a polymer by a radical type polymerization mechanism. These monomers are linked together by different ether and carbon-carbon bonds, which are randomly distributed.
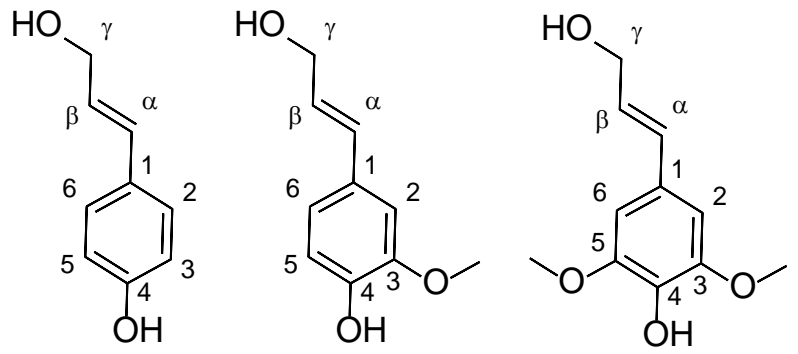

Fig. 1.6. Structures of p-Coumaryl alcohol, coniferyl alcohol and sinapyl alcohol.

The aromatic carbons are indicated by numbers (1-6) and the aliphatic carbons are indicated by Greek letters ( $\alpha, \beta$ and $\gamma$ ). Bonds are indicated by the numbers or letters of the first monomer and an $\mathrm{O}$ is placed in between if the two monomers are connected by an ether bond. For example, the $\beta-0-4$ bond means that the $\beta$ carbon of one monomer forms an ether bond with carbon 4 from the second monomer, as indicated in fig 1.7.

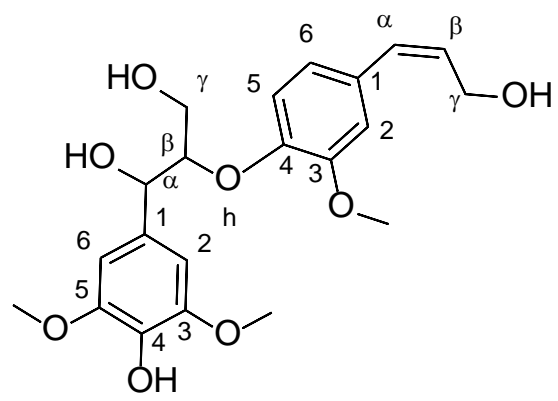

Fig. 1.7. Two lignin monomers connected by a $\beta-0-4$ bond. 


\section{Desired process for biomass delignification using a DES}

The kraft process is currently the benchmark process for biomass delignification. In this process, the lignin is cleaved by a nucleophilic substitution reaction with sulfur, as shown in fig. 1.2. As a result, the lignin produced using the kraft process contains covalently bonded sulfur, making valorization challenging (as discussed previously in section 1 ). Therefore, the lignin produced in the kraft process is combusted. This serves two purposes. A part of the produced heat is used for the process and the excess heat is converted into electricity and sent to the power grid. Second, the covalently bound sulfur can be recovered via a complicated recovery section.

To eliminate all $\mathrm{CO}_{2}$ emissions, the fossil resources for the production of both energy and chemicals have to be replaced by renewable alternatives. It is much harder to replace the fossil resources for the production of chemicals, than to replace the fossil resources for the production of energy (as discussed in section 1). Lignocellulosic biomass can be a sustainable resource for the production of chemicals, which is readily available. Unfortunately, the available amounts of lignocellulosic biomass are limited. Therefore, in view of the author, it is key to use this resource as much as possible for the production of chemicals, rather than energy.

Due to the nature of the Kraft process, the produced lignin contains high amounts of sulfur, making it hard to use it as a feedstock for the production of chemicals. DES based delignification processes can delignify biomass without the need for sulfur. This means that DES delignification processes can produce lignin that does not contain any sulfur, which is more suitable as feedstock for chemicals. Therefore, DES based processes can produce more chemical products, rather than energy compared to the kraft process. Since it is harder to replace chemical resources with renewable alternatives than energy resources, DES based delignification processes are more desirable than the kraft process. Despite the advantages of the proposed process, alternative energy sources have to be implemented simultaneously to fulfil the energy demands the process and to replace the energy that the kraft process currently provides to the power grid. Examples include, but are not limited to, wind, solar, geothermal and hydropower. The input-output structure of both processes are schematically shown in fig. 1.8. 


\section{Current industrial situation}

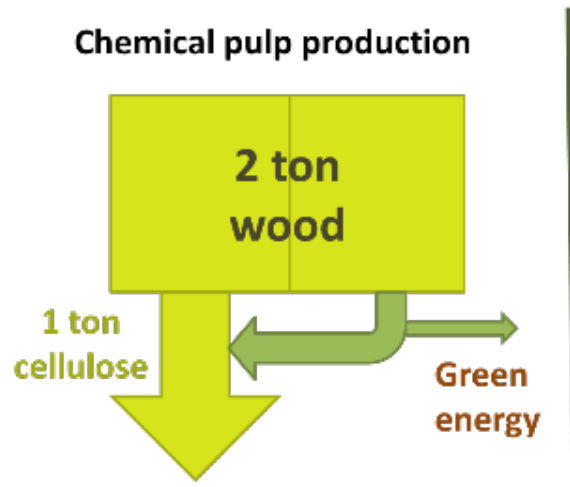

Fossil chemicals production

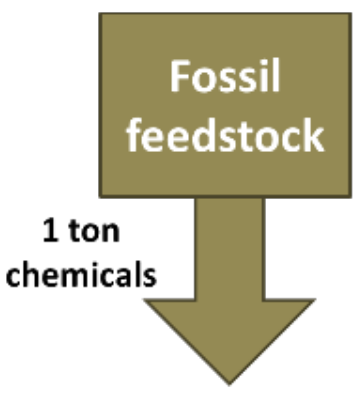

\section{$\downarrow$}

Desired DES pulping processes

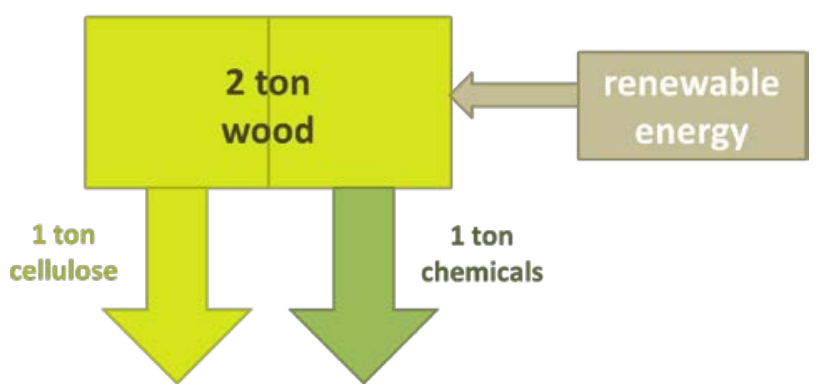

Fig. 1.8. Conceptual comparison between the input-output structures of the current industrial situation and the desired DES delignification process. Picture was adapted from the ProviDES final report [33].

\section{Scope and outline of the thesis}

In this thesis, one commonly used DES comprised of choline chloride and lactic acid was used for studies on biomass delignification. This DES is inexpensive, biodegradable, has a low viscosity and has a large range in which it is liquid [34]. Furthermore, it was often used in other studies on biomass delignification [12]. This DES was also used in the rest of this thesis. 


\section{Chapter 1}

In chapter 2, the influence of choline chloride on the delignification mechanism was studied. It was clear that the delignification mechanism was based on acid-catalyzed hydrolysis [12]. Although it was clear that the addition of choline chloride to lactic acid improved the delignification rate, it's exact role was unclear and further studied in this chapter.

The only known ways to regenerate lignin from DES involve precipitation of lignin by addition of cold water to DES. In an industrial process, this water has to be separated from the DES by evaporation, which is highly energy intensive. Therefore, an alternative regeneration method involving liquid-liquid extraction (LLX) was developed in chapter 3. Six solvents were screened and 2-methyltetrahydrofuran was selected for further studies. In chapter $\mathbf{4}$ it was investigated whether full lignin recovery can be obtained using LLX and a comparison was made with cold-water precipitation.

In chapter 5, a conceptual process was designed for biomass delignification using DES. The energy consumption of this process was estimated and optimized using additional experiments.

In chapter 6, the conclusions of this thesis are summarized and an outlook on delignification processes using DES is given.

In chapter 2-5 the following research questions are answered:

Chapter 2: Why does the delignification rate of biomass using lactic acid increase when choline chloride is added?

Chapter 3: $\quad$ Can lignin be recovered from DES by liquid-liquid extraction using an organic solvent?

Chapter 4: $\quad$ How does the recovery of lignin from DES using liquid-liquid extraction compare to recovery using precipitation in cold water?

Chapter 5: How does a conceptual process for biomass delignification using DES compare to the kraft process? 


\section{Bibliography}

[1] The Future of Petrochemicals, International Energy Agency, 2018.

[2] Atmospheric CO2 Data at Mauna Loa Observatory, Scripps Institution of Oceanography, 2020.

[3] H.S. Eggleston, L. Buendia, K. Miwa, T. Ngara, K. Tanabe, 2006 IPCC Guidelines for National Greenhouse Gas Inventories, Intergovernmental Panel on Climate Change, 2006.

[4] M. Ek, G. Gellerstedt, G. Henriksson, Wood chemistry and wood biotechnology, De Gruyter, Berlin, 2009. doi:10.1515/9783110213409.

[5] N. Kosaric, Z. Duvnjak, A. Farkas, H. Sahm, S. Bringer-Meyer, O. Goebel, D. Mayer, Ethanol, in: Ullmann's Encycl. Ind. Chem., Wiley, Weinheim, 2011: pp. 1-72. doi:10.1002/14356007.a09_587.pub2.

[6] H.E. Hoydonckx, W.M. Van Rhijn, W. Van Rhijn, D.E. De Vos, P.A. Jacobs, Furfural and Derivatives, in: Ullmann's Encycl. Ind. Chem., Wiley, Weinheim, 2007. doi:10.1002/14356007.a12_119.pub2.

[7] W.P.M. van Swaaij, S.R.A. Kersten, W. Palz, Biomass Power for the World, Pan Stanford, 2015.

[8] FAO Yearbook of Forest Products 2017, Food and agriculture organization of the United Nations, Rome, 2019.

[9] R. Rinaldi, R. Jastrzebski, M.T. Clough, J. Ralph, M. Kennema, P.C.A. Bruijnincx, B.M. Weckhuysen, Paving the Way for Lignin Valorisation: Recent Advances in Bioengineering, Biorefining and Catalysis, Angew. Chemie Int. Ed. 55 (2016) 8164-8215. doi:10.1002/anie.201510351.

[10] M. Ragnar, G. Henriksson, M.E. Lindström, M. Wimby, J. Blechschmidt, S. Heinemann, Pulp, in: Ullmann's Encycl. Ind. Chem., Wiley, Weinheim, 2014. doi:10.1002/14356007.a18_545.pub4.

[11] M. Francisco, A. van den Bruinhorst, M.C. Kroon, New natural and renewable low transition temperature mixtures (LTTMs): screening as solvents for lignocellulosic biomass processing, Green Chem. 14 (2012) 2153-2157. doi:10.1039/C2GC35660K.

[12] C. Alvarez-Vasco, R. Ma, M. Quintero, M. Guo, S. Geleynse, K.K. Ramasamy, M. Wolcott, X. Zhang, Unique low-molecular-weight lignin with high purity extracted from wood by deep eutectic solvents (DES): a source of lignin for valorization., Green Chem. 18 (2016) 51335141. doi:10.1039/c6gc01007e.

[13] D.J.G.P. Van Osch, L.J.B.M. Kollau, A. Van Den Bruinhorst, S. Asikainen, M.A.A. Rocha, M.C. Kroon, Ionic liquids and deep eutectic solvents for lignocellulosic biomass fractionation, Phys. Chem. Chem. Phys. 19 (2017) 2636-2665. doi:10.1039/c6cp07499e.

[14] A.P. Abbott, D. Boothby, G. Capper, D.L. Davies, R. Rasheed, Deep Eutectic Solvents Formed Between Choline Chloride and Carboxylic Acids, J. Am. Chem. Soc. 126 (2004) 9142-9147. doi:10.1021/ja048266j.

[15] E.L. Smith, A.P. Abbott, K.S. Ryder, Deep Eutectic Solvents (DESs) and Their Applications, Chem. Rev. 114 (2014) 11060-11082. doi:10.1021/cr300162p.

[16] Q. Lu, W. Liu, L. Yang, Y. Zu, B. Zu, M. Zhu, Y. Zhang, X. Zhang, R. Zhang, Z. Sun, J. Huang, X. Zhang, W. Li, Investigation of the effects of different organosolv pulping methods on antioxidant capacity and extraction efficiency of lignin, Food Chem. 131 (2012) 313-317. doi:10.1016/j.foodchem.2011.07.116.

[17] I.P.E. Macário, F. Jesus, J.L. Pereira, S.P.M. Ventura, A.M.M. Gonçalves, J.A.P. Coutinho, F.J.M. Gonçalves, Unraveling the ecotoxicity of deep eutectic solvents using the mixture toxicity theory, Chemosphere. 212 (2018) 890-897. 


\section{Chapter 1}

doi:10.1016/j.chemosphere.2018.08.153.

[18] G. García, S. Aparicio, R. Ullah, M. Atilhan, Deep eutectic solvents: Physicochemical properties and gas separation applications, Energy and Fuels. 29 (2015) 2616-2644. doi:10.1021/ef5028873.

[19] N.R. Mirza, N.J. Nicholas, Y. Wu, K.A. Mumford, S.E. Kentish, G.W. Stevens, Experiments and Thermodynamic Modeling of the Solubility of Carbon Dioxide in Three Different Deep Eutectic Solvents (DESs), J. Chem. Eng. Data. 60 (2015) 3246-3252. doi:10.1021/acs.jced.5b00492.

[20] N. López-Salas, E.O. Jardim, A. Silvestre-Albero, M.C. Gutiérrez, M.L. Ferrer, F. RodríguezReinoso, J. Silvestre-Albero, F. Del Monte, Use of eutectic mixtures for preparation of monolithic carbons with $\mathrm{CO} 2$-adsorption and gas-separation capabilities, Langmuir. 30 (2014) 12220-12228. doi:10.1021/la5034146.

[21] L. Moura, T. Moufawad, M. Ferreira, H. Bricout, S. Tilloy, E. Monflier, M.F. Costa Gomes, D. Landy, S. Fourmentin, Deep eutectic solvents as green absorbents of volatile organic pollutants, Environ. Chem. Lett. 15 (2017) 747-753. doi:10.1007/s10311-017-0654-y.

[22] Q. Pan, X. Shang, J. Li, S. Ma, L. Li, L. Sun, Energy-efficient separation process and control scheme for extractive distillation of ethanol-water using deep eutectic solvent, Sep. Purif. Technol. 219 (2019) 113-126. doi:10.1016/j.seppur.2019.03.022.

[23] A. Söldner, J. Zach, B. König, Deep eutectic solvents as extraction media for metal salts and oxides exemplarily shown for phosphates from incinerated sewage sludge ash, Green Chem. 21 (2019) 321-328. doi:10.1039/c8gc02702a.

[24] F. Lima, J. Gouvenaux, L.C. Branco, A.J.D. Silvestre, I.M. Marrucho, Towards a sulfur clean fuel: Deep extraction of thiophene and dibenzothiophene using polyethylene glycol-based deep eutectic solvents, Fuel. 234 (2018) 414-421. doi:10.1016/j.fuel.2018.07.043.

[25] F. Lima, M. Dave, A.J.D. Silvestre, L.C. Branco, I.M. Marrucho, Concurrent Desulfurization and Denitrogenation of Fuels Using Deep Eutectic Solvents, ACS Sustain. Chem. Eng. 7 (2019) 11341-11349. doi:10.1021/acssuschemeng.9b00877.

[26] A. Mišan, J. Nađpal, A. Stupar, M. Pojić, A. Mandić, R. Verpoorte, Y.H. Choi, The perspectives of natural deep eutectic solvents in agri-food sector, Crit. Rev. Food Sci. Nutr. (2019) 1-29. doi:10.1080/10408398.2019.1650717.

[27] M. Jablonský, A. Haz, V. Majova, Assessing the opportunities for applying deep eutectic solvents for fractionation of beech wood and wheat straw, Cellulose. 26 (2019) 7675-7684. doi:10.1007/s10570-019-02629-0.

[28] Q. Zhang, K. De Oliveira Vigier, S. Royer, F. Jérôme, Deep eutectic solvents: syntheses, properties and applications, Chem. Soc. Rev. 41 (2012) 7108-7146. doi:10.1039/C2CS35178A.

[29] A. Paiva, R. Craveiro, I. Aroso, M. Martins, R.L. Reis, A.R.C. Duarte, Natural Deep Eutectic Solvents - Solvents for the 21st Century, ACS Sustain. Chem. Eng. 2 (2014) 1063-1071. doi:10.1021/sc500096j.

[30] M.A.R. Martins, S.P. Pinho, J.A.P. Coutinho, Insights into the Nature of Eutectic and Deep Eutectic Mixtures, J. Solution Chem. 48 (2019) 962-982. doi:10.1007/s10953-018-0793-1.

[31] B. Schuur, T. Brouwer, D. Smink, L.M.J. Sprakel, Green solvents for sustainable separation processes, Curr. Opin. Green Sustain. Chem. 18 (2019) 57-65. doi:10.1016/j.cogsc.2018.12.009.

[32] A. Mohs, S. Decker, J. Gmehling, The solid-liquid equilibrium of the binary system H2ODMSO and the influence of a salt $(\mathrm{NaCl}, \mathrm{KCl})$ on the thermodynamic behavior: Correlations using a revised LIQUAC model, Fluid Phase Equilib. 304 (2011) 12-20. doi:10.1016/j.fluid.2011.01.026.

[33] ProviDES Final report, Deep Eutectic Solvents in the paper industry, Institute for Sustainable 
Process Technology, Amersfoort, 2018. www.providespaper.eu.

[34] M. Francisco, A. van den Bruinhorst, L.F. Zubeir, C.J. Peters, M.C. Kroon, A new low transition temperature mixture (LTTM) formed by choline chloride+lactic acid:

Characterization as solvent for CO2 capture, Fluid Phase Equilib. 340 (2013) 77-84. doi:10.1016/j.fluid.2012.12.001. 


\section{Chapter 2}

\section{Understanding the role of choline chloride in deep eutectic solvents used for biomass delignification}

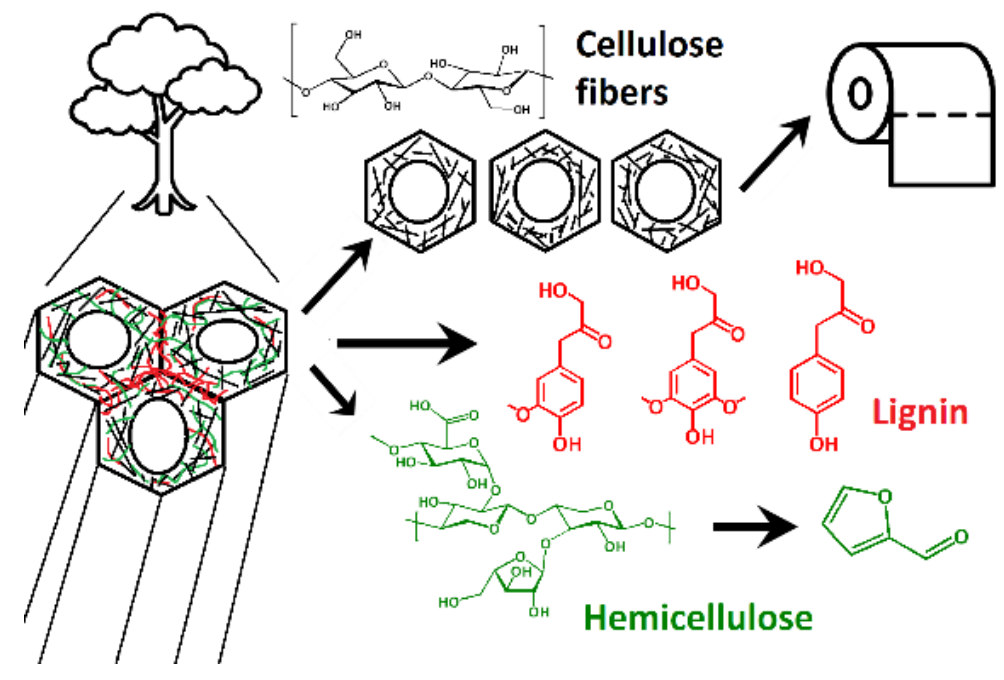




\title{
Understanding the role of choline chloride in deep Eutectic solvents used for biomass delignification
}

\begin{abstract}
The role of choline chloride in biomass delignification by the deep eutectic solvent (DES) containing lactic acid was investigated. In this study, the influence of choline chloride on the pulping of Eucalyptus globulus chips was determined. Pulping experiments were performed at $120^{\circ} \mathrm{C}$ for 8 hours with a DES to wood ratio of 20:1. Various experiments were performed to study the influence of choline chloride on lignin solubility, cleaving reactions and mass transfer in order to gain understanding of the observed pulping results. It was found that the chloride anion is the active component of choline chloride. In fact, the inexpensive salt $\mathrm{NaCl}$ performed as well as choline chloride in that respect. Furthermore, choline chloride it is already effective in a 1:250 molar ratio to lactic acid. It was found by studies on milled wood lignin (MWL) that choline chloride increases the cleavage rate of $\beta-0-4$, and thereby increases the delignification rate of biomass. Furthermore, choline chloride slightly decreased the solubility of lignin in DES and due to an increase in viscosity decreased the estimated mass transfer coefficient. Overall, the delignification rate of eucalyptus by lactic acid increased by the addition of halide salts.
\end{abstract}




\section{Chapter 2}

\section{Introduction}

Lignocellulose can be converted into cellulose fibers and lignin by delignification technologies. The obtained cellulose pulp can be used for paper production, production of other materials, or can be converted to bio-ethanol or other platform chemicals [1-3]. Lignin is an aromatic biopolymer with advocated potential for the chemical industry and current research is focusing on lignin valorization [4,5].

The traditional pulp mills used in the paper making industry make use of kraft pulping, in which the extracted lignin is burnt in the solvent recovery boilers [6]. The kraft mills are highly integrated and energy effective plants [7]. Nevertheless, over the past decades continued scientific efforts have been made to develop alternative pulp mills, in which lignin could be obtained as byproduct of the cellulose fibers [8-10]. An important category is organosolv, a pulping method making use of organic solvents, such as carboxylic acids [11]. For example, Kajimoto et al. investigated delignification of Japanese sugi pine by lactic acid [12]. Lactic acid is a bio-based platform chemical that can be produced following an established fermentation route [3]. During the delignification process, chemical bonds between cellulose and lignin and hemicellulose were broken and cellulose pulp was formed. Both lignin and (hemi)cellulose breakdown products were dissolved in the solvent.

Deep Eutectic Solvents (DESs) [13] are composite solvents with a melting point considerably lower $\left(>50^{\circ} \mathrm{C}\right)[14]$ than would be expected on the pure component melting points of their constituents. Francisco et al. proposed DESs, including mixtures of lactic acid and choline chloride, as suitable solvents for biomass delignification [15]. DES based processes offer many advantages over the traditional kraft or organosolv processes. The major disadvantage of kraft pulping is that the produced lignin contains sulfur, which makes valorization difficult, while organosolv processes requires high amounts of organic solvents, which are often volatile and flammable [16].

DESs were used by various researchers for the fractionation of various types of biomass [1722]. Lignocellulosic biomass has a complex structure, which can change as function of species and thereby influence the delignification rate. For example, Vasco et al. [17] compared the delignification of a hard and softwood species using DES. They removed $79 \%$ of the lignin from poplar (hardwood), while the same treatment could only remove $58 \%$ of the lignin from douglas fir (softwood). Chang et al. [18] and Li et al. [22] made a direct comparison between the delignification of eucalyptus and rice straw by lactic acid and DESs consisting of lactic acid and choline chloride. Both authors found that the lignin content in the cellulose residue obtained by pulping with lactic acid - choline chloride DES was 


\section{Understanding the role of choline chloride in deep Eutectic solvents used for}

biomass delignification

significantly lower than in the cellulose residue obtained by pulping with lactic acid only. Although the presence of choline chloride appears to improve delignification, the exact role of the choline chloride is not clear. Especially since a trend was found that the lignin content in residual cellulose decreased with decreasing amounts of choline chloride from 1:2 choline chloride to lactic acid molar ratio to $1: 15[18,21,22]$, it is not easy to point at one single aspect of the presence of choline chloride that improves the delignification.

Various articles were published about biomass delignification using mixtures of choline chloride and lactic acid [17-22], and various hypotheses were proposed about its role in biomass delignification. Francisco et al. suggested DESs would be good solvents for biomass delignification because of the high solubility of lignin [15]. Other authors who delignified biomass using DESs also suggested that the high amounts lignin removed by the DES resulted from the high solubility of lignin in DES [17]. Liu et al. suggested that the chloride ions in the DES caused the breakdown of lignin carbohydrate complexes [23], while Li et al. presumed that chloride could help to disrupt the intermolecular hydrogen bonding network of biomass and facilitate its dissolution [22]. It can thus be concluded that there are various opinions on the role of the choline chloride, and although these not necessarily contradict each other, it is of importance to investigate these hypotheses to find the most important factors in DES pulping. A good understanding of the role of choline chloride will accelerate the search for better solvents for biomass delignification and the development of effective new pulping processes.

The aim of this paper is to improve the understanding on the role of choline chloride in biomass delignification using lactic acid-based solvents by performing pulping experiments at various lactic acid to choline chloride ratios, including pure lactic acid and aqueous choline chloride. Also pulping experiments using lactic acid with various salts other than choline chloride were studied to investigate the roles of the choline and the chloride separately. Eucalyptus globulus was used as biomass since it is the most cultivated species in fast-growing plantations [24]. In Europe, $13.3 \mathrm{Mm}^{3} / \mathrm{y}$ of eucalyptus is used for papermaking, making it the most used hardwood species for papermaking after birch [25]. The effect of choline chloride on wood swelling was determined by scanning electron microscopy (SEM) and the effective mass transfer coefficients were estimated by model calculations. Next to Eucalyptus wood chips, also DES-pulping experiments were performed using milled wood lignin (MWL) that was obtained by ball milling the eucalyptus. These MWL experiments allowed investigation of the effect of choline chloride on the lignin cleaving reactions without mass transfer effects. Furthermore, the effect of choline chloride on the lignin solubility was studied. 


\section{Chapter 2}

\section{Methodology}

In the last part of the introduction, the scope of the performed study on the role of choline chloride was sketched, and in this methodology section, the various aspects of wood pulping and how to study factors of importance is discussed.

\subsection{Performance of pulping media}

During wood pulping, the wood matrix is delignified and the lignin dissolves in the solvent. When the lignin between the cellulose fibers is removed, the fibers are liberated from the wood matrix and cellulose pulp is formed. Pulping under too harsh conditions or too long times may also break down cellulose fibers, producing cellulose dust, which in this study is defined as fines. In previous studies, both sawdust [26] and wood chips were used [27]. Wood chips are used in the current study because wood is used industrially in this form for the production of cellulose pulp. By studying pulping including mass transfer effects in chips that can play an important role in pulping (as discussed in sub-section 2.2.3.), industrial applicability of the results is improved.

After the pulping experiments, the conversion is defined as the fraction of the chips that was converted into fibers, fines or is dissolved in the DES, and is calculated according to:

Conversion $(\%)=100 \cdot\left(1-\frac{\text { Amount of chips remaining }}{\text { Initial amount of chips }}\right)$

To reach the fiber liberation point, at least $80 \%$ of the lignin initially present in the wood matrix must be removed [28] and therefore, the chip conversion is a good measure for the delignification degree. Also, the yields of cellulose fibers ( $200 \mu \mathrm{m}$ to $2.8 \mathrm{~mm})$ and fines $(<200$ $\mu \mathrm{m})$ were determined. Furthermore, the lignin content in the fibers, undercooked chips and the solvent was determined by resp. the Klason method and cold water precipitation, and the lignin molar weight distribution was determined by GPC. However, ash, extractables and (hemi)cellulose degradation products in the DES were not determined. The degree of delignification was calculated according to:

Delignification $(\%)=100 \cdot\left(1-\frac{\text { Amount of lignin in fibers }+ \text { chips remaining }}{\text { Initial amount of lignin in chips }}\right)$

\subsection{Role of choline chloride}

In wood pulping, many parameters play a role, like the lignin solubility in the solvent, the cleavage rate of lignin and mass transfer effects. The influence of choline chloride on these 


\section{Understanding the role of choline chloride in deep Eutectic solvents used for}

biomass delignification

roles will be investigated, so we can indicate in which fields choline chloride plays a role during DES pulping.

\subsubsection{Solubility}

Various authors suggested DESs as suitable solvents for biomass delignification for their high solubility of lignin $[15,17]$. Therefore, we studied the change in lignin solubility upon the addition of choline chloride to lactic acid by comparing the solubility of a technical lignin in lactic acid with and without the addition of choline chloride. The lignin solubility greatly depends on the used method, because the structure of lignin is highly dependent on its biomass source and method of isolation. Furthermore, lignin is an inhomogeneous polymer, meaning some lignin fractions have a higher solubility than others. In the cloud point method for example [15], the solubility of a solid in a solvent is determined by adding small amounts of solid to a fixed amount of liquid, until the mixture becomes turbid at equilibrium. This method thus determines the solubility of the least soluble lignin fraction. If more lignin is added to this mixture, some of the more soluble fractions may still dissolve and thereby increase the amount of dissolved lignin [29]. This means the lignin solubility is a function of the lignin to solvent ratio and thus, methods like the cloud point method will give a different results than methods which determine the amount of dissolved lignin at a fixed lignin to solvent ratio. This makes comparison of absolute solubility data with other authors difficult.

In this work, we study the role of choline chloride in DESs and therefore, we are merely interested in effect of choline chloride on the lignin solubility in lactic acid. For this reason, we use the most convenient method, which is to add a fixed excess amount of lignin to a fixed amount of liquid [29]. The UV-VIS adsorption of the liquids was taken as a measure of the dissolved lignin. This gives an accurate comparison of the lignin solubility in DES compared to lactic acid and an approximate measure of the absolute solubility.

\subsubsection{Lignin reactions}

For the study on the effect of choline chloride on lignin cleaving reactions, MWL was used as a representative lignin model [30]. Under conditions where MWL is fully soluble in both the DES and lactic acid, the reactions in lignin can be studied without any influences of mass transfer effects, which will play a role if the influence is studied directly on wood.

The cleavage of the $\beta-0-4$ bond in lignin is an important measure for the delignification of wood [31]. The change in $\beta-O-4$ bonds after treatment of MWL can be determined by HSQC 


\section{Chapter 2}

spectroscopy, which is a two dimensional nuclear magnetic resonance technique which is used more often for lignin characterization [17,23,32]. With this technique the bond cleavage can be studied under varying conditions and with different DES compositions, this will show any effects of choline chloride on the cleavage of these bonds. However, multiple types of cleaving and condensation reactions are typically observed in wood delignification [33]. The sum of all these reactions results in a change of the lignin molar weight. This weight was determined by GPC and this data was used to fit an overall lignin cleaving rate constant over the treatments using the model of Marathe et al [34].

\subsubsection{Mass transfer effects}

During wood pulping, the DES molecules must first diffuse into the cell walls, before they can participate in delignification reactions. After the reaction, the lignin must diffuse out of the cell wall again. It was shown by Kanbayashi and Miyafuji that choline based ionic liquids can swell up cell walls to the point where the cell walls break, as they indicated clearly by SEM imaging [35]. Swelling of wood will increase its permeability and thus, lactic acid will diffuse faster into the cell walls and lignin will diffuse faster out of the cell walls, increasing the pulping rate. To investigate whether choline chloride has a similar effect, we treated a wood chip by aqueous choline chloride and checked whether similar effects as described by Kanbayashi and Miyafuji could be observed.

Apart from the diffusion of pulping chemicals into the cell walls, the diffusion of lignin out of the cell walls is another important step in pulping. Zhao made models for the diffusion rate of lignin in acetic acid pulping based on the Stokes-Einstein equation [36]. The effective diffusion constant of lignin is a function of the molar weight of the lignin and the viscosity of the pulping liquid. We measured the viscosity of the DES and lactic acid solutions after pulping and measured the molar weight of the lignins precipitated from these solutions. Using this data we calculated the effective diffusion coefficients according to the same method to investigate whether choline chloride influences the mass transfer rate of lignin in the cell walls.

\section{Methods and materials}

\subsection{Materials}

Air-dry Eucalyptus globulus chips were donated by The Navigator Company. The commercially sized chips (typically 25-35 x 10-25 x 2.5-6 mm, LxWxT) were used as received 


\section{Understanding the role of choline chloride in deep Eutectic solvents used for}

biomass delignification

and contained $21.6 \%$ lignin, $50.6 \%$ glucose, $14.0 \%$ xylose and $1.1 \%$ galactose, as determined by acid hydrolysis using the standard NREL method [37]. Lactic acid (>85\%), choline chloride ( $>98 \%)$, choline hydroxide (46\% in water), sodium sulfate ( $>99 \%)$, sodium chloride $(>99.5 \%)$, TEABr (98\%), TEACl·H2O (>98\%), 1,4-dioxane (99.8\%), acetic acid (99.5\%) and DMSO-d6 (99.96\%) were purchased from Sigma-Aldrich. n-Octane (>98\%) was purchased from VWR and kraft lignin from $\mathrm{TCl}$.

\subsection{Wood delignification experiments}

DESs were prepared by adding lactic acid and the salt of choice to a round-bottom flask equipped with a condenser, and heated to $120^{\circ} \mathrm{C}$ under stirring. Choline chloride was used in a 1:10 to 1:250 molar ratio to lactic acid and all other salts were used in a 1:10 molar ratio. Eucalyptus chips (50 g, dry basis) were directly added to the hot DES (1 kg total) through a free neck in the round-bottom flask $(\varnothing 29 \mathrm{~mm})$. This mixture was kept at $120^{\circ} \mathrm{C}$ for 8 hours under overhead stirring. Next, the mixture was transferred to a pressure filtration setup where the liquid was filtered off under nitrogen pressure ( 3 bar) on a steel mesh $(50 \mu \mathrm{m})$. The solid residue was washed with excess tap water and filtered over three consecutive steel meshes $(2.8 \mathrm{~mm}, 200 \mu \mathrm{m}$ and $50 \mu \mathrm{m})$ to separate the undercooked chips, the fibers and the fines. The residues were dried at $105^{\circ} \mathrm{C}$ to achieve a constant weight. The errors were calculated from one experiment performed in quadruple. From these experiments the standard deviation was calculated, which was converted to the $95 \%$ confidence interval by the t-statistics method.

The Klason lignin content of the sample was determined by hydrolysis of the sample according to standardized NREL procedure [37]. The sample (0.3 g) was added to an Ace glass pressure tube. $72 \%$ sulfuric acid $(3 \mathrm{~mL})$ was added and kept at $30^{\circ} \mathrm{C}$ for one hour while stirring every $10 \mathrm{~min}$. After this, water $(84 \mathrm{~mL})$ was added and the tube was kept at $120^{\circ} \mathrm{C}$ for another hour. The solids were filtered and dried overnight at $105^{\circ} \mathrm{C}$. The lignin content was determined by the ratio between the weights of the solid residue and the initial amount of sample added as determined by an analytical balance (+/- $0.0001 \mathrm{~g}$ ). The acid soluble lignin was determined using a Hach Lange DR5000 UV-VIS spectrophotometer at a wavelength of $320 \mathrm{~nm}$. The errors were calculated from one sample which was analyzed 8 times. From these analyses the standard deviation was calculated, which was converted to the $95 \%$ confidence interval by the t-statistics method. All other samples were analyzed in duplo. 


\section{Chapter 2}

\subsection{MWL production and experiments}

MWL was produced from the same eucalyptus chips as used in the pulping experiments by applying a similar method to that proposed by Björkman [38]. The chips were ground using a hammermill to pass through a steel mesh $(212 \mu \mathrm{m})$. The wood (50 g) was extracted by acetone in a Soxhlet apparatus for $8 \mathrm{~h}$ to remove extractables. The extracted wood was air dried and dispersed in octane $(500 \mathrm{~mL})$. The suspension was then transferred to a rotary ball mill in which it was milled by 35 ceramic balls of $25 \mathrm{~g}$ each for seven days at a rotational speed of $32 \mathrm{rpm}$. The octane was decanted and the suspension was divided equally into eight parts, which were added separately to an agate grinding jar $(250 \mathrm{~mL})$, together with 40 agate grinding balls of $10 \mathrm{~mm}$. Octane was added to the milling jars ( $100 \mathrm{~g}$ per jar). Each part was milled for three days in a Fritsch Pulverisette 5 planetary ball mill at $360 \mathrm{rpm}$. After milling, the suspension was rinsed off the grinding equipment with a wash bottle containing octane. The fractions were combined and the octane was decanted. The rest of the octane was evaporated by a small nitrogen flow overnight. $96 \%$ dioxane in water $(500 \mathrm{~mL})$ was added to the ground eucalyptus and was left seven days for extraction under continuous stirring. The dioxane was separated from the wood residue by centrifuging five min at 9000 $\mathrm{rpm}$. Dioxane was removed from the lignin in a rotary evaporator at $50{ }^{\circ} \mathrm{C}$ and $20 \mathrm{mbar}$. The remaining solids were dissolved in $90 \%$ acetic acid $(20 \mathrm{~mL})$, and the glass was rinsed with the same solution $(10 \mathrm{~mL})$. The liquids were filtered over a glass-fiber filter and precipitated in purified water $(300 \mathrm{~mL})$ under stirring. The water was removed by centrifuging for five $\mathrm{min}$ at $9000 \mathrm{rpm}$. The remaining solids were washed with water $(10 \mathrm{~mL})$, which was then removed in the same way as previously. The solids were dried overnight under vacuum. $A$ total lignin yield of $0.90 \mathrm{~g}$ was obtained from $50 \mathrm{~g}$ eucalyptus.

MWL (50 mg) was placed in an Ace glass pressure tube. $10 \mathrm{~g}$ Lactic acid or $10 \mathrm{~g}$ choline chloride to lactic acid DES (1:10) was added to this pressure tube. Once the lignin was fully dissolved, the pressure tube was heated to $120{ }^{\circ} \mathrm{C}$ for $1 \mathrm{~h}$. After cooling to room temperature, purified water $(30 \mathrm{~mL})$ was added to precipitate the lignin. The solids were separated by centrifuging for three minutes at $9000 \mathrm{rpm}$ and washed with purified water $(10 \mathrm{~mL})$, which was then removed by centrifuging for five min at $9000 \mathrm{rpm}$. The sample was dried overnight under vacuum.

\subsection{Lignin solubility test}

$0.6 \mathrm{~g}$ kraft lignin was added to $3 \mathrm{~g}$ lactic acid or $3 \mathrm{~g}$ choline chloride and lactic acid DES (1:10). These mixtures were shaken overnight in a Julabo SW22 shaking bath at $200 \mathrm{rpm}$ at room temperature. Excess lignin was filtered from the samples using a $0.2 \mu \mathrm{m}$ syringe filter and 


\section{Understanding the role of choline chloride in deep Eutectic solvents used for}

biomass delignification

$30 \mathrm{mg}$ liquid was diluted in $50 \mathrm{~mL}$ ethanol in a volumetric flask. The lignin absorption of these solutions were determined by UV-VIS spectroscopy at $320 \mathrm{~nm}$ using a Hach Lange DR5000 spectrophotometer.

\subsection{Scanning Electron Microscopy (SEM) imaging}

Samples were submerged in water for $72 \mathrm{~h}$, after which a small cut was made perpendicular to the longitudinal direction using a scalpel. Next, it was submerged in liquid nitrogen for a couple of minutes and split from the cut with a hammer. Next, the samples were dried under vacuum for 72 hours. A chromium layer ( $10 \mathrm{~nm}$ ) was applied by a Quorum Q150T ES coater. SEM images were captured by a JEOL JSM 5600 LV at 5 kV and 6000x magnification.

\subsection{NMR spectroscopy}

The samples were prepared by dissolving MWL $(200 \mathrm{mg})$ in DMSO-d6 (600 $\mu \mathrm{L})$. The samples from the MWL hydrolysis experiments were prepared by dissolving the complete precipitate in DMSO-d6 $(300 \mu \mathrm{L})$. All the experiments were carried out in a Bruker Avance II $600 \mathrm{MHz}(14.1 \mathrm{~T})$ spectrometer and the spectra were processed using MestReNova software. 2D HSQC spectra were acquired using the Q-CAHSQC pulse program [39] according to the method described by Constant et al. [32]. Matrices of 2048 data points for the ${ }^{1} \mathrm{H}$-dimension and 256 data points for the ${ }^{13} \mathrm{C}$-dimension were collected applying a relaxation delay of $6 \mathrm{~s}$ and spectral widths from 14 to $-1 \mathrm{ppm}$ and from 200 to $0 \mathrm{ppm}$ for the ${ }^{1} \mathrm{H}$ and ${ }^{13} \mathrm{C}$ dimensions, respectively. The spectra were integrated according to the method described by Constant et al. [32].

\subsection{Gel permeation chromatography}

The weight distribution of the lignins were analyzed by gel permeation chromatography (GPC). For GPC, $50 \mathrm{mg}$ lignin was dissolved in $5 \mathrm{~mL}$ tetrahydrofuran. All samples formed clear solutions in THF, indicating they were fully soluble. An Agilent 1200 series was used with a refractive index detector and a UV detector operating at $254 \mathrm{~nm}$ using three GPC PLgel $3 \mu \mathrm{m}$ MIXED-E columns in series. The column oven was operated at $40{ }^{\circ} \mathrm{C}$ and tetrahydrofuran was the solvent at a flowrate of $1 \mathrm{ml} / \mathrm{min}$. Molecular weights were determined by calibration against polystyrene solutions with molecular weights ranging from 162 to $27,810 \mathrm{Da}$. 


\section{Chapter 2}

\subsection{Lignin cleavage and condensation model}

The cleaving rate of MWL during treatments by lactic acid and DES was modeled by the model of Marathe et al. [34]. Although this model was originally developed for pyrolysis, pulping and pyrolysis treatments cause both cleaving and condensation reactions in lignin. Therefore, this model was deemed suitable for pulping reactions as well. In the model, the molar weight distributions before and after the treatment (as determined by GPC) were converted to a population balance of the degrees of polymerization. In this conversion it was assumed that each lignin polymer is a linear chain, consisting of identical monomers with a weight of $200 \mathrm{gram} / \mathrm{mol}$.

Two kinds of reactions were taken into account. First, lignin polymers with a DP can be cracked according to:

$D P_{i} \rightarrow D P_{j}+D P_{i-j}$

It is assumed that only the bonds connecting the monomer units present in the DP segment can be cracked. Therefore, this segment can be cracked in i-1 different ways. It is also assumed that the possibilities of cracking have the same likelihood, thus the rate constant $\left(k_{k}\right)$ is equal for all cracking reactions. Second, two lignin molecules can polymerize according to the following to the following reaction:

$D P_{j}+D P_{i-j} \rightarrow D P_{i}$

It is assumed that all molecules will polymerize with each other, in all possible combinations. Like in case of cracking, all polymerization possibilities have the same likelihood, thus the reaction rate constant $\left(k_{p}\right)$ is the same for all polymerization reactions. Both rate constants were fitted on the lactic acid treatment. Because the condensation and cleavage rate are highly correlated, the condensation rate of the lactic acid treatment is fixed on the DES treatment and a new cleavage rate is fitted. The ratio between the cleavage rate of the DES and lactic acid treatment is reported. A detailed description of the model can be found in the paper of Marathe et al. [34].

\subsection{Lignin diffusion coefficient estimation}

The effective lignin diffusion coefficients were calculated according to the method described by Zhao et al. [36]. In this method, the Stokes-Einstein equation with adaption to different temperatures by an Arrhenius expression was used to estimate the diffusion coefficient of lignin in pulping liquid. Zhao also showed a calculation for the radius of a lignin 


\section{Understanding the role of choline chloride in deep Eutectic solvents used for}

biomass delignification

molecule as function of the molar weight, and showed a factor to convert the diffusion coefficient to an effective diffusion coefficient in the cell wall. Detailed calculation can be found in the paper of Zhao et al. [36]. The molar weights of the lignins used in these calculations were determined by GPC and the viscosity of the DES liquors was measured using a Brookfield DV-E viscosity meter.

\section{Results}

\subsection{Effect of choline chloride to lactic acid ratio on pulping}

Eucalyptus chips were pulped using lactic acid, aqueous (65\%) choline chloride and a 1:10 molar mixture of choline chloride and lactic acid. This high ratio was chosen because it was shown by various authors that the amount of lignin removal from biomass increases upon a decrease in the amount of choline chloride $[18,21,22]$. These experiments were performed at $120^{\circ} \mathrm{C}$, as this was shown to be effective by Vasco et al. [17]. The reaction time was increased to $8 \mathrm{~h}$, since commercial wood chips were used instead of sawdust. The pulping trial using the aqueous choline chloride did not convert any wood chips, while the trial using only lactic acid showed a wood chip conversion of $49 \%$ to pulp or products dissolved in DES. The trial using DES showed a conversion of $95 \%$. Analysis of the lignin obtained by precipitation after the trials showed an average molar weight of $4300 \mathrm{~g} / \mathrm{mol}$ for the lignin obtained from lactic acid, while the molar weight of the lignin obtained from the DES with choline chloride was only $3200 \mathrm{~g} / \mathrm{mol}$, as can be seen in fig. 2.1. A pulping trial using only lactic acid for a prolonged time of $48 \mathrm{~h}$ was performed, which converted $97 \%$ of the wood chips, which is comparable to the trial with the choline chloride - lactic acid DES of $8 \mathrm{~h}$. Also the fiber yield and residual lignin content in the fibers of this trial are similar to the DES trial, but the molar weight of the lignin was $4150 \mathrm{~g} / \mathrm{mol}$, which is higher than molar weight of the DES lignin.

The $8 \mathrm{~h}$ pulping trials using the DES at $120^{\circ} \mathrm{C}$ were repeated with 5 choline chloride to lactic acid ratios between 1:10 and 1:250. It was found that the conversion did not differ significantly between the 1:10 and 1:50 choline chloride to lactic acid ratios. When this ratio was further increased to $1: 250$ the conversion decreased from 95 to $83 \%$. Also, the lignin content remaining in the fibers did not show a significant difference among all experiments performed, neither did the lignin content in the fibers. The results are summarized in fig. 2.2. 


\section{Chapter 2}

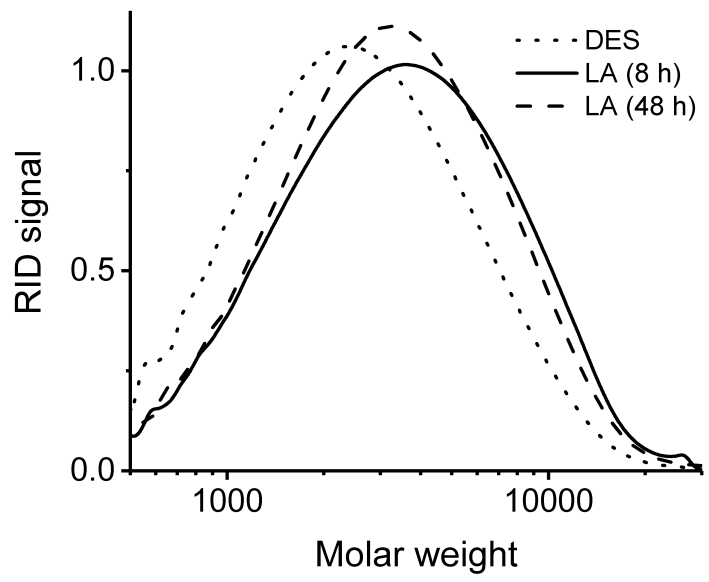

Fig. 2.1. Molar weight distributions of the lignins produced by lactic acid and the 1:10 choline chloride to lactic acid DES, as determined by GPC.

\subsection{Effect of other salts on lactic acid pulping}

In the previous sub-section, it was shown that the addition of small amounts choline chloride to lactic acid significantly increases the biomass conversion rate, but it is yet unknown whether this effect is caused by the cation, anion, or both. Therefore, eucalyptus was treated using lactic acid and various other salts containing choline, tetraethylammonium and sodium cations and chloride, bromide, sulfate and hydroxide as anions. The same conditions were used as with the trial using choline chloride and lactic acid, the results are given in Table 1. From Table 1 it follows that for all experiments using halides as anion an equal or higher conversion than the trial using choline chloride was observed, while all trials using sulfate and hydroxide resulted in a lower conversion than the trial using only lactic acid. When the same anion is used, all tests using sodium or TEA yielded a higher conversion than all trials using choline as cation. No significant differences were found between sodium and TEA as cations. It can thus be concluded that the role of the anion is more pronounced than the role of the cation. 


\section{Understanding the role of choline chloride in deep Eutectic solvents used for}

biomass delignification

Table 2.1. Conversion results (as defined in eq. 1) from biomass delignification experiments using lactic acid and various added salts (column: row matrix elements representing the conversion measured for that specific anion: cation combinations). All experiments were performed using a 1:10 molar ratio of salt to lactic acid at $120^{\circ} \mathrm{C}$ for $8 \mathrm{~h}$.

\begin{tabular}{|l|llll|}
\hline & $\mathrm{Cl}^{-}$ & $\mathrm{Br}$ & $\mathrm{SO}_{4}{ }^{2-}$ & $\mathrm{OH}^{-}$ \\
\hline Choline $^{+}$ & 95 & 95 & 4 & 2 \\
$\mathrm{Na}^{+}$ & 99 & n.d. $^{\mathrm{a}}$ & 37 & n.d. \\
TEA $^{+}$ & 99 & 99 & n.d. & n.d. \\
\hline
\end{tabular}

${ }^{a}$ n.d. is not determined (these were not part of the measured combinations, no specific reason)

\subsection{Effect of choline chloride on lignin solubility}

An excess amount of kraft lignin was added to the same amounts of DES and lactic acid. Kraft lignin was selected since this was also used by Franciso et al. [15]. These mixtures were equilibrated overnight in a shaking bath. After filtering off the excess lignin, the solutions were diluted in ethanol and the absorption was determined by UV-VIS. The UV-VIS absorption was multiplied by the dilution factor of DES or lactic acid in ethanol. This product was taken as a measure of lignin concentration. Lignin concentrations around $10 \mathrm{wt} \%$ were found and the lignin solubility in lactic acid was $4.6 \%$ (relative to the $10 \%$ ) higher than in the DES. Assuming that the values obtained with kraft lignin are representative for the lignin obtained by pulping with DES, it appears that the lignin solubility is not a discerning factor for the overall rate of the delignification process. Considering that on the basis of the lignin content in eucalyptus of typically around 20 percent, and the applied DES to wood ratio of $20: 1$, a lignin concentration around $1 \mathrm{wt} \%$ is obtained when all lignin is removed from the wood. Therefore, it is not surprising that the lignin solubility under applied conditions is not a discerning factor. 


\section{Chapter 2}

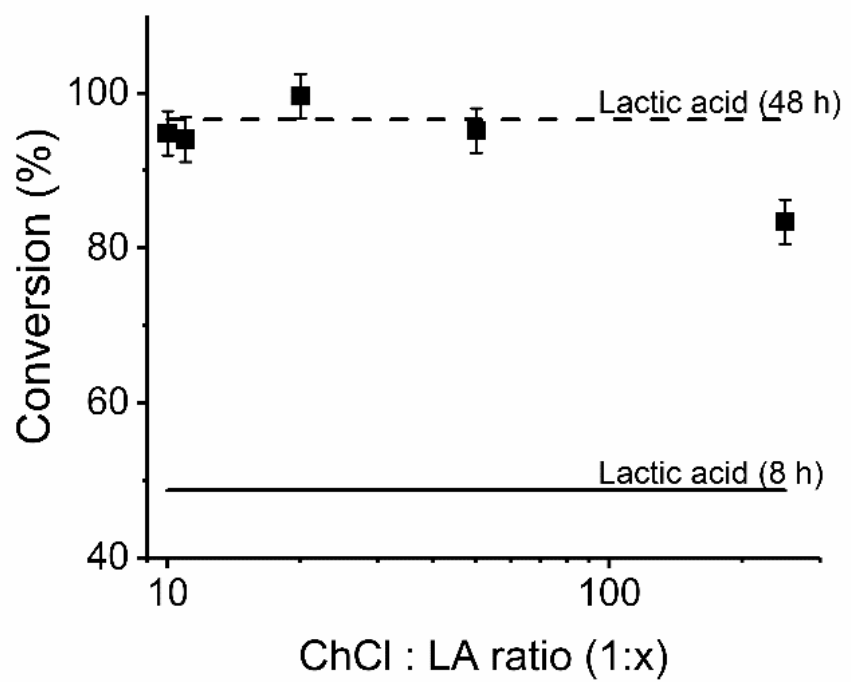

a)

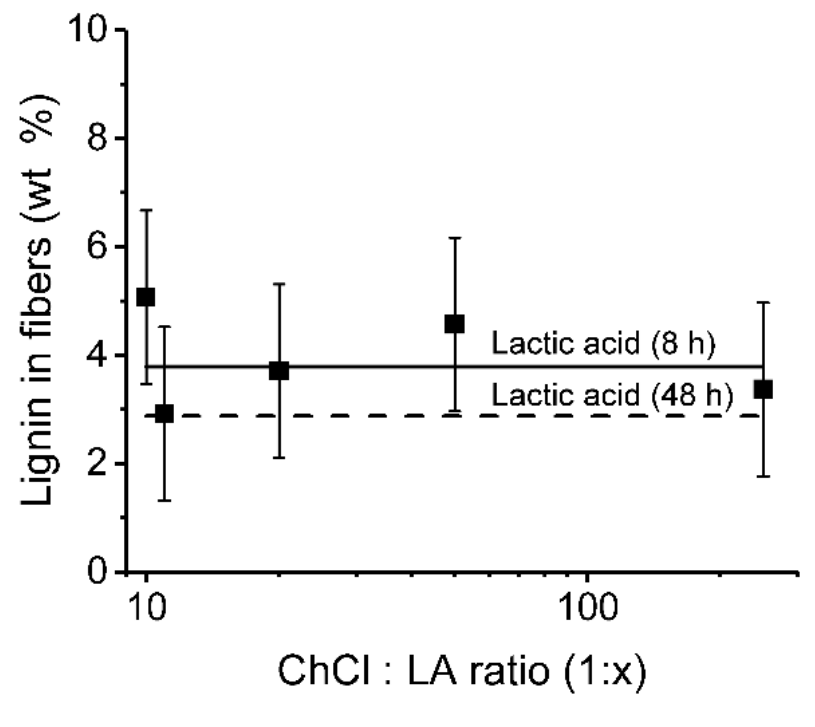

Fig. 2.2. Results of biomass delignification trials of eucalyptus using lactic acid and various DES mixtures containing choline chloride at $120^{\circ} \mathrm{C}$. The symbols show results from delignification trials using the DESs after an $8 \mathrm{~h}$ treatment. Solid lines show the results from the trial with lactic acid for $8 \mathrm{~h}$ and the dashed line the results for $48 \mathrm{~h}$. a: conversion, $\mathrm{b}$ : fiber yield, c: lignin content in the fibers and d: delignification for various molar ratios of choline chloride (1) to lactic acid ( $x$ ). Terminology is defined in section 2. Error bars show the $95 \%$ t-statistic confidence intervals. 
Understanding the role of choline chloride in deep Eutectic solvents used for biomass delignification

b)
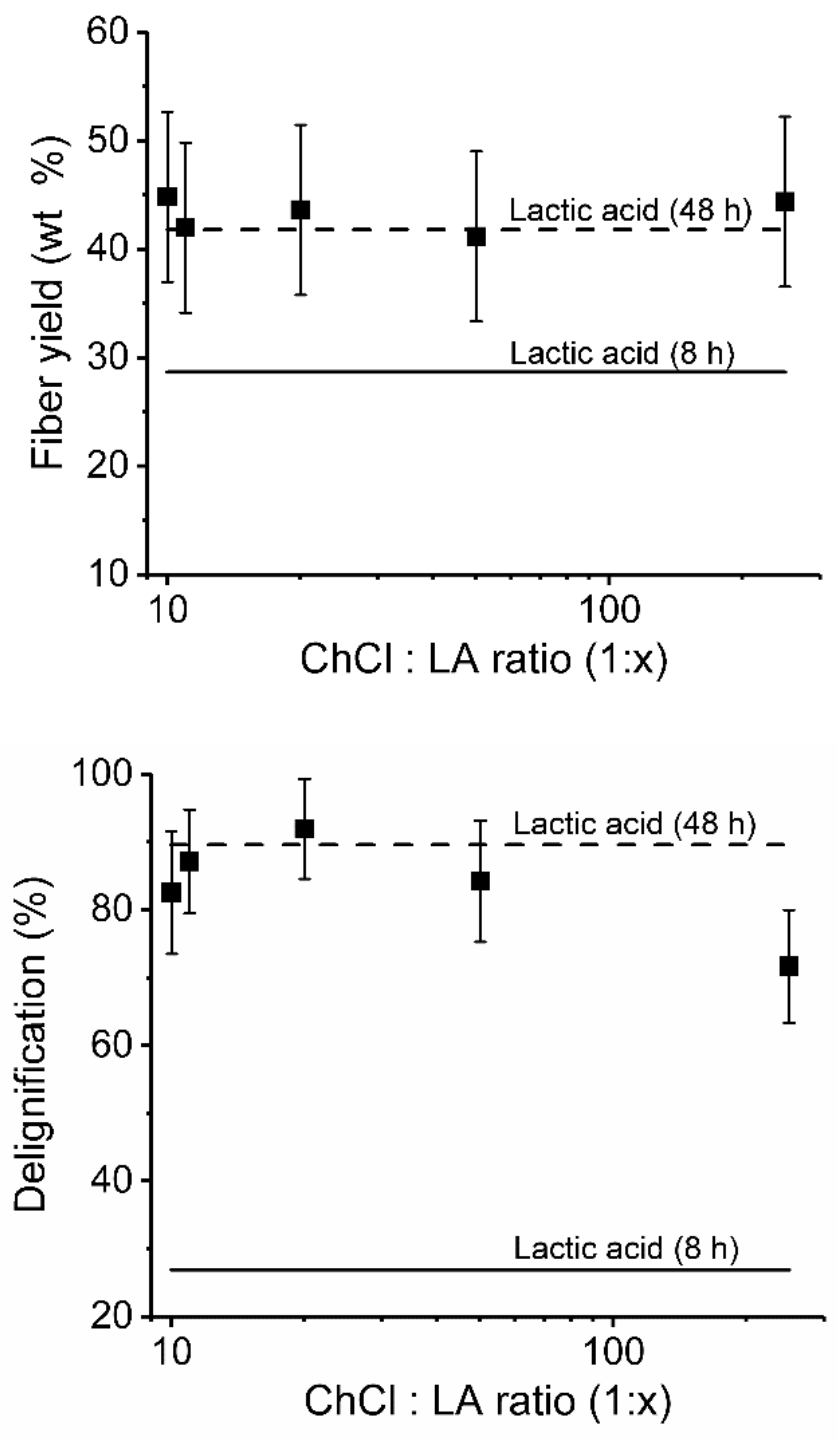


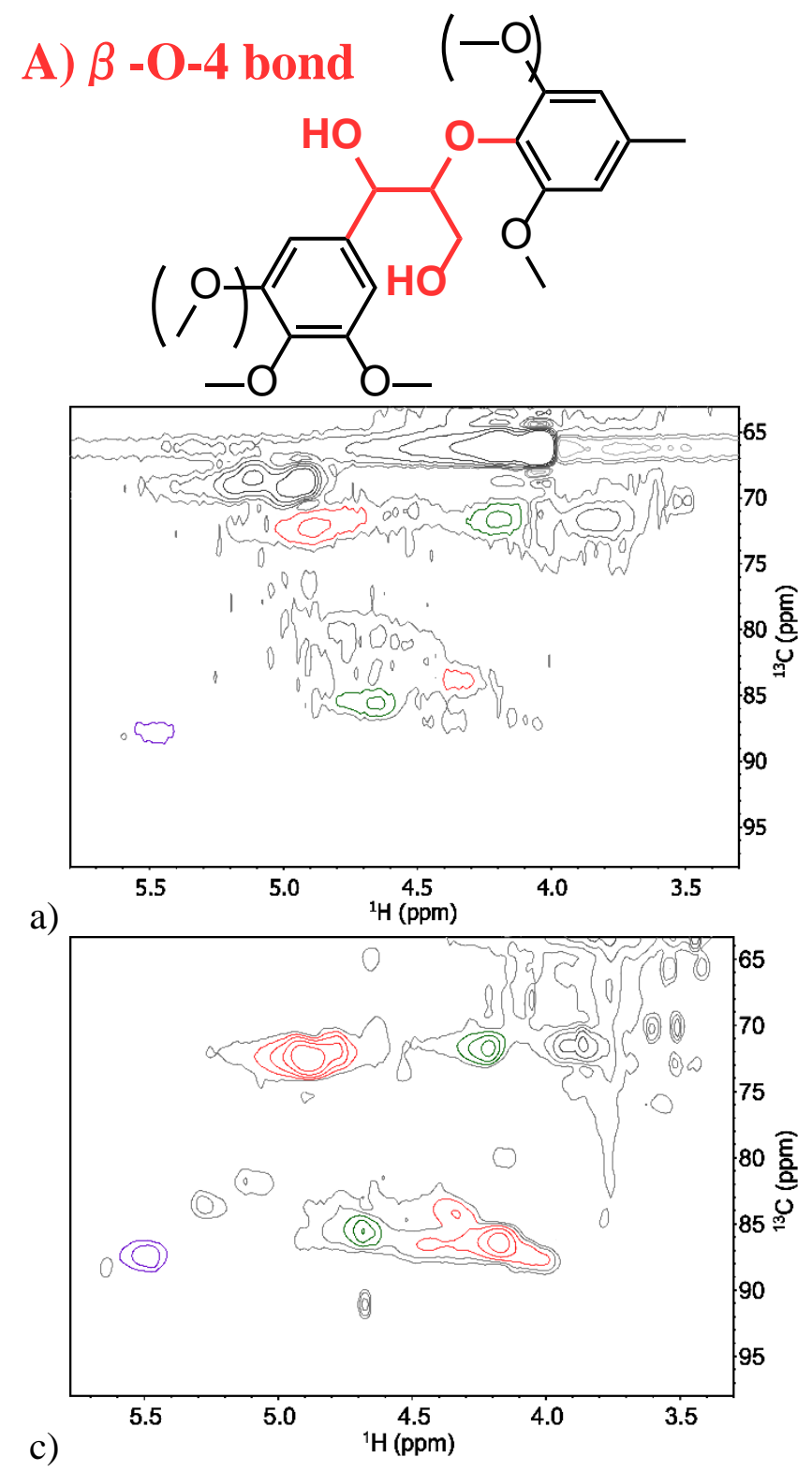

Fig. 2.3. Main lignin bonds A) $\beta-O-4$, B) $\beta-5$ and C) $\beta-\beta$. a-c: $\delta{ }^{1} H$ and $\delta^{13} C, 3.3-5.8$ and $63-98$ ppm, respectively, regions in the 2D HSQC NMR of a: MWL treated by lactic acid, b: MWL treated by DES, c: original MWL. d: Number of inter-aromatic bonds per 100 aromatic rings in MWL before (left) and after treatment by lactic acid (middle) and DES (right) at $120^{\circ} \mathrm{C}$ for $1 \mathrm{~h}$. The tinted bars show the $\beta-0-4$ (red), $\beta-5$ (purple) and $\beta-\beta$ (green) fractions as quantified by HSQC. The grey bars represent bonds that were unidentified. 
Understanding the role of choline chloride in deep Eutectic solvents used for biomass delignification

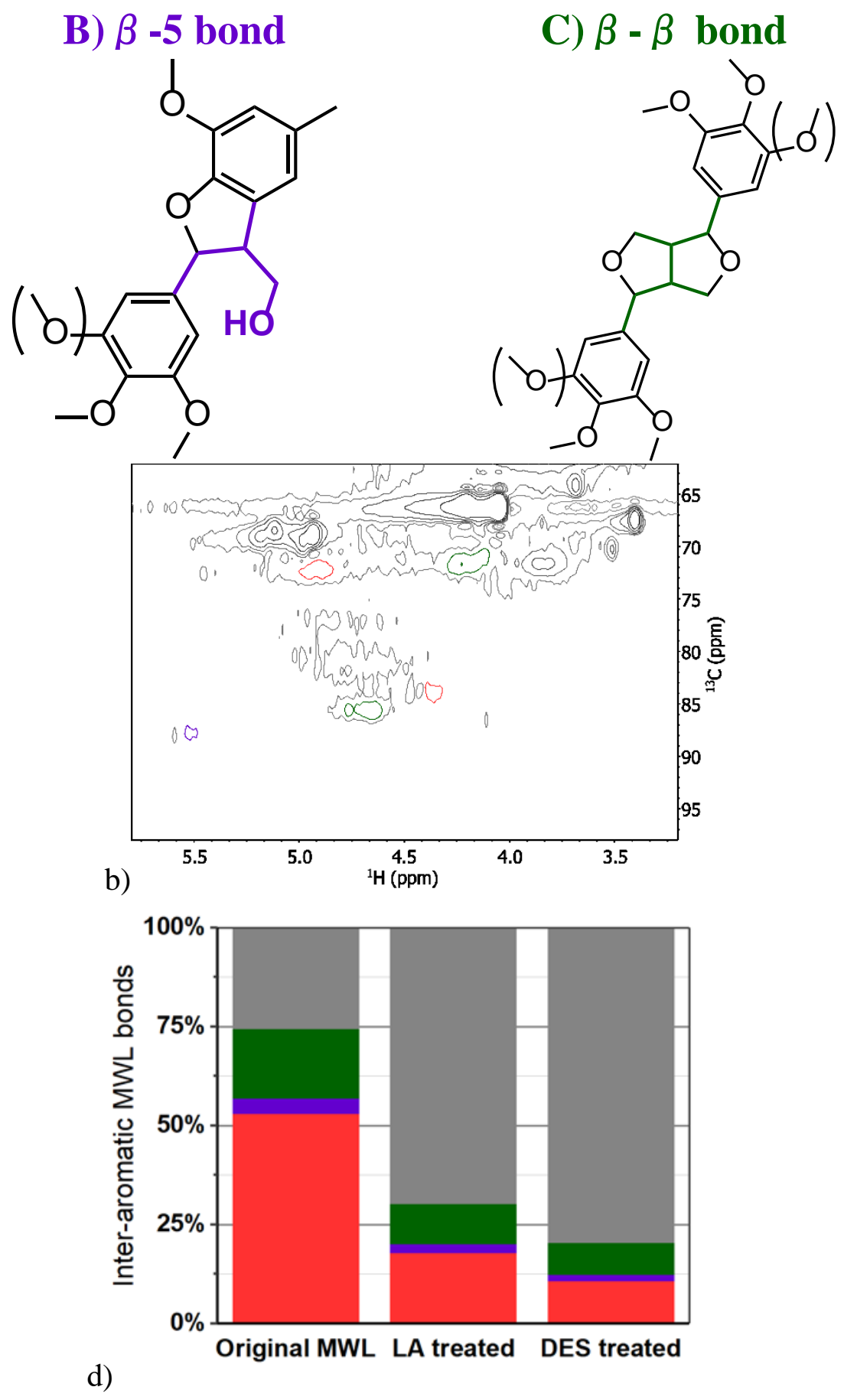




\section{Chapter 2}

\subsection{Effect of choline chloride on inter-lignin cleaving reactions}

The effect of the choline chloride on the lignin cleaving reactions without mass transfer effects was investigated by applying pulping conditions to MWL that was dissolved in lactic acid and DES, respectively. Three inter-aromatic bonds in lignin were quantified by ${ }^{1} \mathrm{H}-{ }^{13} \mathrm{C}$ 2D HSQC NMR spectroscopy and the lignin molar weight distribution was determined by GPC, both before and after treatments using lactic acid, with and without the addition of choline chloride.

Before any treatments, the MWL contained 53 ß-O-4 bonds per 100 aromatic units. After treatment by lactic acid this number decreased to 18 bonds, while after treatment by the $D E S$, this number decreased to 11 , suggesting more bond-breaking activity of the DES than with lactic acid only. Also, the molar weight of the MWL decreased more after the DES treatment than after the lactic acid treatment. The HSQC spectra and the number of $\mathrm{B}-\mathrm{O}-4$, $ß-ß$ and $ß-5$ bonds before and after both treatments are shown in fig. 2.3.

The changes in the molar weight distributions after the treatments were fitted to the model of Marathe et al. [34]. In the fit, the condensation rate constant was kept constant and the cleavage rate constant was fitted to the molar weight distributions. The results of the model satisfactory fit the data and are shown in fig. 2.4. The model showed a $90 \%$ increase in the lignin cleavage rate constant upon the addition of choline chloride to lactic acid.

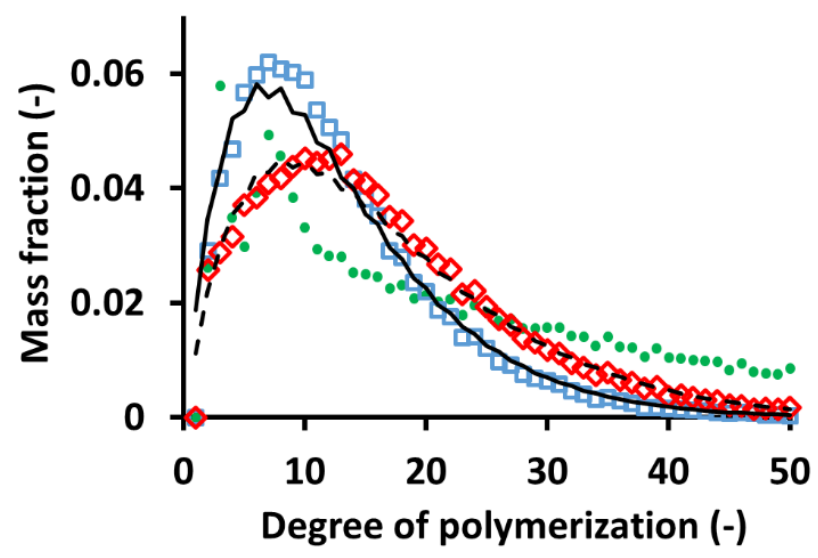

Fig. 2.4. Population balance of MWL before and after treatments at $120^{\circ} \mathrm{C}$ for 1 hour by lactic acid and DES, as determined by GPC. Green dots show the original MWL, red diamonds MWL after treatment by lactic acid and blue squares after treatment by DES. The solid line shows the fit of the DES treatment and the dashed line the fit of the lactic acid treatment. 


\section{Understanding the role of choline chloride in deep Eutectic solvents used for}

biomass delignification

\subsection{Effect of choline chloride on swelling and mass transfer}

A SEM picture (see fig. 2.5) was taken of a eucalyptus chip treated by aqueous choline chloride for 8 hours at $120^{\circ} \mathrm{C}$. After treatment, the chip was split perpendicularly to the longitudinal direction. After cooking in aqueous choline chloride, no obvious signs of swelling, or disruption of the cell walls (as observed by Kanbayashi [35]) could be observed.

The average effective diffusion coefficient of the lignins were calculated according to the method of Zhao et al. [36]. For the calculations the mass average molar weights of the lignins were used as determined by GPC. The lignin produced by lactic acid ( $48 \mathrm{~h}$ ) had an average molar weight of $4150 \mathrm{gram} / \mathrm{mol}$ and the liquor had a viscosity of $0.808 \mathrm{P}$, which resulted in an average effective diffusion coefficient of $5.0 \cdot 10^{-13} \mathrm{~m}^{2} / \mathrm{s}$. The 1:10 choline chloride to lactic acid DES had a viscosity of $0.951 \mathrm{P}$ after pulping and the lignin had an average molar weight of $3200 \mathrm{gram} / \mathrm{mol}$, which resulted in an average effective diffusion coefficient of $4.8 \cdot 10^{-13} \mathrm{~m}^{2} / \mathrm{s}$. Thus, the beneficial effect of the lower lignin molar weight in the DES was counteracted by the increase in viscosity, caused by the addition of choline chloride [40].

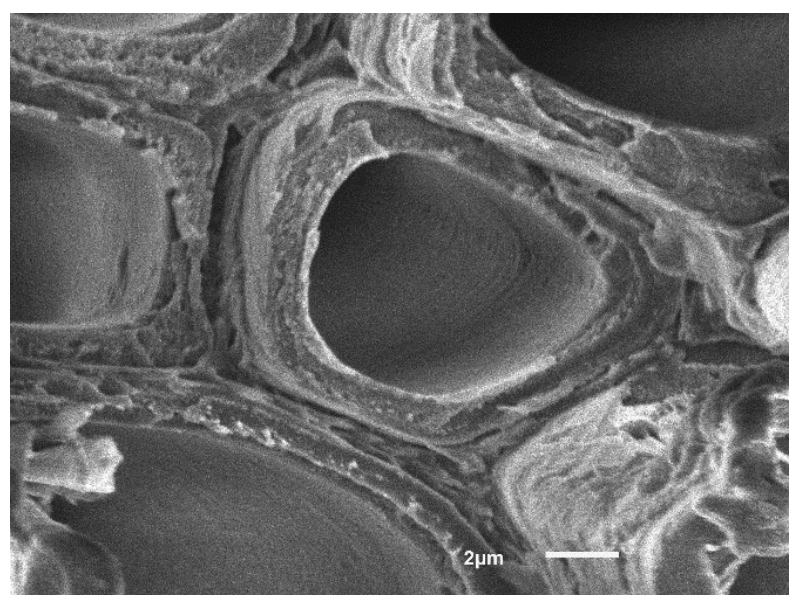

Fig. 2.5. SEM image of eucalyptus treated by aqueous choline chloride ( $65 \mathrm{wt} \%$ ) for $8 \mathrm{~h}$ at $120^{\circ} \mathrm{C}$. 


\section{Chapter 2}

\section{Discussion}

\subsection{The effect of choline chloride on pulping}

The pulping experiments using lactic acid with and without addition of choline chloride show a clear increase in conversion upon the addition of choline chloride. When only lactic acid is used for a prolonged time of $48 \mathrm{~h}$, a similar conversion was observed as in the experiment using DES for $8 \mathrm{~h}$, meaning that although the delignification rate was increased, the addition of choline chloride is not a pre-requisite. Furthermore, this experiment did not show any significant differences in fiber yield or lignin content in the fibers, indicating the observed effects are merely kinetic.

The experiments using various salts other than choline chloride showed that only addition of salts containing halogen anions result in a similar conversion as with choline chloride or higher. However, all salts containing choline as cation show a lower conversion than salts containing $\mathrm{TEA}^{+}$or $\mathrm{Na}^{+}$and the same anion. Based on this comparison, it is concluded that the chloride anion is causing the increased delignification rate when adding choline chloride to the pulping mixture with lactic acid.

\subsection{Effects on Solubility}

Francisco et al. [15] investigated the solubility of kraft lignin in DESs with lactic acid to choline chloride ratios between $1.3: 1$ to $10: 1$. They found that the solubility of lignin increases with decreasing amounts of choline chloride, but the solubility in pure lactic acid was not determined. We compared the solubility of kraft lignin in lactic acid to its solubility in the 10:1 lactic acid to choline chloride DES by adding an excess amount of lignin to the solvents. Lignin solubilities around $10 \mathrm{wt} \%$ were found, consistent with the experiments reported by Francisco. However, the lignin solubility in lactic acid was slightly higher than in the DES. Various authors proposed DESs as suitable solvents for biomass delignification because of their high lignin solubility $[15,17,41]$. However, based on the effects here described, the observed increase of the delignification rate upon the addition of choline chloride to lactic acid is not caused by an increase in lignin solubility. Considering the solubility of lignin in the DES, and the expected maximum concentrations based on the lignin content and wood, and the DES to wood ratio, using DES instead of lactic acid will also not induce a limitation due to the slightly lower lignin solubility. 


\section{Understanding the role of choline chloride in deep Eutectic solvents used for}

biomass delignification

\subsection{Effects on lignin reactions}

From the MWL experiments is seems that the $\beta-0-4$ bonds in lignin are cleaved faster by the DES than by pure lactic acid. Imai et al. [42] treated a $\beta-0-4$ model compound by various acids and found that this model was cleaved faster by $\mathrm{HCl}$ and $\mathrm{HBr}$ than by $\mathrm{H}_{2} \mathrm{SO}_{4}$. They proposed a different reaction mechanism for the cleavage of the $\beta-0-4$ bond by $\mathrm{HCl}$ than by $\mathrm{H}_{2} \mathrm{SO}_{4}$. Briefly, they proposed that the mechanism using $\mathrm{H}_{2} \mathrm{SO}_{4}$ involves the liberation of formaldehyde from the $\gamma$-hydroxymethyl groups in lignin, while the mechanisms using $\mathrm{HCl}$ and $\mathrm{HBr}$ involve a benzyl cation type intermediate. Similar to the observations and conclusions of Imai et al. [42], We presume that the addition of chloride ions to lactic acid allows cleavage of the $\beta-0-4$ bond by a different (faster) reaction mechanism, such as proposed by Imai. [42]. During acidic treatments, $ß-5$ bond may be converted to stilbene structures, while $ß-ß$ structures do not seem to be cleaved by acid hydrolysis $[43,44]$. Thus, these bonds do not split two lignin monomers upon acidic treatments.

By fitting the lignin cleavage and condensation model of Marathe et al. [34] to the molar weight distribution curves obtained after $1 \mathrm{~h}$ treatment of MWL with DES and with lactic acid without choline chloride, a 90\% increase in the cleaving rate of lignin was observed upon the addition of choline chloride to lactic acid. In this approach, the lignin condensation rate was kept constant in this model. Although it is recognized that any possible influence of choline chloride on lignin condensation reactions [45] cannot be excluded with the current results, it does show that chloride has an effect on the reaction rates, and the increased rate of delignification cannot be ascribed to merely mass transfer effects.

As a further support to this statement, Liu et al. postulated that chloride ions help to cleave lignin carbohydrate complexes (LCC) in biomass [23]. However, their result is not fully comparable with ours, since they found that benzyl ether bonds between lignin and carbohydrates were present in MWL, but not in the lignin after their DES treatment of biomass. In our work, we could identify benzyl ether bonds in MWL before and after treatments by both lactic acid and DES. Therefore, it seems that these bonds were not cleaved during the DES treatment. It is plausible that the LCCS from Liu's DES delignification experiments remained in the residual lignin of the cellulose residue. 


\section{Chapter 2}

\subsection{Effects on mass transfer}

Kanbayashi and Miyafuji [35] treated Japanese cedar wood by chloride and bromide based ionic liquids. They found by SEM analysis that the cell walls were broken and dissociated by swelling of the middle layer of the secondary cell wall, which was induced by these ionic liquids. We treated wood chips by an aqueous choline chloride solution and found the wood structure to be intact after the treatment. We did not observe swelling effects similar to those observed by Kanbayashi and Miyafuji [35]. This means the choline chloride does not act as a swelling agent for the wood chips, and increased delignification is not due to easier mass transfer due to swollen wood.

Next to swelling of the wood, also differences in lignin fractions may result in differences in mass transfer rate. As observed from the GPC results, the average molar weight of the lignin produced by DES is lighter than the lignin produced by only lactic acid. Smaller lignin fractions will diffuse faster out of the wood matrix than larger fractions and thereby increase the pulping rate. However, this benefit was counteracted by the higher viscosity of the DES compared to lactic acid. 


\section{Understanding the role of choline chloride in deep Eutectic solvents used for}

biomass delignification

\section{Conclusions and outlook}

Addition of choline chloride to lactic acid increases the pulping rate of eucalyptus chips. Choline chloride is already effective at a ratio of 1:250 to lactic acid, as opposed to the high amounts currently used by other researchers. It was found that the chloride ion is the active ingredient in choline chloride. In fact, an inexpensive salt such as $\mathrm{NaCl}$ performed as well as choline chloride.

The effect of choline chloride on lignin solubility, cleaving reactions and mass transfer were investigated in order to gain understanding of the observed pulping results. Addition of choline chloride to lactic acid slightly decreased the lignin solubility. Studies on MWL showed that the $\beta-0-4$ cleavage rate increased, as demonstrated by HSQC. The wood chips did not show swelling, nor break-up after treatment by aqueous choline chloride. Furthermore, the mass transfer coefficient of lignin in the cell wall slightly decreases when choline chloride is added to lactic acid.

The findings reported in this article can be used as a spur for further solvent development or optimization for biomass delignification. A suitable solvent will preferably be inexpensive, non-toxic and bio-based. The previously proposed DESs have all of these properties, but this study has shown that other options, such as mixtures of organic acids with inorganic salts, should also be considered. Alternatively, one can consider mixtures between organic solvents and $\mathrm{HCl}$ as a catalyst. Many of these mixtures, e.g. ethylene glycol with $\mathrm{HCl}$, have been studied in earlier work [8], and those findings should be taken into account when searching for new (and deep eutectic) solvents for biomass delignification. 


\section{Bibliography}

[1] A.A. Rosatella, S.P. Simeonov, R.F.M. Frade, C.A.M. Afonso, 5-Hydroxymethylfurfural (HMF) as a building block platform: Biological properties, synthesis and synthetic applications, Green Chem. 13 (2011) 754-793. doi:10.1039/C0GC00401D.

[2] S.N. Naik, V. V Goud, P.K. Rout, A.K. Dalai, Production of first and second generation biofuels: A comprehensive review, Renew. Sustain. Energy Rev. 14 (2010) 578-597. doi:10.1016/j.rser.2009.10.003.

[3] M. Dusselier, P. Van Wouwe, A. Dewaele, E. Makshina, B.F. Sels, Lactic acid as a platform chemical in the biobased economy: The role of chemocatalysis, Energy Environ. Sci. 6 (2013) 1415-1442. doi:10.1039/C3EE00069A.

[4] R. Rinaldi, R. Jastrzebski, M.T. Clough, J. Ralph, M. Kennema, P.C.A. Bruijnincx, B.M. Weckhuysen, Paving the Way for Lignin Valorisation: Recent Advances in Bioengineering, Biorefining and Catalysis, Angew. Chemie Int. Ed. 55 (2016) 8164-8215. doi:10.1002/anie.201510351.

[5] N.J. Westwood, I. Panovic, C.S. Lancefield, Chemical Modification of Lignin for Renewable Polymers or Chemicals, in: Z. Fang, J. Smith Richard L. (Eds.), Prod. Biofuels Chem. from Lignin, Springer, Singapore, 2016: pp. 183-216. doi:10.1007/978-981-10-1965-4_7.

[6] M. Ragnar, G. Henriksson, M.E. Lindström, M. Wimby, J. Blechschmidt, S. Heinemann, Pulp, in: Ullmann's Encycl. Ind. Chem., 2014. doi:10.1002/14356007.a18_545.pub4.

[7] A.W. Rudie, P.W. Hart, Catalysis-a potential alternative to kraft pulping, Tappi J. 13 (2014) 13-20.

[8] E. Muurinen, Organosolv Pulping. A Review and Distillation Study Related to Peroxyacid Pulping, PhD Thesis, Univ. Oulu. (2000).

[9] S. Aziz, K. Sarkanen, Organosolv pulping - a review., Tappi J. 72 (1989) 169-175.

[10] P. Stockburg, An overview of near-commercial and commercial solvent-based pulplng processes, Tappi. Vol 76, No (1993) 71-74.

[11] A. Rodriguez, L. Jimenez, Pulping with organic solvents other than alcohols., Afinidad. 65 (2008) 188-196.

[12] T. Kajimoto, Y. Tachibana, Y. Maeda, S. Kubota, T. Hata, Y. Imamura, Characterization of the Pulp-Like Fibers Separated from Sugi with L-Lactic Acid, Mokuzai Gakkaishi. 54 (2008) 319326. doi:10.2488/jwrs.54.319.

[13] A.P. Abbott, D. Boothby, G. Capper, D.L. Davies, R. Rasheed, Deep Eutectic Solvents Formed Between Choline Chloride and Carboxylic Acids, J. Am. Chem. Soc. 126 (2004) 9142-9147. doi:10.1021/ja048266j.

[14] B. Schuur, T. Brouwer, D. Smink, L.M.J. Sprakel, Green solvents for sustainable separation processes, Curr. Opin. Green Sustain. Chem. 18 (2019) 57-65. doi:10.1016/j.cogsc.2018.12.009.

[15] M. Francisco, A. van den Bruinhorst, M.C. Kroon, New natural and renewable low transition temperature mixtures (LTTMs): screening as solvents for lignocellulosic biomass processing, Green Chem. 14 (2012) 2153-2157. doi:10.1039/C2GC35660K.

[16] D.J.G.P. Van Osch, L.J.B.M. Kollau, A. Van Den Bruinhorst, S. Asikainen, M.A.A. Rocha, M.C. Kroon, lonic liquids and deep eutectic solvents for lignocellulosic biomass fractionation, Phys. Chem. Chem. Phys. 19 (2017) 2636-2665. doi:10.1039/c6cp07499e.

[17] C. Alvarez-Vasco, R. Ma, M. Quintero, M. Guo, S. Geleynse, K.K. Ramasamy, M. Wolcott, X. Zhang, Unique low-molecular-weight lignin with high purity extracted from wood by deep eutectic solvents (DES): a source of lignin for valorization., Green Chem. 18 (2016) 5133 5141. doi:10.1039/c6gc01007e. 


\section{Understanding the role of choline chloride in deep Eutectic solvents used for}

biomass delignification

[18] J. Chang, J. Liu, S.J. Guo, X.F.Y. Wang, Investigation into selective separation of lignin in novel deep eutectic solvent, J. South China Univ. Technol. 44 (2016) 14-20. doi:10.3969/j.issn.1000-565X.2016.06.003.

[19] A.K. Kumar, B.S. Parikh, M. Pravakar, Natural deep eutectic solvent mediated pretreatment of rice straw: bioanalytical characterization of lignin extract and enzymatic hydrolysis of pretreated biomass residue., Environ. Sci. Pollut. Res. 23 (2016) 9265-9275. doi:10.1007/s11356-015-4780-4.

[20] M. Jablonský, A. Škulcová, L. Kamenská, M. Vrška, J. Šíma, Deep Eutectic Solvents: Fractionation of Wheat Straw, BioResources. 10 (2015) 8039-8047. doi:10.15376/biores.10.4.8039-8047.

[21] C.W. Zhang, S.Q. Xia, P.S. Ma, Facile pretreatment of lignocellulosic biomass using deep eutectic solvents, Bioresour. Technol. 219 (2016) 1-5. doi:10.1016/j.biortech.2016.07.026.

[22] A.L. Li, X.D. Hou, K.P. Lin, X. Zhang, M.H. Fu, Rice straw pretreatment using deep eutectic solvents with different constituents molar ratios: Biomass fractionation, polysaccharides enzymatic digestion and solvent reuse, J. Biosci. Bioeng. 126 (2018) 346-354. doi:10.1016/j.jbiosc.2018.03.011.

[23] Y. Liu, W. Chen, Q. Xia, B. Guo, Q. Wang, S. Liu, Efficient Cleavage of Lignin - Carbohydrate Complexes and Ultrafast Extraction of Lignin Oligomers from Wood Biomass by MicrowaveAssisted Treatment with Deep Eutectic Solvent, ChemSusChem. 10 (2017) 1692-1700. doi:10.1002/cssc.201601795.

[24] J.R. Dillen, S. Dillén, M.F. Hamza, Pulp and Paper: Wood Sources, in: Ref. Modul. Mater. Sci. Mater. Eng., Elsevier, 2016. doi:10.1016/B978-0-12-803581-8.09802-7.

[25] CEPI, Key Statistics, European pulp and paper industry, Confederation of European Paper Industries, Brussels, 2018.

[26] J.L.K. Mamilla, U. Novak, M. Grilc, B. Likozar, Natural deep eutectic solvents (DES) for fractionation of waste lignocellulosic biomass and its cascade conversion to value-added biobased chemicals, Biomass and Bioenergy. 120 (2019) 417-425. doi:10.1016/j.biombioe.2018.12.002.

[27] T. Klamrassamee, V. Champreda, V. Reunglek, N. Laosiripojana, Comparison of homogeneous and heterogeneous acid promoters in single-step aqueous-organosolv fractionation of eucalyptus wood chips, Bioresour. Technol. 147 (2013) 276-284. doi:10.1016/j.biortech.2013.08.015.

[28] E. Brännvall, The Limits of Delignification in Kraft Cooking, BioResources. 12 (2017) 20812107. doi:10.15376/biores.12.1.2081-2107.

[29] E.I. Evstigneev, Factors affecting lignin solubility, Russ. J. Appl. Chem. 84 (2011) 1040-1045. doi:10.1134/S1070427211060243.

[30] W.G. Glasser, C.A. Barnett, The structure of lignins in pulps. II. a comparative evaluation of isolation methods, Holzforschung. 33 (1979) 78-86. doi:10.1515/hfsg.1979.33.3.78.

[31] T. McDonough, The chemistry of organosolv delignification, Tappi J. 76 (1993) 186-193.

[32] S. Constant, H.L.J. Wienk, A.E. Frissen, P. de Peinder, R. Boelens, D.S. van Es, R.J.H. Grisel, B.M. Weckhuysen, W.J.J. Huijgen, R.J.A. Gosselink, P.C.A. Bruijnincx, New insights into the structure and composition of technical lignins: a comparative characterisation study, Green Chem. 18 (2016) 2563-2910. doi:10.1039/C5GC03043A.

[33] J. Gierer, Chemistry of delignification. Part 1: General concept and reactions during pulping., Wood Sci. Technol. 19 (1985) 289-312. doi:10.1007/BF00350807.

[34] P.S. Marathe, R.J.M. Westerhof, S.R.A. Kersten, Fast pyrolysis of lignins with different molecular weight: Experiments and modelling, Appl. Energy. 236 (2019) 1125-1137. doi:10.1016/j.apenergy.2018.12.058. 


\section{Chapter 2}

[35] T. Kanbayashi, H. Miyafuji, Effect of ionic liquid treatment on the ultrastructural and topochemical features of compression wood in Japanese cedar (Cryptomeria japonica), Sci. Rep. 6 (2016) 1-8. doi:10.1038/srep30147.

[36] X. Zhao, R. Wu, D. Liu, Evaluation of the mass transfer effects on delignification kinetics of atmospheric acetic acid fractionation of sugarcane bagasse with a shrinking-layer model, Bioresour. Technol. 261 (2018) 52-61. doi:10.1016/j.biortech.2018.03.140.

[37] A. Sluiter, B. Hames, R. Ruiz, C. Scarlata, J. Sluiter, D. Templeton, D. Crocker, Determination of Structural Carbohydrates and Lignin in Biomass, NREL/TP; 510-42618. Golden, CO, 2012.

[38] A. Bjorkman, Studies on Finely Divided Wood. Part I. Extraction of lignin with neutral solvents, Sven. Papperstidning. 59 (1956) 477-485.

[39] H. Koskela, I. Kilpeläinen, S. Heikkinen, Some aspects of quantitative 2D NMR, J. Magn. Reson. 174 (2005) 237-244. doi:10.1016/j.jmr.2005.02.002.

[40] M. Francisco, A. Van Den Bruinhorst, M.C. Kroon, Low-transition-temperature mixtures (LTTMs): A new generation of designer solvents, Angew. Chemie - Int. Ed. 52 (2013) 30743085. doi:10.1002/anie.201207548.

[41] Y.L. Loow, T.Y. Wu, G.H. Yang, L.Y. Ang, E.K. New, L.F. Siow, J. Md. Jahim, A.W. Mohammad, W.H. Teoh, Deep eutectic solvent and inorganic salt pretreatment of lignocellulosic biomass for improving xylose recovery, Bioresour. Technol. 249 (2018) 818-825. doi:10.1016/j.biortech.2017.07.165.

[42] T. Imai, T. Yokoyama, Y. Matsumoto, Revisiting the mechanism of $\beta-0-4$ bond cleavage during acidolysis of lignin IV: dependence of acidolysis reaction on the type of acid, J. Wood Sci. 57 (2011) 219-225. 10.1007/s10086-010-1166-6.

[43] K. Lundquist, K. Hedlund, Acid degradation of lignin. V. Degradation products related to the phenylcoumaran type of structure., Acta Chem. Scand. 25 (1971) 2199-2210.

[44] K. Lundquist, R. Lundgren, Acid degradation of lignin. VII. Cleavage of ether bonds., Acta Chem. Scand. 26 (1972) 2005-2023.

[45] S. Yasuda, Y. Abe, Y. Hirokaga, Behavior of Lignin in Organic Acid Pulping. Part III. Additive Effects of Potassium and Sodium Halides on Delignification, Holzforschung. 45 (1991) 79-82. doi:10.1515/hfsg.1991.45.s1.79. 


\section{Chapter 3}

\section{Recovery of lignin from deep eutectic solvents by liquid-liquid extraction}

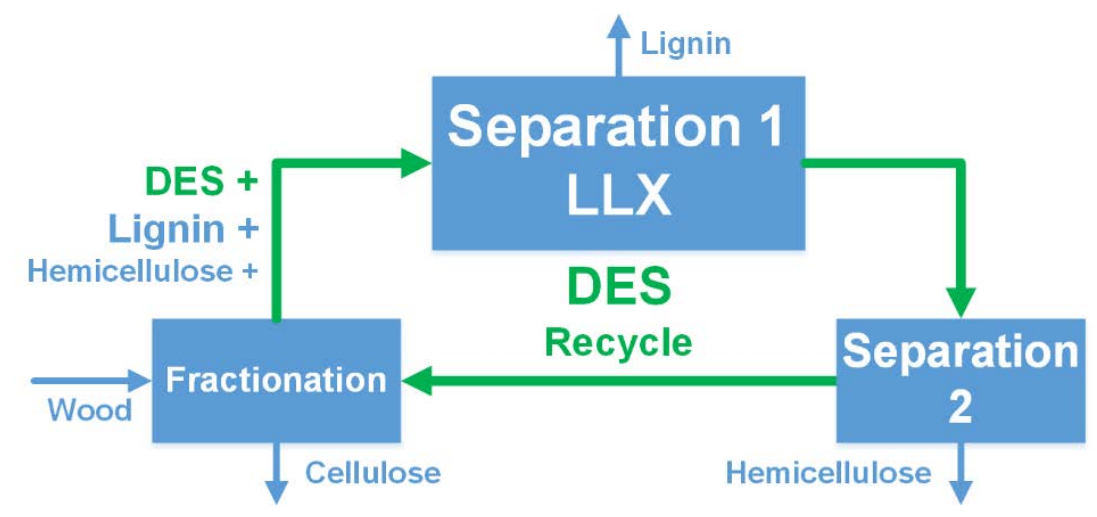




\begin{abstract}
After biomass fractionation using deep eutectic solvents (DESs), solvent recovery is an essential step. Laboratory routine is to precipitate lignin using cold water, however large amounts of water are required, resulting in energy intensive operations. Therefore, we propose liquid-liquid extraction as alternative method for industrial applications, and have studied this to recover lignin from a DES consisting of lactic acid and choline chloride, which we applied in various ratios. In this study six solvents were investigated for this purpose, from which 2-methyl tetrahydrofuran (2-MTHF) was selected for further studies. The phase equilibria between the DES and 2-MTHF were determined at 25,50 and $75{ }^{\circ} \mathrm{C}$. At least $30 \mathrm{wt} \%$ choline chloride in the DES was required to form two phases. Addition of more choline chloride decreases the mutual solubility of 2-MTHF and lactic acid. The overall equilibrium lignin distribution between DES and solvent did not change much with varying DES compositions, but the distribution was dependent on the molar mass of lignin. The low molar weight fractions showed a distribution coefficient around 1, while for the heavy fractions the distribution coefficient was below 0.1 . Addition of water changes the system greatly, and high molar mass lignin extraction is tremendously enhanced. At $25 \mathrm{wt}$ $\%$ water in the DES, the minimum distribution coefficient was 4, allowing effective extraction of lignin from DES by 2-MTHF.
\end{abstract}




\section{Introduction}

DESs are composite solvents that exhibit deep eutectic behavior upon mixing the constituents, meaning the melting points of these mixtures is reduced considerably more $\left(>50^{\circ} \mathrm{C}\right.$ ) than would be the case for ideal mixtures $[1,2]$. These solvents can easily be prepared in numerous ways by combining a hydrogen bond donor and acceptor [3] and are often biocompatible, biodegradable [4] and can have a low toxicity [5].

Lignocellulose can be converted into cellulose fibers and lignin by delignification technologies. The obtained cellulose pulp can be used for paper production, production of other materials, or can be converted to bio-ethanol or other platform chemicals [6-8]. Lignin is an aromatic biopolymer with advocated potential for the chemical industry and current research is focusing on lignin valorization [9]. The traditional pulp mills used in the paper making industry make use of kraft pulping, in which the extracted lignin is burnt in the solvent recovery boilers [10]. The kraft mills are highly integrated and energy effective plants [11]. Nevertheless, over the past decades continued scientific efforts have been made to develop alternative pulp mills, in which lignin could be obtained as byproduct of the cellulose fibers [12-14]. Recently, DESs have often been used for biomass delignification [15-21]. DES based processes offer many advantages over the traditional kraft or organosolv processes. The major disadvantage of kraft pulping is that the produced lignin contains sulfur, which makes valorization difficult, while organosolv processes requires high amounts of organic solvents, which are often volatile and flammable [22].

Regeneration of DESs is most often performed by precipitation of either the solute [23] or solvent [24-25] in an anti-solvent. Especially in biomass fractionation, large amounts of water are required as anti-solvent for the precipitation of lignin [16]. To recover the DES, these anti-solvents forming a homogeneous mixture with the DES must be evaporated from the DES, which is very energy intensive. Therefore, alternative separation techniques are desired, and will aid industrial applicability of DESs. Yoo et al. recovered phenolic compounds from DES using resins [26], but required large solvent volumes to elute the extractants from these resins. Tian et al. recovered flavonoids from DESs by sorption, but this required high dilutions of DES in water [27]. Liang et al. used electrodialysis membranes to recover DESs after biomass fractionation [28], but needed high dilutions of DES in water to achieve this. 
Liquid-liquid extraction is a separation technique that can be energy efficient [29], and has been reported for biorefineries, e.g. for lipid extraction from microalgae [30,31] and fractionation of pyrolytic bio-oils [32,33]. Stiefel et al. investigated equilibria of lignin between 2-methyl tetrahydrofuran (2-MTHF) and alkali solutions [34] and showed that lignin can be recovered by liquid-liquid extraction (LLX). Hu converted fructose to 5-HMF in DES and showed the product can be recovered later on by LLX with ethyl acetate [35]. In line with these promising results with LLX, we investigated the possibilities to recover lignin from DESs by LLX.

In this study we performed a solvent screening to find suitable solvents for extraction of lignin from a DES comprised of L-lactic acid (LA) and choline chloride ( $\mathrm{ChCl}$ ). Of primary importance for LLX is that the solvents are not miscible with the DES, or at least show limited mutual miscibility. Then, a high lignin distribution to afford a low solvent to feed ratio is beneficial for the required energy improving the sustainability. Because a low environmental footprint and low toxicity is highly desired, also the (eco)toxicity was evaluated. In the screening procedure two phase formation was investigated first, just as the sustainability and finally the lignin extractability of the suitable solvents. For the selected DES - solvent combination, the phase behavior was studied and further studies were performed on the lignin distribution between the solvent and DES.

\section{Experimental Section}

\subsection{Materials}

Lactic acid (>85\%), choline chloride (>98\%), 1,4-dioxane (99.8\%), 2-MTHF(>99\%, 250 ppm BHT), $\nu$-valerolactone (GVL, 99\%), Guaiacol (natural, >99\%), cyclopentyl methyl ether (CPME, >99.9\%, 50 ppm BHT) and Cyrene (99\%) were purchased from Sigma-Aldrich. Crystalline L-lactic acid was kindly donated by Corbion. Eucalyptus globulus wood chips were kindly supplied by The Navigator Company.

\subsection{Solvent screening}

Screening of solvents for liquid-liquid extraction of lignin from DES requires a lignin-loaded DES, which was accomplished by using DES comprised of $\mathrm{ChCl}$ and $\mathrm{LA}$ in a 1:10 molar ratio that was previously used in pulping experiments [15]. In these pulping experiments, $50 \mathrm{~g}$ of eucalyptus chips were treated by $1 \mathrm{~kg}$ DES for 8 hours at $120^{\circ} \mathrm{C}$. Afterwards, the DES with dissolved lignin was filtered from the cellulose fibers over a $50 \mu \mathrm{m}$ steel mesh. In the LLX solvent screening experiments, $5 \mathrm{~mL}$ solvent was added to $2.5 \mathrm{~mL}$ DES obtained from pulping. The vials were shaken at room temperature over-night at $200 \mathrm{rpm}$ in a Julabo 


\section{Chapter 3}

SW22 shaking bath. Two phase formation was determined visually. When two phases were observed, an estimate of the lignin distribution over the phases was made using UVvis absorption spectrometry (aromatics from lignin show much stronger UV absorbance than the solvents). To facilitate this, the settled phases were separated and diluted in ethanol. The lignin concentrations were estimated by UV-VIS absorption at $320 \mathrm{~nm}$ using a Hach Lange DR5000 spectrophotometer. The overall average distribution coefficients of lignin species measured at $320 \mathrm{~nm}$ were calculated by dividing the concentration in the solvent phase by the concentration in the DES phase. Next to the averaged distribution as determined for the solvent screening experiments, for the selected solvent also the lignin molar weight distribution was determined in both the original DES and in the organic solvents after extraction were determined by gel permeation chromatography (GPC). The lignin molar weight distribution in the DES raffinates could not be determined since they were not fully soluble in the GPC eluent resulting in solids deposition on the column.

\subsection{2-MTHF-DES phase equilibria}

$3 \mathrm{~g}$ 2-MTHF and $3 \mathrm{~g}$ DES composed of crystalline LA and $\mathrm{ChCl}$ were added to a glass vial. This vial was shaken at $200 \mathrm{rpm}$ at over night at 25,50 or $75^{\circ} \mathrm{C}$ in a Julabo SW22 shaking bath. The two phases were allowed to settle and were separated. Concentrations of $\mathrm{ChCl}$, LA and 2-MTHF were analyzed by high performance liquid chromatography (HPLC). An Agilent 1200 system was equipped with a Hi-Plex-H column operated at $60{ }^{\circ} \mathrm{C}$ and a refractive index detector at $55^{\circ} \mathrm{C} .5 \mathrm{mM}$ sulfuric acid in water was used as mobile phase with a flowrate of $0.6 \mathrm{~mL} / \mathrm{min}$.

\subsection{Lignin extraction experiments}

Lignin extraction experiments were performed using lignin that was previously recovered from the DES by precipitation. Precipitation was done by addition of three $g$ water per $g$ DES. The lignin was separated by centrifugation, washed twice with water and dried in vacuum. Crystalline lactic acid, choline chloride and 2-MTHF were added to a flask to form $3 \mathrm{~g}$ of DES comprising of $\mathrm{ChCl}$ : LA ratios between 1:1.1 and 1:2.4, and $3 \mathrm{~g}$ solvent phase at equilibrium. $50 \mathrm{mg}$ lignin that was previously obtained by cold water precipitation from another portion of DES after the same pulping procedure was added per vial. For the experiments with varying water contents a $1: 1.7 \mathrm{ChCl}$ : LA DES at equilibrium was used. 0.15 to $3 \mathrm{~g}$ water was added to the vials to create water contents varying from 5 to $50 \mathrm{wt}$ $\%$ based on the DES. These vials were shaken at $200 \mathrm{rpm}$ at $50{ }^{\circ} \mathrm{C}$ over night in a Julabo SW22 shaking bath. The phases were separated and analyzed by GPC. 
Recovery of lignin from deep eutectic solvents by liquid-liquid extraction

\subsection{GPC analysis}

For GPC, an Agilent 1200 series was used with a refractive index detector and a UV detector operating at $254 \mathrm{~nm}$ using 3 GPC PLgel $3 \mu \mathrm{m}$ MIXED-E columns in series. The column was operated at $40{ }^{\circ} \mathrm{C}$ and a $95: 5$ (v:v) tetrahydrofuran and water mixture was the solvent at a flowrate of $1 \mathrm{~mL} / \mathrm{min}$. Molecular weight distributions were calibrated using polystyrene solutions having molecular weights ranging from 162 to $27,810 \mathrm{Da}$. The product of the UV absorbance and the dilution factor were used as measure for the lignin concentrations in both the DES and 2-MTHF phase. The distribution coefficients were calculated by dividing this product for the 2-MTHF phase by the product for the DES phase.

\subsection{Karl-Fischer titration}

The water content of the DES used in the pulping experiment was determined by KarlFischer titration using a Metrohm $787 \mathrm{KF}$ Titrino. Hydranal composite 5 ( $5 \mathrm{mg}$ water/mL) was titrated from a $20 \mathrm{~mL}$ burette in a 3:1 (v:v) mixture of methanol and dichloromethane. The sample was measured in duplo with a relative error $<1 \%$.

\section{Results and discussion}

\subsection{Solvent screening}

The first requirement for a suitable LLX solvent is the formation of two phases. Considering the high polarity of the DES phase, organic solvents that have an apolar character should be accessed. For lignin extraction from DES, in order to make a real benign process, it would be preferable if the solvent could be bio-based. Six solvents were selected for this screening that all have limited polarity. The first solvent investigated is dioxane, which is not bio-based, but serves as benchmark, since this cyclic ether is commonly used as a solvent for dissolving lignin [36,37]. Although the acute toxicity of dioxane is relatively low (5170 $\mathrm{mg} / \mathrm{kg}$ is lethal for rats) and it is bio-degradable [38], because dioxane is produced from petrochemicals [39], another cyclic ether was also investigated, namely 2-MTHF [40]. This solvent is produced from pentosan [41], does not seem to be genotoxic or mutagenic $[42,43]$, and is used in the OrganoCat process to extract lignin [34]. Also, the ether CPME was accessed, as it has been suggested that this solvent can be produced from biological sources [44,45], and its higher boiling point and greater stability and narrow explosion range make a greener and safer alternative to dioxane [46]. Guaiacol was selected as an aromatic solvent, which may be produced by hydrocracking of lignin [47], or from pyrolytic bio-oils [48]. GVL [49] and cyrene [50] were 


\section{Chapter 3}

also selected as bio-based ketone solvents, which are produced from hemicellulose and cellulose.

The selected solvents were equilibrated with $\mathrm{ChCl}$ - LA (1:10) DES and two phase formation was determined visually. GVL, guaiacol and cyrene turned out to be miscible with the DES, and are therefore not suitable for liquid-liquid extraction using this DES. For the solvents that did form a biphasic system, the overall distribution coefficient of the lignin over the solvent phase and the DES phase (total lignin in solvent over total lignin in DES) was estimated by UV-VIS spectroscopy, see Table 3.1. The highest distribution coefficient was found for dioxane, followed by 2-MTHF and CPME showed the lowest overall average lignin distribution coefficient .

Table 3.1. Overview of solvent screening with 6 solvents for liquid-liquid extraction with lactic acid choline chloride DES. Miscibility with DES, solubility of lignin and bio-based origin are shown.

\begin{tabular}{|l|l|l|r|}
\hline Solvent & 2-phase formation & Bio-based & $\begin{array}{l}\text { Distribution } \\
\text { coefficient (-) }\end{array}$ \\
\hline 1,4-Dioxane & Yes & No & 0.46 \\
\hline 2-MTHF & Yes & Yes & 0.31 \\
\hline GVL & No & Yes & - \\
\hline Guaiacol & No & Possibly & 0.11 \\
\hline CPME & Yes & Possibly & - \\
\hline Cyrene & No & Yes & \\
\hline
\end{tabular}

To get further insight in the lignin distribution, the molar weight distribution of the extracted lignins was compared to the molar weight distribution of the original lignin in DES. The molar weight distributions are plotted in fig. 3.1, from which it was found that both dioxane and 2-MTHF could extract lignin with a broad range of molar weight fractions from the DES, while CPME could only extract the lower molar weight fractions. Presumably, the lower polarity of CPME compared to dioxane and 2-MTHF reduces its ability to extract these lignin fractions. Although this behavior may be useful in the fractionation of lignin when low molar weight fractions are desired in further applications, 
it is in the current study left out of consideration since the objective of this study was to find a solvent that can recover as much lignin from the DES as possible. Considering the bio-based nature of 2-MTHF, in combination with the reasonable lignin distribution, it was decided to investigate the lignin extraction in more detail for 2-MTHF.

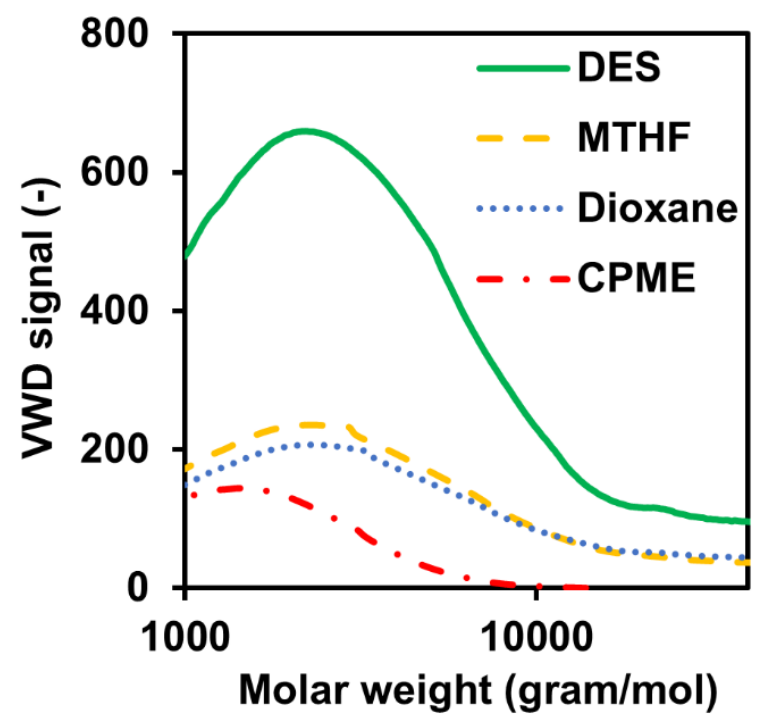

Fig. 3.1. Molar weight distributions of the lignin originally dissolved in the DES and the lignin extracted by the solvents. Raw variable wave detector (VWD) signals are shown. The solid green line shows the molar weight distribution of lignin in the original DES and the dashed yellow, the dotted blue, and dash-dotted red lines the molar weight distributions of lignin in 2-MTHF, Dioxane and CPME after extraction.

\subsection{Phase behavior Studies for $2-\mathrm{MTHF}$ with $\mathrm{ChCl}$ and LA}

Before the extraction of lignin was studied further, the phase behavior between DES and 2-MTHF was studied further since the constituents of the DES may have a different partitioning between the DES and solvent [51]. Therefore, the partitioning of the DES constituents and the solvent were determined at three temperatures. The phase equilibrium results are shown in fig. 3.2. From this figure it follows that the temperature dependence of the equilibria is very small, because the tie lines are similar at the different temperature measurements. Furthermore, lactic acid concentrations in the 2-MTHF phase after equilibration are significant with fractions from 12 to $36 \mathrm{wt} \%$. Where the lactic acid showed significant partitioning into the 2-MTHF phase, choline chloride hardly transferred, and as a result all DES phases contained more than $30 \mathrm{wt} \%$ choline chloride, 


\section{Chapter 3}

but no choline chloride was found in the 2-MTHF phases. A mixture comprised of $14 \mathrm{wt} \%$ choline chloride, $36 \mathrm{wt} \% 2-\mathrm{MTHF}$ and $50 \mathrm{wt} \%$ lactic acid formed a homogeneous liquid. From a process point of view, the LA that leached to the 2-MTHF must be washed from the produced lignin when the 2-MTHF is evaporated. The amount of LA leached to the 2MTHF decreased with increasing amounts of $\mathrm{ChCl}$. During pulping, the $\mathrm{ChCl}$ concentration is an important factor in the delignification rate [15], and addition of more $\mathrm{ChCl}$ to a 10:1 LA to ChCl DES decreases the delignification rate. Therefore, the optimal amount of choline chloride -from a process point of view- will be a trade-off between the delignification rate and the amount of lactic acid leaching to the solvent phase.

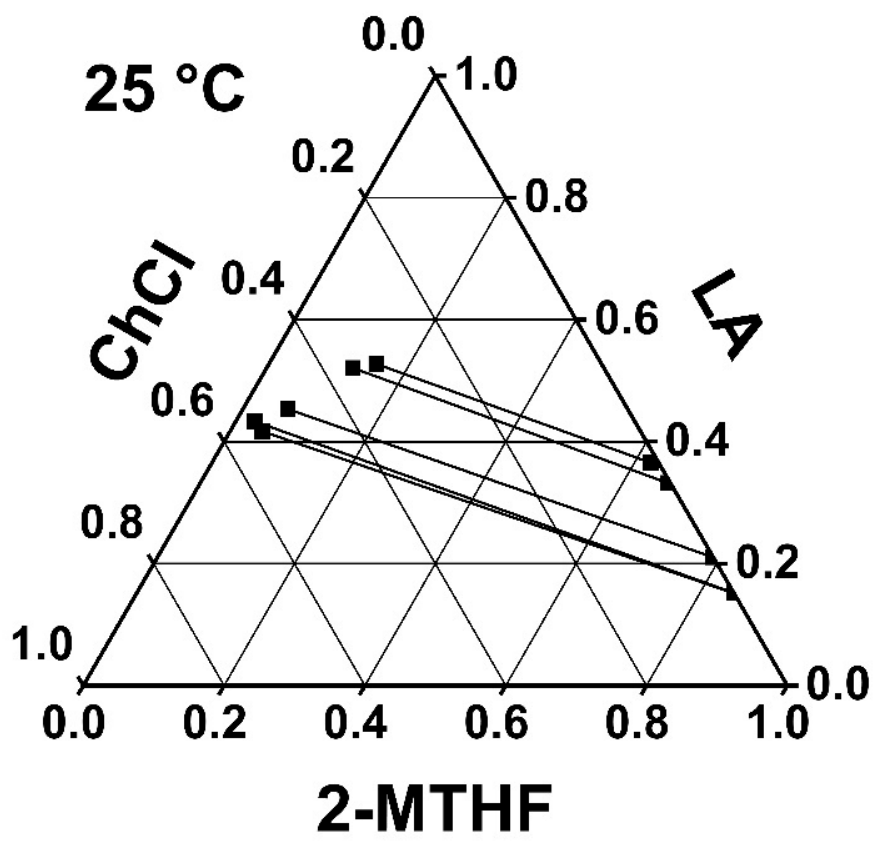

Fig. 3.2. Phase diagram with liquid-liquid equilibrium data between choline chloride, lactic acid and 2-MTHF at 25,50 and $75^{\circ} \mathrm{C}$. The axis show the mass fractions of the constituents. 

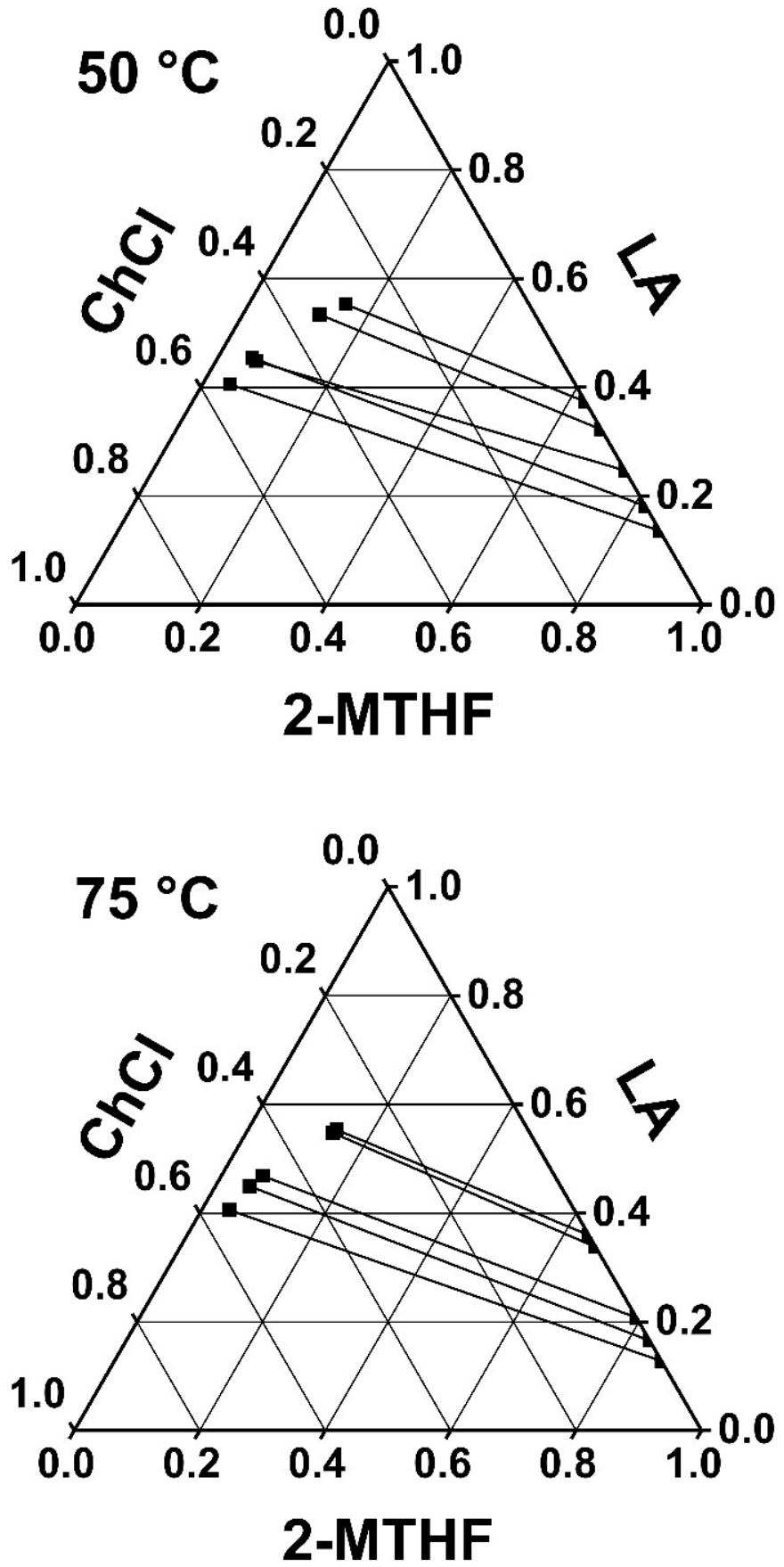


\section{Chapter 3}

\subsection{Influence of DES composition on lignin extraction}

Since the DES composition is an important factor in the process design, the distribution of lignin between the DES and solvent was investigated for 4 different DES compositions varying in $\mathrm{ChCl}$ to LA molar ratio from 1:1.1 to 1:2.4. The results for these trials are shown in fig. 3.3. For every DES composition, the distribution coefficient of low molecular weight fractions is higher than the high molecular weight fractions, but does not seem to be influenced much by the DES composition. It is remarkable that all distribution coefficients are lower than the distribution coefficient obtained from the initial screening. The initial screening was performed using a DES that was directly obtained from a biomass fraction experiment, while the experiments in this series to investigate on the effect of the DES composition were performed using lignin precipitated from this biomass fractionation experiment. The lower distribution compared to the distribution obtained with the DES directly from the pulping experiment is possibly caused by a difference in nature of the UV absorbing species present in the DES, and the lignin that did precipitate. During pulping, (hemi)cellulose from the wood matrix can be hydrolyzed to form glucose and xylose, which may react further to (hydroxymethyl)furfural and humin, which are also UV responsive. Analysis by HPLC showed that (hydroxymethyl)furfural was extracted by 2MTHF, while glucose and xylose remained in the DES. These compounds may likely not precipitate from the DES, and are thus not present in the further studies using redissolved lignin that was first precipitated. These components will thus interfere with the results of the initial screening, but not with the further studies using precipitated lignin [35]. Also, the DES used in the solvent screening experiments after fractionation contained $12.8 \pm 0.1$ wt \% water (as determined by Karl-Fischer titration), while the DESs used in these lignin extraction experiments were ambient dry. The presence of water in the system may also have a strong influence on the lignin distribution. 


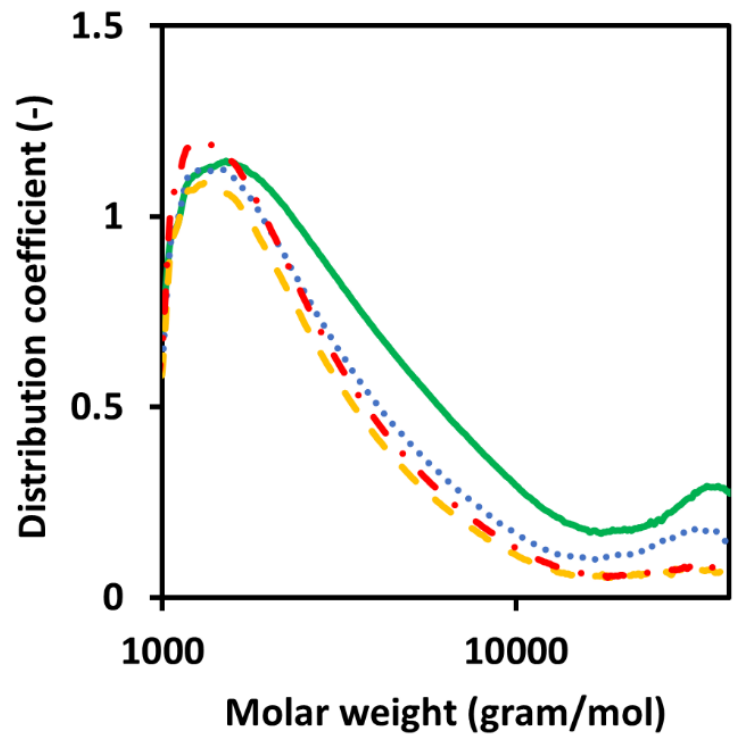

Fig. 3.3. Distribution of lignin between DES and 2-MTHF at $50{ }^{\circ} \mathrm{C}$. Choline chloride to lactic acid equilibrium molar ratios: 1:2.4 (green-solid), 1:1.7 (blue-dotted), 1:1.4 (yellowdashed) and 1:1.1 (red-dash-dotted).

\subsection{Influence of water}

The lignin distribution was determined at 5 different water concentrations in the DES and the results are shown in fig. 3.4. The lignin extraction by 2-MTHF is greatly enhanced by the addition of water. Especially the extraction of the higher molar weight fractions improves more upon the addition of water than the extraction of the lower molar weight fractions. At 25 wt \% water in the DES, the minimum distribution coefficient was 4 , allowing effective extraction of lignin from DES by 2-MTHF using a countercurrent LLX method.

Soares et al. determined the solubility of organosolv and kraft lignin in the propionic acid Urea DES and found the highest lignin solubility at 50\% DES in water [52]. Also the lignin solubility in low hydrogen-bonding capacity solvents -such as 2-MTHF- is greatly enhanced when a little water is added to them. The presence of water thus seems to both limit the solubility of lignin in DES by interfering with the hydrogen bonds between lignin and DES, while at the same time also facilitating hydrogen bonding connections for solvents that are only hydrogen bond acceptors. 


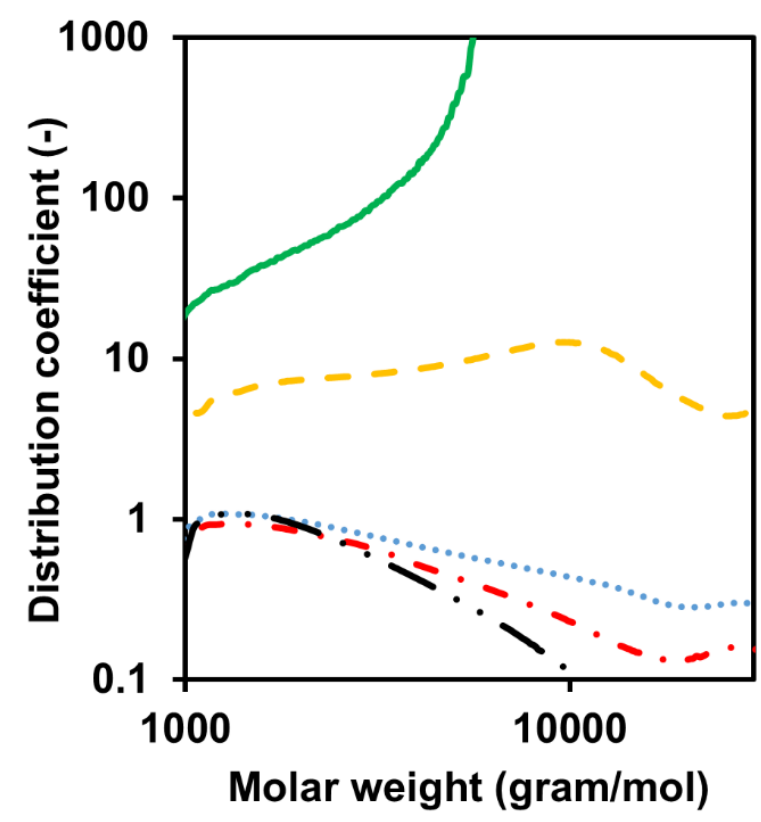

Fig. 3.4. Distribution of lignin between DES and 2-MTHF at $50{ }^{\circ} \mathrm{C}$. Various amounts of water were added to the DES: 50\% (green-solid), 25\% (yellow-dashed), 10\% (blue-dotted), $5 \%$ (red-dash-dotted) and dry (black-dot-dot-dashed). For the parts of the green line that are out of the graph, no lignin fractions were found in the DES phase, and thus the distribution coefficient is infinite.

\subsection{Industrial applicability}

In this article we describe an alternative method for the recovery of lignin from DES by LLX. However, the addition of an extra solvent inherently increases the complexity and thus the costs of the process. Therefore, the energy saving should be significant to justify the increased complexity. For this reason, we elaborate on the potential energy savings that can be achieved by replacing cold water precipitation by LLX.

The water content is an important factor in both the pulping and the recovery stage. For example, Kumar et al. [18] found that lignin removal from rice straw increased upon the addition of small amounts of water to DES. Furthermore, many authors $[15,20,21]$ use lactic acid syrup for the preparation of DES used for biomass fractionation, which contains around 15 wt \% water. Also, wood is a hygroscopic material, meaning it will naturally contain significant amounts of water. It thus seems reasonable that the DES after pulping 
can contain around 25 wt \% water, which allows for successful extraction using 2-MTHF without adding additional water.

Soares et al. studied the solubility of two technical lignin in mixtures comprised of water and various DES [53]. They found that the lignin solubility in a DES comprised of lactic acid and choline chloride decreased by a factor 7 when the water content was shifted from 25 to $75 \mathrm{wt} \%$, which seems sufficient for industrial application. In order to achieve this shift, $2 \mathrm{~kg}$ of water must be added to $1 \mathrm{~kg}$ of pulping liquid (containing $25 \%$ water), which must subsequently be removed by evaporation. The heat of evaporation of water is $2.3 \mathrm{~kJ} / \mathrm{kg}$, meaning $4.6 \mathrm{~kJ}$ is required for the recovery of $1 \mathrm{~kg}$ pulping liquid using cold water precipitation.

In Section 3.4 we showed that the distribution coefficient of lignin is $>4$ for all molar weight fraction when the DES contains $25 \mathrm{wt} \%$ water. This means that the minimum solvent to feed ratio is $1 / 4=0.25$. However, the lignin distribution coefficient may change during multi-stage extractions. Therefore, we assume a conservative solvent to feed ratio of 0.5 . This means that for the regeneration of $1 \mathrm{~kg}$ pulping liquid, $0.5 \mathrm{~kg} 2-\mathrm{MTHF}$ must be removed from the extracted lignin, for example by evaporation. The heat of evaporation of 2-MTHF is only $0.40 \mathrm{~kJ} / \mathrm{kg}$ [54], meaning the heat required to regenerate $1 \mathrm{~kg}$ DES used for pulping is only $0.20 \mathrm{~kJ}$, and since no water evaporation is necessary in this approach, a saving of over $95 \%$ compared to cold water precipitation can be achieved. Although these calculations are still preliminary, the potential savings justify further studies on recovery of lignin from DES by more complicated LLX. 


\section{Conclusions}

2-MHTF was found as a suitable extractant for lignin recovery from a DES comprised of choline chloride and L-lactic acid. In biphasic systems with 2-MTHF, at least $30 \mathrm{wt} \%$ choline chloride in the DES was found because of large amounts of lactic acid being transferred to the 2-MTHF phase. The more choline chloride in the system, the lower the leaching of lactic acid to the 2-MTHF phase. The distribution of lower molar weight fractions was higher than the high molar weight fractions, and did not seem to depend on the DES composition. Also, the influence of water on lignin extraction was studied and the lignin extraction improved upon addition of water. At $25 \mathrm{wt} \%$ water, the lignin distribution was larger than 4 for all lignin molar weights, showing that all lignin can be recovered by LLX with a few countercurrent stages. It can thus be concluded that LLX with 2-MTHF is an industrially applicable method for the recovery of lignin from DES. For the design of a DES based biomass fractionation process all components from biomass must be recovered from the DES. For the fractionation trial described in this paper, $55 \%$ of the initial biomass is recovered as solid material by filtration and $20 \%$ of the initial biomass consists of lignin. The rest of the biomass consists of predominantly (hemi)cellulose breakdown products, which may be separated from the DES by membranes [28] or converted in-situ [35]. More research on the identification and recovery of these components is required to design a process for biomass fractionation using DES. 


\section{Bibliography}

[1] B. Schuur, T. Brouwer, D. Smink, L.M.J. Sprakel, Green solvents for sustainable separation processes, Curr. Opin. Green Sustain. Chem. 18 (2019) 57-65. doi:10.1016/j.cogsc.2018.12.009.

[2] L.J.B.M. Kollau, M. Vis, A. Van Den Bruinhorst, A.C.C. Esteves, R. Tuinier, Quantification of the liquid window of deep eutectic solvents, Chem. Commun. 54 (2018) 13351-13354. doi:10.1039/c8cc05815f.

[3] F.J. V Gomez, M. Espino, M.A. Fernández, M.F. Silva, A Greener Approach to Prepare Natural Deep Eutectic Solvents, ChemistrySelect. 3 (2018) 6122-6125. doi:10.1002/slct.201800713.

[4] Q. Lu, W. Liu, L. Yang, Y. Zu, B. Zu, M. Zhu, Y. Zhang, X. Zhang, R. Zhang, Z. Sun, J. Huang, X. Zhang, W. Li, Investigation of the effects of different organosolv pulping methods on antioxidant capacity and extraction efficiency of lignin, Food Chem. 131 (2012) 313-317. doi:10.1016/j.foodchem.2011.07.116.

[5] I.P.E. Macário, F. Jesus, J.L. Pereira, S.P.M. Ventura, A.M.M. Gonçalves, J.A.P. Coutinho, F.J.M. Gonçalves, Unraveling the ecotoxicity of deep eutectic solvents using the mixture $\begin{array}{lllll}\text { toxicity } & & \end{array}$ doi:10.1016/j.chemosphere.2018.08.153.

[6] A.A. Rosatella, S.P. Simeonov, R.F.M. Frade, C.A.M. Afonso, 5-Hydroxymethylfurfural (HMF) as a building block platform: Biological properties, synthesis and synthetic applications, Green Chem. 13 (2011) 754-793. doi:10.1039/C0GC00401D

[7] S.N. Naik, V. V Goud, P.K. Rout, A.K. Dalai, Production of first and second generation biofuels: A comprehensive review, Renew. Sustain. Energy Rev. 14 (2010) 578-597. doi:10.1016/j.rser.2009.10.003.

[8] M. Dusselier, P. Van Wouwe, A. Dewaele, E. Makshina, B.F. Sels, Lactic acid as a platform chemical in the biobased economy: The role of chemocatalysis, Energy Environ. Sci. 6 (2013) 1415-1442. doi:10.1039/C3EE00069A.

[9] R. Rinaldi, R. Jastrzebski, M.T. Clough, J. Ralph, M. Kennema, P.C.A. Bruijnincx, B.M. Weckhuysen, Paving the Way for Lignin Valorisation: Recent Advances in Bioengineering, Biorefining and Catalysis, Angew. Chemie Int. Ed. 55 (2016) 8164-8215. doi:10.1002/anie.201510351.

[10] M. Ragnar, G. Henriksson, M.E. Lindström, M. Wimby, J. Blechschmidt, S. Heinemann, Pulp, Ullmann's Encycl. Ind. Chem. (2014). doi:10.1002/14356007.a18_545.pub4.

[11] A.W. Rudie, P.W. Hart, Catalysis-a potential alternative to kraft pulping, Tappi J. 13 (2014) 13-20.

[12] E. Muurinen, Organosolv Pulping. A Review and Distillation Study Related to Peroxyacid Pulping, PhD Thesis, Univ. Oulu. (2000).

[13] S. Aziz, K. Sarkanen, Organosolv pulping - a review., Tappi J. 72 (1989) 169-175.

[14] P. Stockburger, An overview of near-commercial and commercial solvent-based pulping processes., Tappi J. 76 (1993) 71-74.

[15] D. Smink, A. Juan, B. Schuur, S.R.A. Kersten, Understanding the Role of Choline Chloride in Deep Eutectic Solvents Used for Biomass Delignification, Ind. Eng. Chem. Res. (2019). doi:10.1021/acs.iecr.9b03588.

[16] C. Alvarez-Vasco, R. Ma, M. Quintero, M. Guo, S. Geleynse, K.K. Ramasamy, M. Wolcott, X. Zhang, Unique low-molecular-weight lignin with high purity extracted from wood by deep eutectic solvents (DES): a source of lignin for valorization., Green Chem. 18 (2016) 5133- 


\section{Chapter 3}

5141. doi:10.1039/c6gc01007e.

[17] J. Chang, J. Liu, S.J. Guo, X.F.Y. Wang, Investigation into selective separation of lignin in novel deep eutectic solvent, J. South China Univ. Technol. 44 (2016) 14-20. doi:10.3969/j.issn.1000-565X.2016.06.003.

[18] A.K. Kumar, B.S. Parikh, M. Pravakar, Natural deep eutectic solvent mediated pretreatment of rice straw: bioanalytical characterization of lignin extract and enzymatic hydrolysis of pretreated biomass residue., Environ. Sci. Pollut. Res. Int. 23 (2015) 9265-9275. doi:10.1007/s11356-015-4780-4.

[19] M. Jablonský, A. Škulcová, L. Kamenská, M. Vrška, J. Šíma, Deep Eutectic Solvents: Fractionation of Wheat Straw, BioResources. $10 \quad$ (2015) 8039-8047. doi:10.15376/biores.10.4.8039-8047.

[20] C.W. Zhang, S.Q. Xia, P.S. Ma, Facile pretreatment of lignocellulosic biomass using deep eutectic solvents, Bioresour. Technol. 219 (2016) 1-5. doi:10.1016/j.biortech.2016.07.026.

[21] A.L. Li, X.D. Hou, K.P. Lin, X. Zhang, M.H. Fu, Rice straw pretreatment using deep eutectic solvents with different constituents molar ratios: Biomass fractionation, polysaccharides enzymatic digestion and solvent reuse, J. Biosci. Bioeng. 126 (2018) 346-354. doi:10.1016/j.jbiosc.2018.03.011.

[22] D.J.G.P. Van Osch, L.J.B.M. Kollau, A. Van Den Bruinhorst, S. Asikainen, M.A.A. Rocha, M.C. Kroon, Ionic liquids and deep eutectic solvents for lignocellulosic biomass fractionation, Phys. Chem. Chem. Phys. 19 (2017) 2636-2665. doi:10.1039/c6cp07499e.

[23] A.K. Das, M. Sharma, D. Mondal, K. Prasad, Deep eutectic solvents as efficient solvent system for the extraction of k-carrageenan from Kappaphycus alvarezii, Carbohydr. Polym. 136 (2016) 930-935. doi:10.1016/j.carbpol.2015.09.114.

[24] Z. Maugeri, P. de Maria, Novel choline-chloride-based deep-eutectic-solvents with renewable hydrogen bond donors: levulinic acid and sugar-based polyols, RSC Adv. 2 (2012) 421-425. doi:10.1039/C1RA00630D.

[25] M. Francisco, A. Van Den Bruinhorst, M.C. Kroon, Low-transition-temperature mixtures (LTTMs): A new generation of designer solvents, Angew. Chemie - Int. Ed. 52 (2013) 30743085. doi:10.1002/anie.201207548.

[26] D.E. Yoo, K.M. Jeong, S.Y. Han, E.M. Kim, Y. Jin, J. Lee, Deep eutectic solvent-based valorization of spent coffee grounds, Food Chem. 255 (2018) 357-364. doi:doi.org/10.1016/j.foodchem.2018.02.096.

[27] H. Tian, J. Wang, Y. Li, W. Bi, D.D.Y. Chen, Recovery of Natural Products from Deep Eutectic Solvents by Mimicking Denaturation, ACS Sustain. Chem. Eng. 7 (2019) 9976-9983. doi:10.1021/acssuschemeng.9b01012.

[28] X. Liang, Y. Fu, J. Chang, Effective separation, recovery and recycling of deep eutectic solvent after biomass fractionation with membrane-based methodology, Sep. Purif. Technol. 210 (2019) 409-416. doi:10.1016/j.seppur.2018.08.021.

[29] M. Blahušiak, A. Kiss, K. Babić, S. R.A. Kersten, G. Bargeman, B. Schuur, Insights into the selection and design of fluid separation processes, Sep. Purif. Technol. 194 (2017) 301-318. doi:10.1016/j.seppur.2017.10.026.

[30] Y. Du, B. Schuur, C. Samorì, E. Tagliavini, D.W.F. Brilman, Secondary amines as switchable solvents for lipid extraction from non-broken microalgae, Bioresour. Technol. 149 (2013) 253-260. doi:10.1016/j.biortech.2013.09.039.

[31] Y. Du, B. Schuur, D.W.F. Brilman, Maximizing Lipid Yield in Neochloris oleoabundans Algae Extraction by Stressing and Using Multiple Extraction Stages with N-Ethylbutylamine as Switchable Solvent, Ind. Eng. Chem. Res. 56 (2017) 8073-8080. doi:10.1021/acs.iecr.7b01032.

[32] X. Li, L.C. Luque-Moreno, S.R.G. Oudenhoven, L. Rehmann, S.R.A. Kersten, B. Schuur, 


\section{Recovery of lignin from deep eutectic solvents by liquid-liquid extraction}

Aromatics extraction from pyrolytic sugars using ionic liquid to enhance sugar fermentability, Bioresour. Technol. 216 (2016) 12-18. doi:10.1016/j.biortech.2016.05.035.

[33] L. Cesari, L. Canabady-Rochelle, F. Mutelet, Separation of phenols from lignin pyrolysis oil using ionic liquid, Sep. Purif. Technol. 209 (2019) 528-534. doi:10.1016/j.seppur.2018.07.083.

[34] S. Stiefel, D. Di Marino, A. Eggert, I.R. Kühnrich, M. Schmidt, P.M. Grande, W. Leitner, A. Jupke, M. Wessling, Liquid/liquid extraction of biomass-derived lignin from lignocellulosic pretreatments, Green Chem. 19 (2017) 93-97. doi:10.1039/c6gc02270g.

[35] S. Hu, Z. Zhang, Y. Zhou, B. Han, H. Fan, W. Li, J. Song, Y. Xie, Conversion of fructose to 5hydroxymethylfurfural using ionic liquids prepared from renewable materials, Green Chem. 10 (2008) 1280-1283. doi:10.1039/b810392e.

[36] P.J. Deuss, C.W. Lahive, C.S. Lancefield, N.J. Westwood, P.C.J. Kamer, K. Barta, J.G. de Vries, Metal Triflates for the Production of Aromatics from Lignin, ChemSusChem. 9 (2016) 29742981. doi:10.1002/cssc.201600831.

[37] C.W. Lahive, P.J. Deuss, C.S. Lancefield, Z. Sun, D.B. Cordes, C.M. Young, F. Tran, A.M.Z. Slawin, J.G. de Vries, P.C.J. Kamer, N.J. Westwood, K. Barta, Advanced Model Compounds for Understanding Acid-Catalyzed Lignin Depolymerization: Identification of Renewable Aromatics and a Lignin-Derived Solvent, J. Am. Chem. Soc. 138 (2016) 8900-8911. doi:10.1021/jacs.6b04144.

[38] M. Kinne, M. Poraj-Kobielska, S.A. Ralph, R. Ullrich, M. Hofrichter, K.E. Hammel, Oxidative cleavage of diverse ethers by an extracellular fungal peroxygenase, J. Biol. Chem. 284 (2009) 29343-29349. doi:10.1074/jbc.M109.040857.

[39] K.S. Surprenant, Dioxane, Ullmann's Encycl. Ind. Chem. (2000). doi:10.1002/14356007.a08_545.

[40] F. Jérôme, R. Luque, Bio-Based Solvents, Wiley, 2017.

[41] V. Pace, P. Hoyos, L. Castoldi, P. Domínguez de María, A.R. Alcántara, 2Methyltetrahydrofuran (2-MeTHF): A Biomass-Derived Solvent with Broad Application in Organic Chemistry, ChemSusChem. 5 (2012) 1369-1379. doi:10.1002/cssc.201100780.

[42] V. Antonucci, J. Coleman, J.B. Ferry, N. Johnson, M. Mathe, J.P. Scott, J. Xu, Toxicological Assessment of 2-Methyltetrahydrofuran and Cyclopentyl Methyl Ether in Support of Their Use in Pharmaceutical Chemical Process Development, Org. Process Res. Dev. 15 (2011) 939-941. doi:10.1021/op100303c.

[43] K. Bluhm, S. Heger, R. Redelstein, J. Brendt, N. Anders, P. Mayer, A. Schaeffer, H. Hollert, Genotoxicity of three biofuel candidates compared to reference fuels, Environ. Toxicol. Pharmacol. 64 (2018) 131-138. doi:10.1016/j.etap.2018.10.003.

[44] C. Breil, A. Meullemiestre, M. Vian, F. Chemat, Bio-Based Solvents for Green Extraction of Lipids from Oleaginous Yeast Biomass for Sustainable Aviation Biofuel, Molecules. 21 (2016) 196-210. doi:10.3390/molecules21020196.

[45] W.M.A. Wan Mahmood, C. Theodoropoulos, M. Gonzalez-Miquel, Enhanced microalgal lipid extraction using bio-based solvents for sustainable biofuel production, Green Chem. 19 (2017) 5723-5733. doi:10.1039/C7GC02735D.

[46] K. Watanabe, N. Yamagiwa, Y. Torisawa, Cyclopentyl Methyl Ether as a New and Alternative Process Solvent, Org. Process Res. Dev. 11 (2007) 251-258. doi:10.1021/op0680136.

[47] D. Meier, J. Berns, O. Faix, U. Balfanz, W. Baldauf, Hydrocracking of organocell lignin for phenol production, Biomass and Bioenergy. 7 (1994) 99-105. doi:10.1016/09619534(95)92632-I.

[48] X. Li, S.R.A. Kersten, B. Schuur, Extraction of Guaiacol from Model Pyrolytic Sugar Stream with Ionic Liquids, Ind. Eng. Chem. Res. 55 (2016) 4703-4710. doi:10.1021/acs.iecr.6b00100. 


\section{Chapter 3}

[49] D.M. Alonso, S.G. Wettstein, J.A. Dumesic, Gamma-valerolactone, a sustainable platform molecule derived from lignocellulosic biomass, Green Chem. 15 (2013) 584-595. doi:10.1039/C3GC37065H.

[50] J. Sherwood, M. De bruyn, A. Constantinou, L. Moity, C.R. McElroy, T.J. Farmer, T. Duncan, W. Raverty, A.J. Hunt, J.H. Clark, Dihydrolevoglucosenone (Cyrene) as a bio-based alternative for dipolar aprotic solvents, Chem. Commun. 50 (2014) 9650-9652. doi:10.1039/C4CC04133J.

[51] F.O. Farias, H. Passos, J.A.P. Coutinho, M.R. Mafra, pH Effect on the Formation of DeepEutectic-Solvent-Based Aqueous Two-Phase Systems, Ind. Eng. Chem. Res. 57 (2018) 16917-16924. doi:10.1021/acs.iecr.8b04256.

[52] B. Soares, D.J.P. Tavares, J.L. Amaral, A.J.D. Silvestre, C.S.R. Freire, J.A.P. Coutinho, Enhanced Solubility of Lignin Monomeric Model Compounds and Technical Lignins in Aqueous Solutions of Deep Eutectic Solvents, ACS Sustain. Chem. Eng. 5 (2017) 4056-4065. doi:10.1021/acssuschemeng.7b00053.

[53] B. Soares, A.J.D. Silvestre, P.C. Rodrigues Pinto, C.S.R. Freire, J.A.P. Coutinho, Hydrotropy and Cosolvency in Lignin Solubilization with Deep Eutectic Solvents, ACS Sustain. Chem. Eng. 7 (2019) 12485-12493. doi:10.1021/acssuschemeng.9b02109.

[54] J. William E. Acree, J.S. Chickos, Phase Transition Enthalpy Measurements of Organic and Organometallic Compounds, National Institute of Standards and Technology, Gaithersburg MD, 2019. doi:10.18434/T4D303. 


\section{Chapter 4}

\section{Comparing multistage liquid-liquid extraction with cold water precipitation for improvement of lignin recovery from deep eutectic solvents}

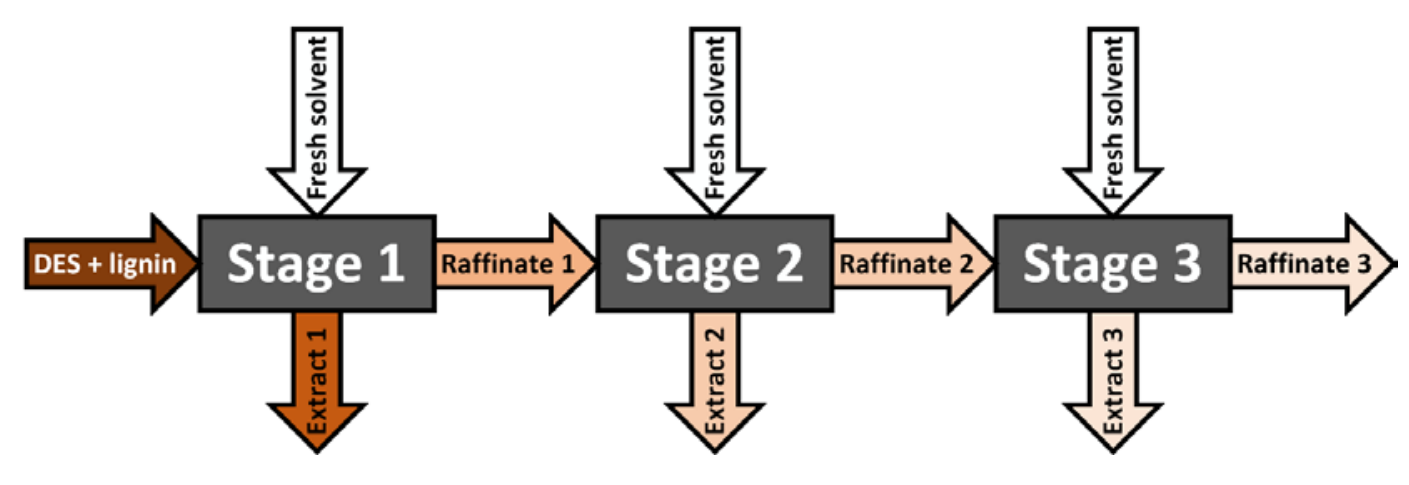




\title{
Comparing multistage liquid-liquid extraction with cold water precipitation for improvement of lignin recovery from deep eutectic solvents
}

\begin{abstract}
After biomass fractionation using deep eutectic solvents (DES), solvent recovery is an essential step. Recovery of lignin from DES by liquid-liquid extraction (LLX) may provide large energy savings compared to cold water precipitation. Lignin that is dissolved in DES from biomass fractionation is inhomogeneous, meaning it has various fractions with different molar weights and possibly variations in functional group densities. Therefore, it is important to compare recoverability of every lignin fraction by LLX with cold-water precipitation. In this work, the recovery of lignin from a DES comprised of $30 \mathrm{wt} \%$ choline chloride and $70 \mathrm{wt} \%$ lactic acid was studied. Three cross-current extractions were performed using 2-MTHF. This method recovered $95 \%$ of the lignin fractions around 2,000 $\mathrm{g} / \mathrm{mol}$ and $85 \%$ of the lignin fractions around $10,000 \mathrm{~g} / \mathrm{mol}$. No inter-aromatic ether bonds were found in the lignin remaining in the DES raffinate by heteronuclear single quantum coherence spectroscopy (HSQC), indicating the remaining lignin in the DES is has a highly condensed nature. Cold water precipitation could fully recover the lignin fractions above $4,000 \mathrm{~g} / \mathrm{mol}$ using $3.5 \mathrm{~kg}$ water per kg DES. However, only half of the lignin fraction of 1,000 $\mathrm{g} / \mathrm{mol}$ was recovered. Briefly, LLX is more suitable for the recovery of low molar weight fractions, while cold water precipitation is more suitable for the heavy molar weight fractions. For industrial applications, a combination of both approaches is essential for full lignin recovery.
\end{abstract}




\section{Chapter 4}

\section{Introduction}

Deep eutectic solvents (DESs) are composite solvents that exhibit deep eutectic behavior upon mixing the constituents. One attempt to define DESs states that the melting points of these mixtures is reduced considerably more $\left(>50^{\circ} \mathrm{C}\right)$ than would be the case for ideal mixtures [1,2]. Many mixtures that have been reported as being DESs do have a much lower melting point than the pure components. However, these melting points are often close to ideal melting points that can be calculated thermodynamically [3]. Furthermore, the melting points determined for these mixtures may differ significantly upon the methods used. For example, the melting point of the DES comprised of choline chloride and lactic acid in a 1:10 ratio was determined by Crespo et al. [3], and by Francisco et al. [4]. Crespo et al. [3] found the melting point to be close to the ideal melting point of $11^{\circ} \mathrm{C}$ using a capillary method, while Franciso et al. [4] found a melting point of $-66^{\circ} \mathrm{C}$ for the same mixture by differential scanning calorimetry (DSC). Possibly, the results obtained by the DSC method used by Francisco et al. [4] deviate because of supercooling in the DSC [5]. Furthermore, the hygroscopic nature of DESs may also make characterization difficult since water strongly influences phase behavior [6].

Regardless of what a formal definition of DESs should be, these composite solvents that exhibit their low transition temperatures [7] due to hydrogen bonding, raised wide attention in academia. Since these solvents can easily be prepared in numerous ways by combining a hydrogen bond donor and acceptor[8] and are often biocompatible, biodegradable [9] and can have a low toxicity [10]. DESs have been used for various applications, such as, CO2 capture [11-13], air pollutant removal [14], extractive distillation [15], metal extractions [16], desulfurization [17,18] and biomass fractionation [19-22].

Regeneration of DESs is most often performed by precipitation of either the solute $[23,24]$ or solvent $[7,25]$ in an anti-solvent. Especially in biomass fractionation this approach is popular, but large amounts of water are required as anti-solvent for the precipitation of lignin [26]. In our previous study [27], we proposed LLX using hydrophobic solvents to recover lignin from DES, since LLX can be energy efficient [28]. It was found that 2-MTHF is a suitable extraction solvent to recover lignin from a DES comprising of lactic acid and choline chloride from single stage equilibrium extraction studies [27]. This solvent was selected because it could extract lignin of all molar weights and because it is bio-based [27]. In precipitation, an anti-solvent is added to the DES, which decreases the affinity of lignin with the mixture, causing the lignin to precipitate. This antisolvent must be removed from the DES before re-use of the DES. In LLX, the DES is contacted with an immiscible solvent. If 


\section{Comparing multistage liquid-liquid extraction with cold water precipitation for improvement of lignin recovery from deep eutectic solvents}

the lignin has a higher affinity to the solvent than to the DES, it will move from the DES to the solvent phase. The solvent can later be removed from the lignin by a simple evaporation step.

Lignin is an inhomogeneous polymer and contains various linkages and functional groups. Various authors used either LLX [29-31], fractional precipitation [32-34], or partial solubility [32,35-39] to fractionate a lignin in two or more fractions with different properties. This means that some lignin fractions may be better extracted and/or precipitated from the DES than others. Therefore, it is vital to determine to what extent different lignin fractions can be recovered from DESs. Compared to the prior study, where only single stage extractions of lignin were described, we here describe a more extensive study on multistage crosscurrent LLX to recover lignins from a lactic acid and choline chloride mixture. Furthermore, we compared the multistage extraction method to cold water precipitations using various amounts of cold water. The results in this paper give more in-depth insight in the extractability of the lignin fractions, and how full lignin removal can be approached.

In this study, lignin extractions from a DES comprised of lactic acid and choline chloride using 2-MTHF were studied in a cross-current sequence, and results for lignin-in-DES solutions obtained via different procedures were compared. In our studies we always used Eucalyptus globulus as source for the lignin, but the preparation of the lignin containing DES was varied. Lignin was extracted directly from the prepared lignin-in-DES mixture, and lignin that was previously obtained by precipitation was redissolved in the DES and then recovered again. the lignin concentrations in the extracts were determined by gel permeation chromatography (GPC). Later, the lignin fractions were isolated from all extract and raffinate streams and characterized by fourier-transform infrared spectroscopy (FT-IR) and HSQC to compare the general structure and bonds in the lignin fractions. Also, the recoverability of different lignin fractions by cold water precipitation was studied as function of the water to DES phase ratio using GPC.

\section{Methods and materials}

\subsection{Chemicals}

Lactic acid (>90\%) and 2-MTHF (Emplura) were ordered from VWR. Choline chloride ( $>98 \%)$ and butylated hydroxytoluene (BHT) (>99\%) were ordered from Sigma-Aldrich. Crystalline lactic acid was kindly provided by Corbion. DMSO-d6 (D, 99.9\%) was ordered from 


\section{Chapter 4}

Cambridge Isotope Laboratories. Air-dry Eucalyptus globulus chips were kindly provided by The Navigator Company. The commercial size chips (typically 25-35 × 10-25 × 2.5-6 mm, L $\times \mathrm{W} \times \mathrm{T}$ ) were used as received and contained $21.6 \%$ lignin, $50.6 \%$ glucose, $14.0 \%$ xylose, and $1.1 \%$ galactose, as determined by acid hydrolysis using the standard NREL method [40].

\subsection{Experimental methods}

\subsubsection{Preparation of lignin-in-DES mixtures}

$210 \mathrm{~g}$ Choline chloride, $490 \mathrm{~g}$ lactic acid (>90\%) and $300 \mathrm{~g}$ water were added to a round bottom flask fitted with a condenser. The mixture was heated under continuous stirring to form a homogeneous liquid, which started to boil at $112^{\circ} \mathrm{C}$. Water was released from the mixture until the temperature reached $120^{\circ} \mathrm{C}$ and $50 \mathrm{~g}$ wood chips (oven dry basis, $10.9 \mathrm{wt}$ $\%$ water) were added through a free neck ( $\varnothing 29 \mathrm{~mm}$ ). The mixture was kept at $120^{\circ} \mathrm{C}$ for 8 $\mathrm{h}$ under continuous stirring. The mixture was filtered while hot over a $53 \mu \mathrm{m}$ steel mesh and contained $17.4 \mathrm{wt} \%$ water, as determined by Karl-Fischer titration (see section 2.3.4.).

\subsubsection{Cross-current extraction experiments}

$20 \mathrm{~g}$ of the prepared lignin-in-DES mixture (see section 2.2.1.) and $20 \mathrm{~g}$ 2-MTHF were added to a $50 \mathrm{~mL}$ double-walled stirred cell, which was kept at $50^{\circ} \mathrm{C}$ using a Julabo $\mathrm{F} 25$ water bath. The cell was stirred over night to reach equilibrium. After extraction, the phases were settled and the top phase was removed and renewed by a solution of $30 \mathrm{wt} \%$ crystalline lactic acid in 2-MTHF to avoid excess leaching of lactic acid. The lignin concentrations in the extract phases were determined by GPC. The lignin concentrations in the raffinate phases were calculated by mass balance since they were not fully soluble in the GPC eluent. The distribution coefficients were calculated as the ratios between the concentrations in the extract phases, over the concentrations in the raffinate phases, and the recoveries were calculated by mass balance.

Also three stage extractions with lignin that was obtained by cold water precipitation according to the method described in our previous paper [27] were performed. $15 \mathrm{~g}$ Crystalline lactic acid, $8 \mathrm{~g}$ choline chloride and $15 \mathrm{~g}$ 2-MTHF were added to the stirred cell described in the previous section. The mixture forms $18 \mathrm{~g}$ of extract and $18 \mathrm{~g}$ of DES raffinate (comprised of 30:70 w:w choline chloride to lactic acid), as determined from the equilibrium [27]. $6 \mathrm{~g}$ water was added to the DES to adjust the initial water content in the DES to $25 \mathrm{wt}$ $\% .300 \mathrm{mg}$ lignin was added to the stirred cell and the mixture was stirred over-night to reach equilibrium. Three extractions were performed using the same method as described in the previous paragraph. The lignin concentrations in the extract and raffinate phases 


\section{Comparing multistage liquid-liquid extraction with cold water precipitation for improvement of lignin recovery from deep eutectic solvents}

were determined by GPC. The distribution coefficients were calculated as the ratios between the concentrations in the extract phases, over the concentrations in the raffinate phases, and the recoveries were calculated by mass balance according to equation (1).

$$
\text { Recovery }(\%)=\frac{\sum_{i=1}^{n} C_{\text {raffinate }, i} * m_{\text {raffinate }, i}}{C_{D E S, \text { initial }} * m_{D E S, \text { initial }}} * 100
$$

In which $\mathrm{C}$ is the lignin concentration, $\mathrm{m}$ the mass of the phase and $\mathrm{n}$ the extraction stage.

\subsubsection{Isolation of lignin fractions}

To obtain sufficient lignin from each fraction for characterization, an additional set of extractions were performed on larger scale using a modified procedure. For the isolation of the lignin from the first raffinate and extract phase, $100 \mathrm{~g}$ lignin-in-DES mixture and $100 \mathrm{~g}$ 2-MTHF were added to a separatory funnel. The mixture was shaken vigorously for several minutes and the phases were settled and separated at room temperature. A minor amount of precipitate was found on the interface between the extract and raffinate phase. 2-MTHF was removed from the extract phase by rotavap at $50{ }^{\circ} \mathrm{C}$ and $200 \mathrm{mbar}$ until no further 2MTHF evaporated from the mixture. Both phases were added to $300 \mathrm{~mL}$ water under stirring to precipitate the lignin. The lignin fractions from the extract and raffinate phases and the precipitate found between the two fractions were separated by centrifuge, washed twice with $20 \mathrm{~mL}$ water and dried overnight under vacuum.

For the isolation of the second and third raffinate and extract phases, $330 \mathrm{~g}$ lignin-in-DES mixture and $330 \mathrm{~g}$ 2-MTHF were added to a separatory funnel. The mixture was shaken vigorously for several minutes and the phases were settled and separated at room temperature. After the extraction, $190 \mathrm{~g}$ DES raffinate and $450 \mathrm{~g}$ 2-MTHF extract were recovered and a minor amount was lost during separation. All raffinate was added to $190 \mathrm{~g}$ of $30 \mathrm{wt} \%$ crystalline lactic acid in 2-MTHF. The mixture was shaken vigorously for several minutes and the phases were settled and separated. $190 \mathrm{~g}$ DES raffinate and $165 \mathrm{~g}$ 2-MTHF extract were obtained. $100 \mathrm{~g}$ of this raffinate was added to another $100 \mathrm{~g}$ of the $30 \mathrm{wt} \%$ crystalline lactic acid in 2-MTHF mixture. The mixture was shaken vigorously for several minutes and the phases were settled and separated. $100 \mathrm{~g}$ DES raffinate and $90 \mathrm{~g}$ 2-MTHF extract was obtained. 2-MTHF was removed from both raffinates by rotavap at $50{ }^{\circ} \mathrm{C}$ and 200 mbar until no further 2-MTHF evaporated from the mixture. All raffinates and extracts were precipitated in excess (1:3 w:w) water. The lignin fractions from the extracts and raffinates were separated by centrifuge, washed twice with $20 \mathrm{~mL}$ water and dried 


\section{Chapter 4}

overnight under vacuum. Insufficient lignin was recovered from the $3^{\text {rd }} 2-M T H F$ extract for analysis.

\subsubsection{Cold water precipitation}

The lignin-in-DES mixture (see section 2.2.1.) and water were both mixed at room temperature in various ratios to form a total of $1 \mathrm{~g}$ in a $1.5 \mathrm{~mL}$ Eppendorf centrifuge tube. The mixtures were shaken thoroughly and left over night at room temperature. The solids were separated by centrifugation at $14,000 \mathrm{rpm}$ for 10 minutes. The lignin content in the supernatant was determined by GPC.

\subsection{Analytical methods}

\subsubsection{GPC}

An Agilent 1200 series was used with a refractive index detector and a UV detector operating at $254 \mathrm{~nm}$ using 3 GPC PLgel $3 \mu \mathrm{m}$ MIXED-E columns in series. The column was operated at $40{ }^{\circ} \mathrm{C}$ and a $95: 5(\mathrm{v}: \mathrm{v})$ tetrahydrofuran and water mixture was the solvent at a flowrate of $1 \mathrm{~mL} / \mathrm{min}$. Molecular weight distributions were calibrated using polystyrene solutions having molecular weights ranging from 162 to $27,810 \mathrm{~g} / \mathrm{mol}$.

\subsubsection{HSQC}

Lignin samples were dissolved in DMSO-d6 and analyzed using a Bruker Ascend $400 \mathrm{MHz}$ spectrometer. Data was acquired using the hsqcetgp pulse program provided by Bruker. Matrices of 512 data points for the ${ }^{1} \mathrm{H}$-dimension and 256 data points for the ${ }^{13} \mathrm{C}$-dimension were collected applying a relexation delay of $1.5 \mathrm{~s}$ and spectral widths from -1 ppm to 11 ppm and from 210 to $0 \mathrm{ppm}$ in the ${ }^{1} \mathrm{H}$ and ${ }^{13} \mathrm{C}$ dimensions, respectively. The $2 \mathrm{D} \mathrm{HSQC}$ spectra were processed using MestReNova software.

\subsubsection{FT-IR}

FT-IR analyses were performed on solid lignin fractions isolated from the raffinates and extracts. The analysis was carried out at room temperature using a Bruker Tensor 27 spectrometer equipped with an attenuated total reflection system and a deuterated triglycine sulphate detector. Absorbance was measured in the range 650 to $4000 \mathrm{~cm}-1$ with a spectral resolution of $4 \mathrm{~cm}^{-1}$, and 16 scans were performed. No baseline corrections were applied.

\subsubsection{Karl-Fischer titration}


Comparing multistage liquid-liquid extraction with cold water precipitation for improvement of lignin recovery from deep eutectic solvents

The water content of lignin in DES mixture was determined by Karl-Fischer titration using a Metrohm $787 \mathrm{KF}$ Titrino. Hydranal composite 5 (5 mg water $/ \mathrm{mL}$ ) was titrated from a $20 \mathrm{~mL}$ burette in a 3:1 (v:v) mixture of methanol and dichloromethane. The sample was measured in duplo with a relative error $<1 \%$.

\section{Results and discussion}

\subsection{Cross-current extractions using actual pulping DES}

Cross-current extractions were performed to investigate the extractability of lignin from the prepared lignin-in-DES mixture. Three stage extractions were performed using 2-MTHF. The lignin concentrations in the solvent phases were determined by GPC and the concentrations in the DES phases were calculated by mass balance. From these concentrations the distribution coefficients of lignin among the 2-MTHF and DES were calculated, as well as the total recovery of lignin from the DES (see section 2.2.2.). The results are shown in fig. 4.1. From this figure, it can be seen that the total lignin recovery after 3 extraction stages was approximately $95 \%$ for the fractions around $2,000 \mathrm{~g} / \mathrm{mol}$, and decreased to around $85 \%$ for the fraction around $10,000 \mathrm{~g} / \mathrm{mol}$. The distribution coefficient in the first stage was around 2.5 for all lignin fractions, dropped below 1 in the last stage. Therefore, further extraction stages seemed ineffective. Because the lignin remaining in the DES could not be extracted by 2-MTHF, we conjecture that the remaining lignin has a different chemical nature compared to the lignin that was extracted by 2-MTHF. Therefore, lignin from each fraction was isolated using a modified procedure for FT-IR and HSQC analysis to elaborate on their structures (see section 3.3.). 

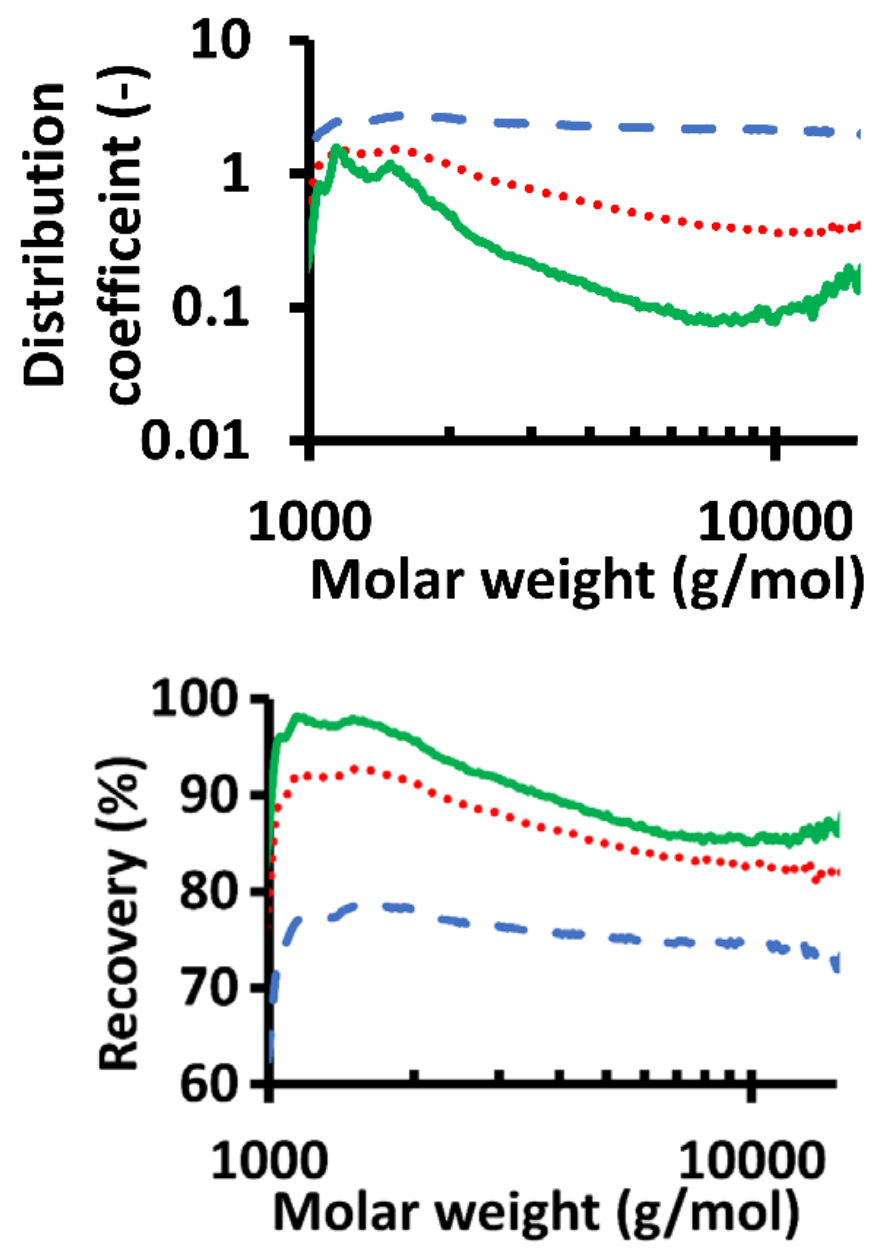

Fig. 4.1. Results of the cross-current extractions of lignin from the lignin-in-DES solution by 2-MTHF in 3 stages (Stage 1 is dashed, 2 dotted and 3 solid lines). A 1:1 DES to solvent ratio was used and extractions were performed at $50{ }^{\circ} \mathrm{C}$. The initial DES contained $17.6 \%$ water. The top figure shows the distribution coefficients and the bottom figure shows the total lignin recovery, as calculated by mass balance.

\subsection{Cross-current extraction using precipitated lignin}

In the previous section, lignin was extracted directly from the prepared lignin in DES mixture. However, this mixture does not only contain lignin, but also (hemi)cellulose 


\section{Comparing multistage liquid-liquid extraction with cold water precipitation for improvement of lignin recovery from deep eutectic solvents}

breakdown products, such as glucose, xylose, furfural, HMF or humins. These substances may influence the lignin distribution, and therefore, the extraction experiments from section 3.1. were repeated using lignin that was previously obtained by cold water precipitation, to see whether extraction of a model lignin produced by the same pulping procedure is representable for the actual system. However, some lignin fractions may remain soluble during cold water precipitation (see section 3.4.), and are therefore not present in the precipitated lignin used in the previous section. This means that the distribution of these fractions cannot be measured in this experiment. The results from this experiment are shown in fig. 4.2. From this figure it can be seen that the distribution coefficient in the $1^{\text {st }}$ stage is between 4 and 10 , which is in accordance with the earlier determined equilibrium [27]. In the $3^{\text {rd }}$ stage, the distribution coefficient dropped to a value lower than 1 for all lignin fractions. This was also seen in the direct extractions from the lignin-in-DES mixture. The lignin recovery after 3 stages of the fractions between 1,000 and $10,000 \mathrm{~g} / \mathrm{mol}$ was around $95 \%$, while the recovered dropped to $85 \%$ for the lignin fractions around $20,000 \mathrm{~g} / \mathrm{mol}$.

The main difference between the total recovery of lignin extracted directly from the ligninin-DES mixture and the lignin that was previously obtained by precipitation can be found in the region between 3,000 and $10,000 \mathrm{~g} / \mathrm{mol}$. For the first lignin, the recovery drops from $95 \%$ to $85 \%$ between these molar weights, while for the second lignin (previously precipitated) the recovery remains constant around $95 \%$ and only drops to $85 \%$ at a molar weight around $20,000 \mathrm{~g} / \mathrm{mol}$. However, for both lignins the full recovery for the lowest molar weight fraction is around $95 \%$ and the recovery of the highest molar weight fraction around $85 \%$, indicating that the lignin model is reasonably representative for the actual lignin-in-DES mixture.

\subsection{Analysis of DES fractions}

In the previous sections it was shown that the lignin extractability from DES decreased one order of magnitude in the $3^{\text {rd }}$ extraction stage, compared to the $1^{\text {st }}$ stage. We conjectured that this was caused by a difference in chemical nature between the lignin extracted by 2MTHF and the lignin remaining in the DES. Therefore, we performed larger scale extractions using a modified procedure to be able to isolate enough lignin from each raffinate and extract fraction, in order to study the chemical natures by FT-IR and HSQC. In this procedure, lignin was extracted from the lignin-in-DES mixture using multiple extractions with 2-MTHF using a separatory funnel at room temperature. The lignins were isolated from each fraction using cold water precipitation. 

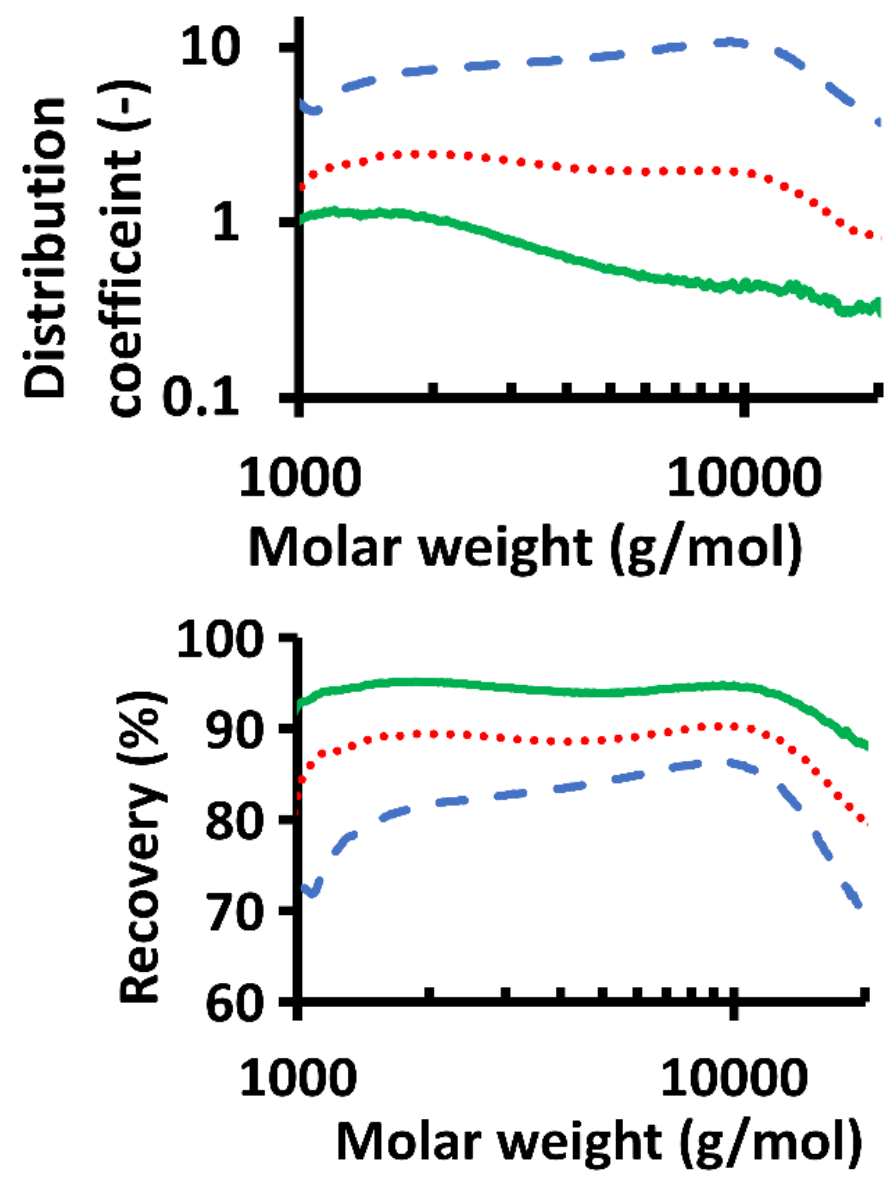

Fig. 4.2. Results from the cross-current extractions of lignin by 2-MTHF from a DES comprised of lactic acid and choline chloride in 3 stages (Stage 1 is dashed, 2 dotted and 3 solid lines). Extractions were performed at $50{ }^{\circ} \mathrm{C}$ using a 1:1 DES to solvent ratio. The initial DES contained $25 \%$ water. The left figure shows the distribution coefficients and the right figure shows the total lignin recovery, as calculated by mass balance.

In theory, FT-IR provides information on all chemical bonds present in a lignin structure [35] and HSQC gives information on the general structure and ether bonds present in lignin $[35,41]$. These factors may influence lignin solubility and by performing these analysis on both lignin fractions, it may become clear why some lignin fractions are better extracted than others. The FT-IR spectra (see fig. 4.3) of the lignins in the DES raffinates and 2-MTHF extracts show only minor differences. There are only minor differences between the spectra of the lignin from the $1^{\text {st }}$ and $2^{\text {nd }}$ DES raffinates, while the spectrum of the lignin in the $3^{\text {rd }}$ 
Comparing multistage liquid-liquid extraction with cold water precipitation for improvement of lignin recovery from deep eutectic solvents

raffinate is similar to the $2^{\text {nd }}$ raffinate. Also the spectrum of the lignin in the $1^{\text {st }} 2-\mathrm{MTHF}$ extract is similar to the three spectra of the lignins in the three DES raffinates. Some extra peaks appear in the $2^{\text {nd }} 2-\mathrm{MTHF}$ extract at 859,888,1157, 1133,1310 and $1358 \mathrm{~cm}^{-1}$. However, all of these peaks can be attributed to the presence of a contamination of BHT in the lignin. The FT-IR spectrum of BHT is shown in the supplementary data. BHT is an additive that is present as stabilizer in 2-MTHF, which was left in the lignin sample after the removal of 2-MTHF. Since the lignin concentration in the $1^{\text {st }}$ extract is much higher than in the $2^{\text {nd }}$ extract, and the BHT concentration in 2-MTHF is constant, the BHT contamination in lignin from the $2^{\text {nd }}$ extract is much higher than from the $1^{\text {st }}$ extract. Not enough lignin could be isolated from the $3^{\text {rd }}$ extract phase for analysis.

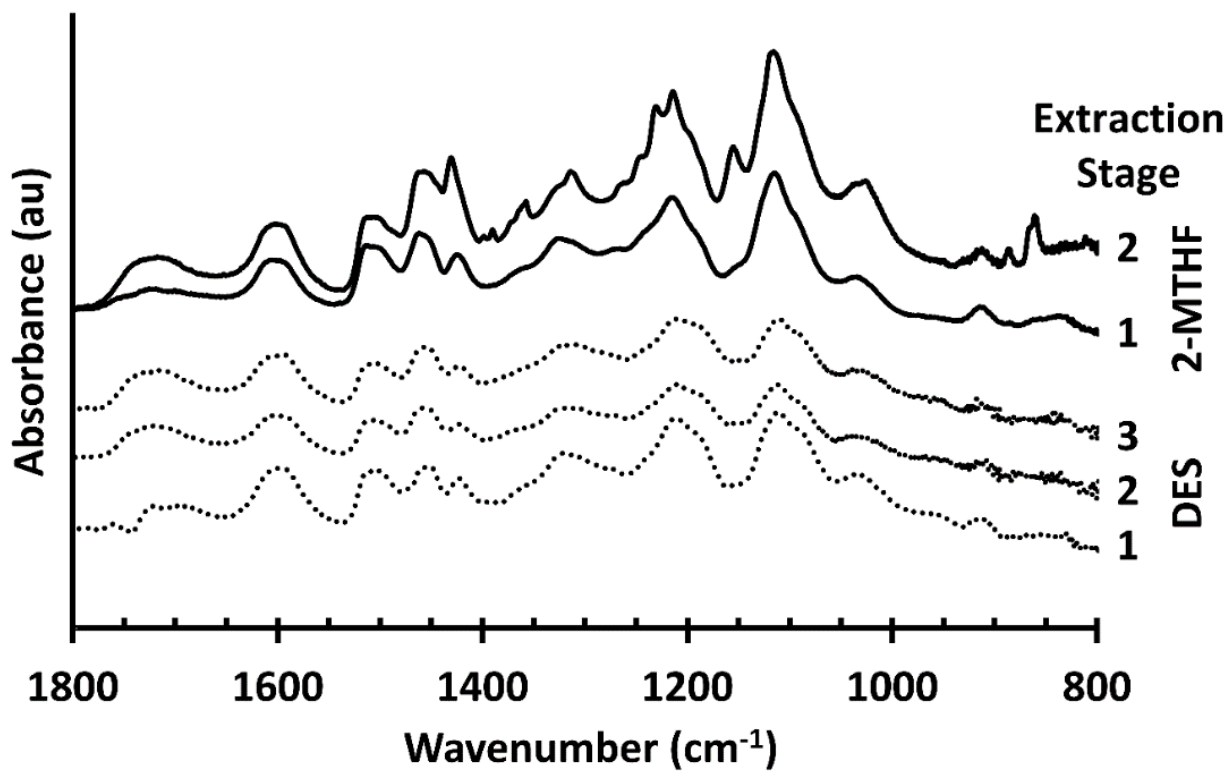

Fig. 4.3. FT-IR spectra of the lignins isolated from the DES raffinates (dotted) and 2-MTHF extracts (solid). 

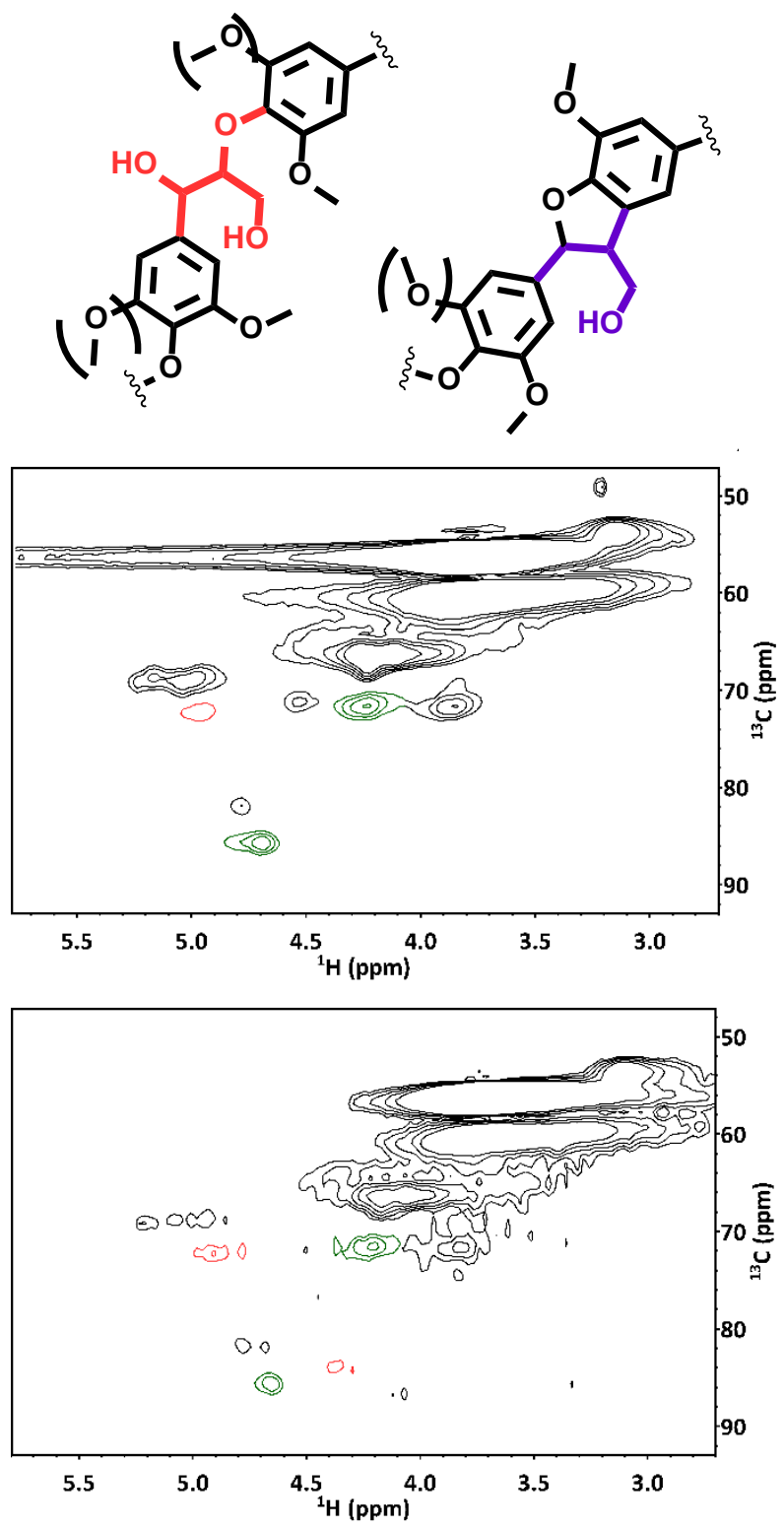

Fig. 4.4. ${ }^{1} \mathrm{H}^{13} \mathrm{C}$ HSQC spectra of the lignin isolated from the DES raffinates and 2-MTHF extracts in the aliphatic oxygenated side chain region $\left(\delta_{C} / \delta_{H}=47-93 / 2.7-5.8 \mathrm{ppm}\right)$. On top of the figures, the structures of the three main inter-aromatic ether bonds are shown: $\beta-O-$ 4 (left, red), $\beta-5$ (middle, purple) and $\beta-\beta$ (right, green). The peaks identified to these bonds in the spectra are labeled by color ( $\beta-5$ bonds were not found in the spectra). Top left: lignin from the $1^{\text {st }} 2-M T H F$ extract, Top right: lignin from the $2^{\text {nd }} 2-M T H F$ extract, Bottom left: lignin from the $1^{\text {st }} D E S$ raffinate, Bottom right: lignin from the $2^{\text {nd }} D E S$ raffinate. 
Comparing multistage liquid-liquid extraction with cold water precipitation for improvement of lignin recovery from deep eutectic solvents
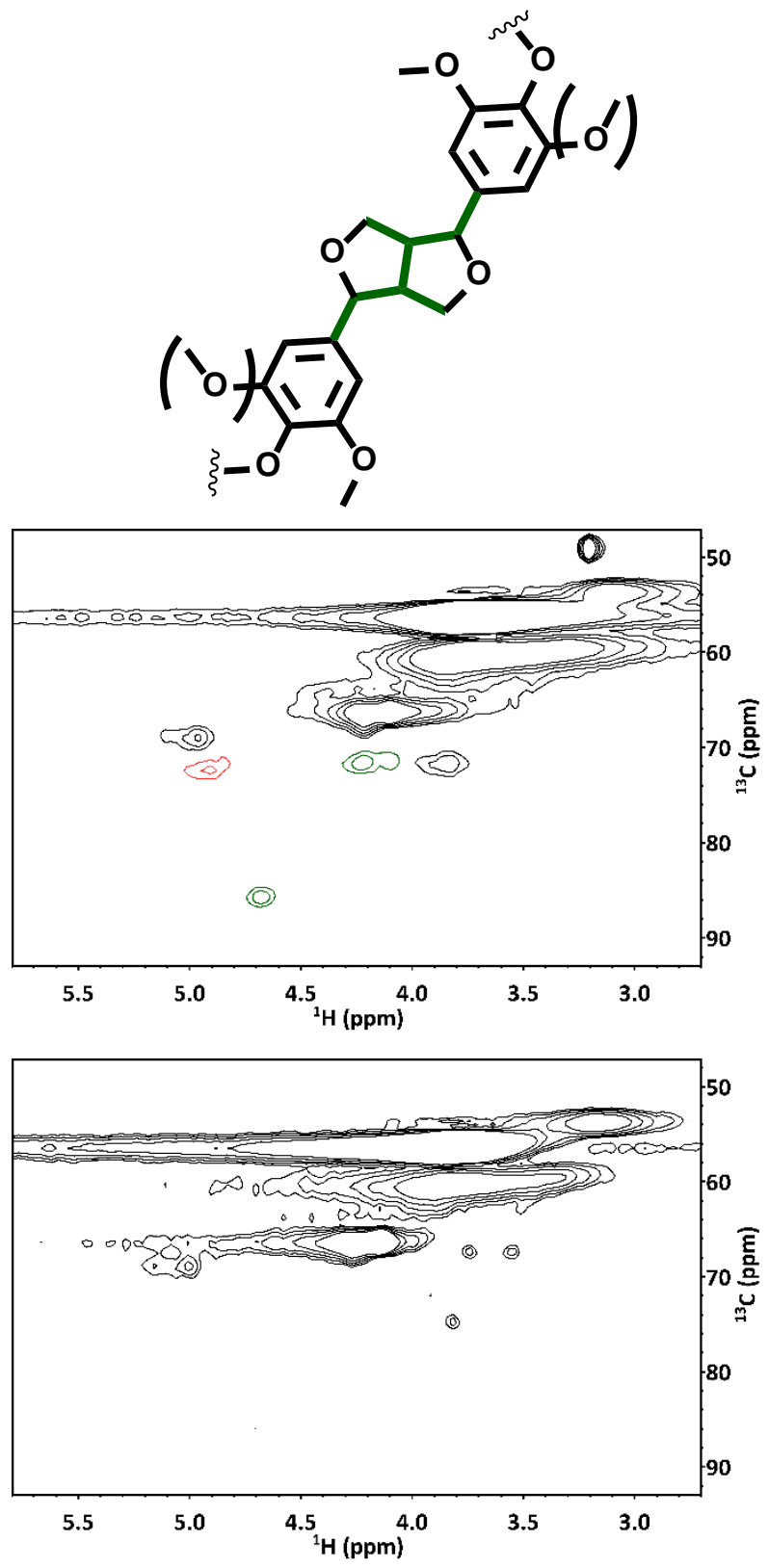

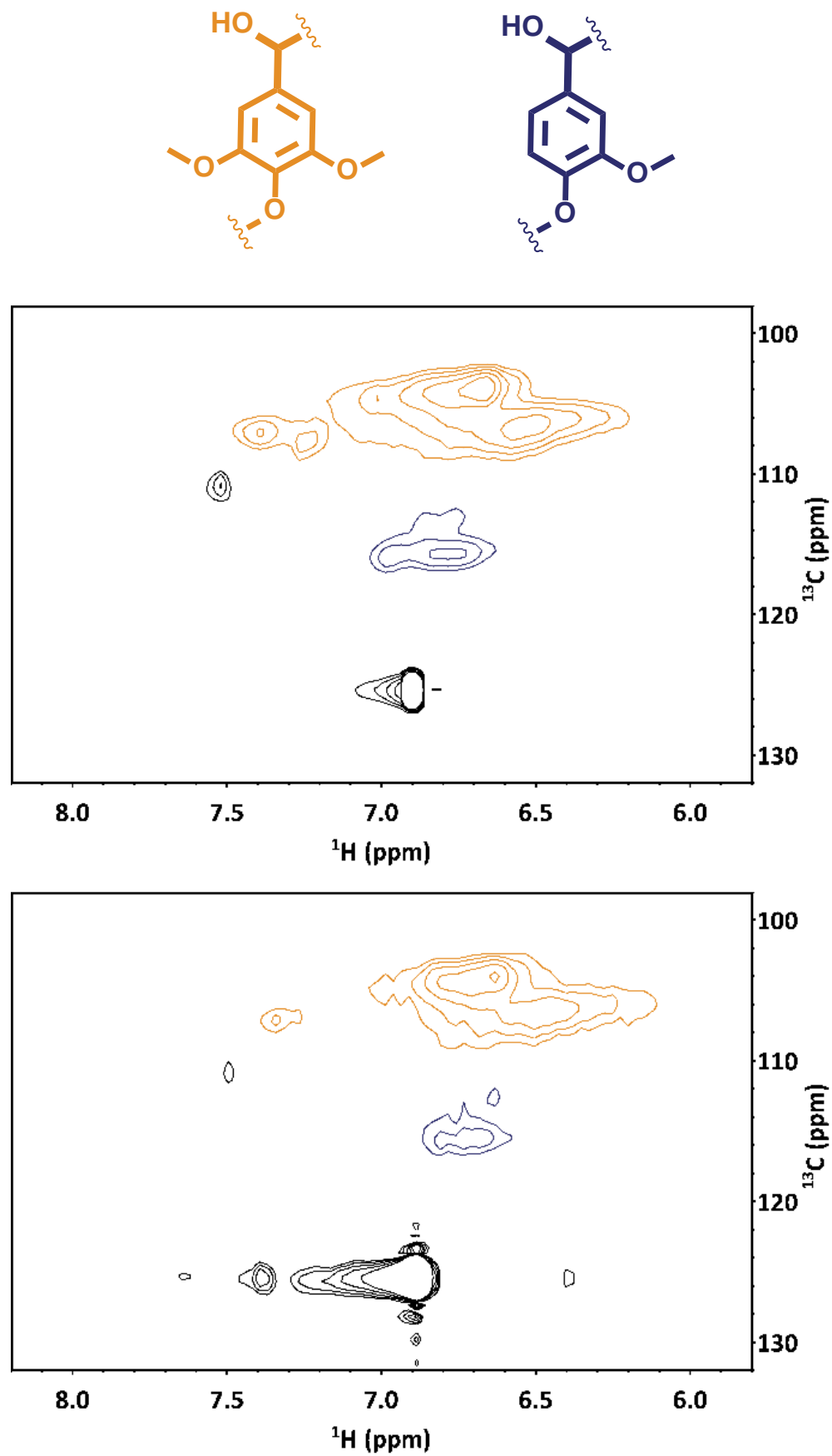

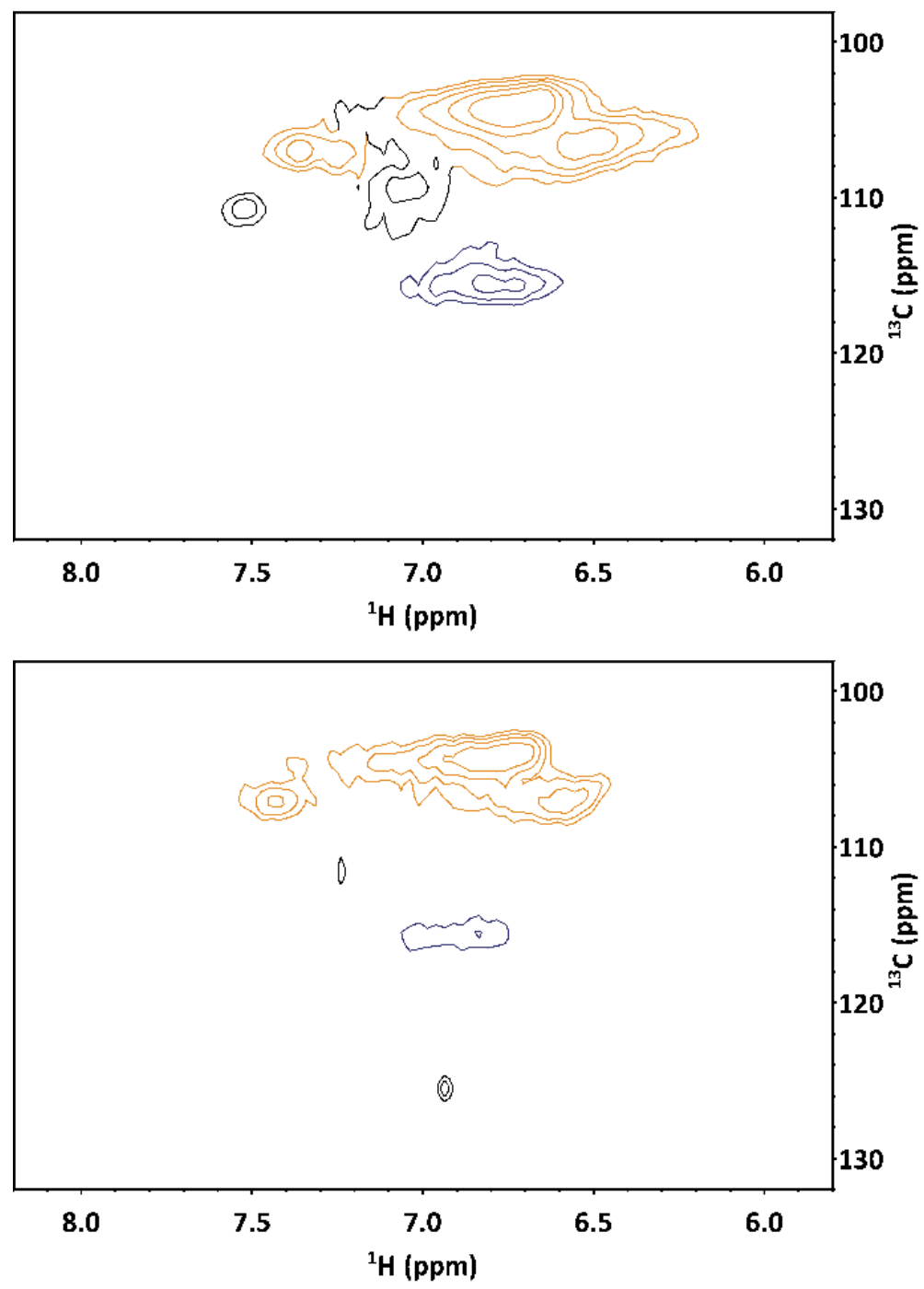

Fig. 4.5. ${ }^{1} \mathrm{H}-{ }^{13} \mathrm{C}$ HSQC spectra of the lignin isolated from the DES raffinates and 2-MTHF extracts in the aromatic region $\left(\delta_{c} / \delta_{H}=98-132 / 5.8-8.2 \mathrm{ppm}\right)$. On top of the figures, the structures of the two main aromatic units are shown: syringyl (left, orange) and guaiacyl (right, blue). The peaks identified to these units in the spectra are labeled by color. Top left: lignin from the $1^{\text {st }} 2-\mathrm{MTHF}$ extract, Top right: lignin from the $2^{\text {nd }} 2-\mathrm{MTHF}$ extract, Bottom left: lignin from the $1^{\text {st }} D E S$ raffinate, Bottom right: lignin from the $2^{\text {nd }}$ DES raffinate. 


\section{Chapter 4}

The HSQC spectra of the lignins in the DES raffinates and 2-MTHF extracts are shown in fig. 4.4. and fig. 4.5. The spectra of the oxygenated side chain region show the presence of ether bonds between the aromatic units. The $\beta-0-4$ bonds $\left(\delta_{c} / \delta_{H}=72.1 / 4.9\right)$ and $\beta-\beta$ bonds $\left(\delta_{c} / \delta_{H}\right.$ $=85.8 / 4.7)$ can be clearly identified in the spectra of the two 2-MTHF extracts and the first DES raffinate. However, they do not show in the $2^{\text {nd }}$ and $3^{\text {rd }}$ DES raffinate. The $\beta-5$ bonds could not be identified in any lignin fraction. Furthermore, the spectra show the methoxy groups in the lignin $\left(\delta_{c} / \delta_{H}=56.3 / 3.7\right)$ and impurities of lactic acid $\left(\delta_{c} / \delta_{H}=69.0 / 5.0\right.$ and $66.6 / 4.2)$ and choline chloride $\left(\delta_{C} / \delta_{H}=53.6 / 3.2\right)$. The spectra of the aromatic region show the presence of guaiacyl $\left(\delta_{C} / \delta_{H}=115.7 / 6.8\right)$ and synapyl $\left(\delta_{c} / \delta_{H}=103.9 / 6.7\right)$ units in all lignin fractions. Furthermore, the spectra of the two 2-MTHF extracts clearly show the contamination of $\mathrm{BHT}\left(\delta_{\mathrm{c}} / \delta_{\mathrm{H}}=125.5 / 6.9\right)$. Reference spectra of all impurities are shown in the ESI.

There are two main differences between the lignin that was extracted by 2-MTHF, compared to the lignin that remained in the DES raffinate. First of all, the lignin that remained in the raffinate has a higher molar weight than the lignin that was extracted by 2MTHF. Second, the lignins that were extracted by 2-MTHF contained inter-aromatic ether bonds, such as $\beta-0-4$ and $\beta-\beta$ bonds, whereas these bonds were not found in the lignin that remained in the DES raffinate. These observations suggest that the lignin that remains in the DES raffinate has a highly condensed nature, compared to the lignin that was extracted by 2-MTHF.

\subsection{Recovery by cold water precipitation}

The current laboratory benchmark to recover lignin from DES is precipitation of lignin by addition of the DES to water or aqueous mixtures [26]. We also studied the recovery of lignin by cold water precipitation to make a direct comparison between both techniques. Water and the lignin-in-DES mixture were mixed in various ratios. The precipitated lignin was separated by centrifuge and the concentration of lignin remaining in the supernatant was determined by GPC. The recovery was calculated from the lignin concentration in the supernatant and the lignin concentration in the original DES. The results of these experiments are shown in fig. 4.6. 




Fig. 4.6. Recovery of lignin by cold water precipitation using various DES to water mass ratios, 1:3.5 (solid), 1:1.7 (dot), 1:0.85 (dash), 1:0.42 (dash-dot), 1:0.22 (dash-dot-dot).

From Figure 7 it becomes apparent that only minor amounts of water are required to precipitate a fraction of the lignin, $0.22 \mathrm{~g}$ water per $\mathrm{g}$ DES was enough to precipitate roughly half of the lignin fraction around $20,000 \mathrm{~g} / \mathrm{mol}$. However, the lower molar weight fraction remained partly soluble in the water-DES mixture. Even when $3.5 \mathrm{~g}$ water per $\mathrm{g}$ DES, about half the lignin fraction around $1,000 \mathrm{~g} / \mathrm{mol}$ was recovered from the DES. We reckon that higher water to DES ratios are not viable for industrial application since the added water must be removed from the DES by evaporation, which is highly energy intensive. Therefore, these ratios were not studied in this work.

\subsection{Comparison between LLX and cold water precipitation}

The recovery of lignin from a DES comprised of lactic acid and choline chloride was studied for two methods, LLX using 2-MTHF and precipitation using cold water. Large differences were found between the two methods. For LLX around $95 \%$ of the lignin fraction around $2,000 \mathrm{~g} / \mathrm{mol}$ could be removed, while for lignin fractions exceeding $10,000 \mathrm{~g} / \mathrm{mol}$, only $85 \%$ could be removed. Cold water precipitation could fully remove all lignin fractions above $4,000 \mathrm{~g} / \mathrm{mol}$, while only $50 \%$ of the lignin around $1,000 \mathrm{~g} / \mathrm{mol}$ could be removed. In summary, recovery of the low molar weight lignin fractions is preferred by LLX, while recovery of the high molar weight fraction is preferred by cold water precipitation. Industrially, LLX is preferred over cold water precipitation since further removal of water from DES is highly energy intensive. However, a high (>95\%) lignin recovery is required for industrial applicability. In this study, the application of LLX was limited to DES with a water content equal or smaller than 25 wt \%. In a previous study, we showed that the lignin 


\section{Chapter 4}

distribution is highly dependent on the water concentration [27], and especially the distribution of the high molar weight fractions is affected by the water content. Therefore, we suggest LLX as the preferred method, with the addition of water to a total amount of 25 to $50 \mathrm{wt} \%$ based on the DES. In principle, the high molar weight lignin fractions can be precipitated by water addition prior or after LLX, but since the addition of water aids LLX, it is preferred to add water before LLX. Water can also be added during LLX to aid the extraction of the high molar weight fractions [27]. The advantage of this method is that the number of unit operations is reduced, but precipitation before LLX produces a light and a heavy molar weight lignin fraction, which may bring more value to the produced lignins.

\section{Conclusion}

Cross-current extractions of lignin from a DES comprised of choline chloride and lactic acid were performed. It was found that $95 \%$ of the molar weight fraction around $2,000 \mathrm{~g} / \mathrm{mol}$ and $85 \%$ of the fractions above $10,000 \mathrm{~g} / \mathrm{mol}$ could be recovered in 3 stages. Additional extraction stages were not performed, since the distribution coefficients dropped one order of magnitude from stage 1 to 3 . Similar results were obtained when the lignin was directly extracted from the pulping DES, compared to the extraction of precipitated lignin that was re-dissolved in the DES. The lignin in DES was fractionated using a one stage extraction by 2-MTHF. Both fractions were analyzed by FT-IR and HSQC. It was found that the lignin that remained in the DES raffinate after two extractions did not contain any $\beta-\beta$ or $\beta-0-4$ bonds. Together with the high molar weight of the lignin remaining in the DES, this suggests that the lignin remaining in the DES is highly condensed. Recovery of lignin by cold water precipitation could fully recovery the lignin fractions heavier than $4,000 \mathrm{~g} / \mathrm{mol}$, but only half of the lignin fraction around $1,000 \mathrm{~g} / \mathrm{mol}$ could be removed by the addition of $3.5 \mathrm{~g}$ water per g DES. For industrial applications, a combination of both approaches will be desirable due to their complementary nature of lignin recovery. 


\section{Comparing multistage liquid-liquid extraction with cold water precipitation for improvement of lignin recovery from deep eutectic solvents}

\section{Bibliography}

[1] B. Schuur, T. Brouwer, D. Smink, L.M.J. Sprakel, Green solvents for sustainable separation processes, Curr. Opin. Green Sustain. Chem. 18 (2019) 57-65. doi:10.1016/j.cogsc.2018.12.009.

[2] L.J.B.M. Kollau, M. Vis, A. Van Den Bruinhorst, A.C.C. Esteves, R. Tuinier, Quantification of the liquid window of deep eutectic solvents, Chem. Commun. 54 (2018) 13351-13354. doi:10.1039/c8cc05815f.

[3] E.A. Crespo, L.P. Silva, M.A.R. Martins, M. Bülow, O. Ferreira, G. Sadowski, C. Held, S.P. Pinho, J.A.P. Coutinho, The Role of Polyfunctionality in the Formation of [Ch]Cl-Carboxylic AcidBased Deep Eutectic Solvents, Ind. Eng. Chem. Res. 57 (2018) 11195-11209. doi:10.1021/acs.iecr.8b01249.

[4] M. Francisco, A. van den Bruinhorst, M.C. Kroon, New natural and renewable low transition temperature mixtures (LTTMs): screening as solvents for lignocellulosic biomass processing, Green Chem. 14 (2012) 2153-2157. doi:10.1039/C2GC35660K

[5] S. Gibout, E. Franquet, D. Haillot, J.-P. Bedecarrats, J.-P. Dumas, Challenges of the Usual Graphical Methods Used to Characterize Phase Change Materials by Differential Scanning Calorimetry, Appl. Sci. 8 (2018) 66. doi:10.3390/app8010066.

[6] X. Meng, K. Ballerat-Busserolles, P. Husson, J.-M. Andanson, Impact of water on the melting temperature of urea + choline chloride deep eutectic solvent, New J. Chem. 40 (2016) 44924499. doi:10.1039/C5NJ02677F.

[7] M. Francisco, A. Van Den Bruinhorst, M.C. Kroon, Low-transition-temperature mixtures (LTTMs): A new generation of designer solvents, Angew. Chemie - Int. Ed. 52 (2013) 30743085. doi:10.1002/anie.201207548.

[8] F.J. V Gomez, M. Espino, M.A. Fernández, M.F. Silva, A Greener Approach to Prepare Natural Deep Eutectic Solvents, ChemistrySelect. 3 (2018) 6122-6125. doi:10.1002/slct.201800713.

[9] Q. Lu, W. Liu, L. Yang, Y. Zu, B. Zu, M. Zhu, Y. Zhang, X. Zhang, R. Zhang, Z. Sun, J. Huang, X. Zhang, W. Li, Investigation of the effects of different organosolv pulping methods on antioxidant capacity and extraction efficiency of lignin, Food Chem. 131 (2012) 313-317. doi:10.1016/j.foodchem.2011.07.116.

[10] I.P.E. Macário, F. Jesus, J.L. Pereira, S.P.M. Ventura, A.M.M. Gonçalves, J.A.P. Coutinho, F.J.M. Gonçalves, Unraveling the ecotoxicity of deep eutectic solvents using the mixture toxicity theory, Chemosphere. 212 (2018) 890-897. doi:10.1016/j.chemosphere.2018.08.153.

[11] G. García, S. Aparicio, R. Ullah, M. Atilhan, Deep eutectic solvents: Physicochemical properties and gas separation applications, Energy and Fuels. 29 (2015) 2616-2644. doi:10.1021/ef5028873.

[12] N.R. Mirza, N.J. Nicholas, Y. Wu, K.A. Mumford, S.E. Kentish, G.W. Stevens, Experiments and Thermodynamic Modeling of the Solubility of Carbon Dioxide in Three Different Deep Eutectic Solvents (DESs), J. Chem. Eng. Data. 60 (2015) 3246-3252. doi:10.1021/acs.jced.5b00492.

[13] N. López-Salas, E.O. Jardim, A. Silvestre-Albero, M.C. Gutiérrez, M.L. Ferrer, F. RodríguezReinoso, J. Silvestre-Albero, F. Del Monte, Use of eutectic mixtures for preparation of monolithic carbons with CO2-adsorption and gas-separation capabilities, Langmuir. 30 (2014) 12220-12228. doi:10.1021/la5034146.

[14] L. Moura, T. Moufawad, M. Ferreira, H. Bricout, S. Tilloy, E. Monflier, M.F. Costa Gomes, D. Landy, S. Fourmentin, Deep eutectic solvents as green absorbents of volatile organic 


\section{Chapter 4}

pollutants, Environ. Chem. Lett. 15 (2017) 747-753. doi:10.1007/s10311-017-0654-y.

[15] Q. Pan, X. Shang, J. Li, S. Ma, L. Li, L. Sun, Energy-efficient separation process and control scheme for extractive distillation of ethanol-water using deep eutectic solvent, Sep. Purif. Technol. 219 (2019) 113-126. doi:10.1016/j.seppur.2019.03.022.

[16] A. Söldner, J. Zach, B. König, Deep eutectic solvents as extraction media for metal salts and oxides exemplarily shown for phosphates from incinerated sewage sludge ash, Green Chem. 21 (2019) 321-328. doi:10.1039/c8gc02702a.

[17] F. Lima, J. Gouvenaux, L.C. Branco, A.J.D. Silvestre, I.M. Marrucho, Towards a sulfur clean fuel: Deep extraction of thiophene and dibenzothiophene using polyethylene glycol-based deep eutectic solvents, Fuel. 234 (2018) 414-421. doi:10.1016/j.fuel.2018.07.043.

[18] F. Lima, M. Dave, A.J.D. Silvestre, L.C. Branco, I.M. Marrucho, Concurrent Desulfurization and Denitrogenation of Fuels Using Deep Eutectic Solvents, ACS Sustain. Chem. Eng. 7 (2019) 11341-11349. doi:10.1021/acssuschemeng.9b00877.

[19] D. Smink, A. Juan, B. Schuur, S.R.A. Kersten, Understanding the Role of Choline Chloride in Deep Eutectic Solvents Used for Biomass Delignification, Ind. Eng. Chem. Res. 58 (2019) 16348-16357. doi:10.1021/acs.iecr.9b03588.

[20] D.J.G.P. Van Osch, L.J.B.M. Kollau, A. Van Den Bruinhorst, S. Asikainen, M.A.A. Rocha, M.C. Kroon, lonic liquids and deep eutectic solvents for lignocellulosic biomass fractionation, Phys. Chem. Chem. Phys. 19 (2017) 2636-2665. doi:10.1039/c6cp07499e.

[21] A. Mišan, J. Nađpal, A. Stupar, M. Pojić, A. Mandić, R. Verpoorte, Y.H. Choi, The perspectives of natural deep eutectic solvents in agri-food sector, Crit. Rev. Food Sci. Nutr. (2019). doi:10.1080/10408398.2019.1650717.

[22] M. Jablonsky, A. Haz, V. Majova, Assessing the opportunities for applying deep eutectic solvents for fractionation of beech wood and wheat straw, Cellulose. 26 (2019) 7675-7684. doi:10.1007/s10570-019-02629-0.

[23] A.K. Das, M. Sharma, D. Mondal, K. Prasad, Deep eutectic solvents as efficient solvent system for the extraction of K-carrageenan from Kappaphycus alvarezii, Carbohydr. Polym. 136 (2016) 930-935. doi:10.1016/j.carbpol.2015.09.114.

[24] E.S. Morais, P. V Mendonça, J.F.J. Coelho, M.G. Freire, C.S.R. Freire, J.A.P. Coutinho, A.J.D. Silvestre, Deep Eutectic Solvent Aqueous Solutions as Efficient Media for the Solubilization of Hardwood Xylans, ChemSusChem. 11 (2018) 753-762. doi:10.1002/cssc.201702007.

[25] Z. Maugeri, P. de Maria, Novel choline-chloride-based deep-eutectic-solvents with renewable hydrogen bond donors: levulinic acid and sugar-based polyols, RSC Adv. 2 (2012) 421-425. doi:10.1039/C1RA00630D.

[26] C. Alvarez-Vasco, R. Ma, M. Quintero, M. Guo, S. Geleynse, K.K. Ramasamy, M. Wolcott, X. Zhang, Unique low-molecular-weight lignin with high purity extracted from wood by deep eutectic solvents (DES): a source of lignin for valorization., Green Chem. 18 (2016) 51335141. doi:10.1039/c6gc01007e.

[27] D. Smink, S.R.A. Kersten, B. Schuur, Recovery of lignin from deep eutectic solvents by liquidliquid extraction, Sep. Purif. Technol. 235 (2019) 116127. doi:10.1016/j.seppur.2019.116127.

[28] M. Blahušiak, A. Kiss, K. Babić, S. R.A. Kersten, G. Bargeman, B. Schuur, Insights into the selection and design of fluid separation processes, Sep. Purif. Technol. 194 (2017) 301-318. doi:10.1016/j.seppur.2017.10.026.

[29] K. Lundquist, R. Simonson, K. Tingsvik, On the composition of dioxane-water extracts of milled spruce wood: characterization of hydrophilic constituents., Nord. Pulp Pap. Res. J. 5 (1990) 107-113. doi:10.3183/npprj-1990-05-03-p107-113.

[30] K. Lundquist, B. Ohlsson, R. Simonson, Isolation of lignin by means of liquid-liquid extraction., Sven. Papperstidning. 80 (1977) 143-144.

[31] S. Gao, J. Zhao, X. Wang, Y. Guo, Y. Han, J. Zhou, Lignin Structure and Solvent Effects on the 


\section{Comparing multistage liquid-liquid extraction with cold water precipitation}

for improvement of lignin recovery from deep eutectic solvents

Selective Removal of Condensed Units and Enrichment of S-Type Lignin, Polymers (Basel). 10 (2018) 967. doi:10.3390/polym10090967.

[32] V. Rohde, S. Böringer, B. Tübke, C. Adam, N. Dahmen, D. Schmiedl, Fractionation of three different lignins by thermal separation techniques-A comparative study, GCB Bioenergy. 11 (2019) 206-217. doi:10.1111/gcbb.12546.

[33] F.H. Yorston, The fractional precipitation of alkali lignin., Pulp Pap. Mag. Canada. 29 (1930) 264.

[34] A.E. Markham, Q.P. Peniston, J.L. McCarthy, Lignin. III. Fractional precipitation of barium lignosulfonates from water by ethanol., J. Am. Chem. Soc. 71 (1949) 3599-3601. doi:10.1021/ja01179a006.

[35] C.S. Lancefield, S. Constant, P. de Peinder, P.C.A. Bruijnincx, Linkage Abundance and Molecular Weight Characteristics of Technical Lignins by Attenuated Total Reflection-FTIR Spectroscopy Combined with Multivariate Analysis, ChemSusChem. 12 (2019) 1139-1146. doi:10.1002/cssc.201802809.

[36] P.S. Marathe, R.J.M. Westerhof, S.R.A. Kersten, Fast pyrolysis of lignins with different molecular weight: Experiments and modelling, Appl. Energy. 236 (2019) 1125-1137. doi:10.1016/j.apenergy.2018.12.058.

[37] R.W. Thring, S.L. Griffin, The heterogeneity of two Canadian kraft lignins, Can. J. Chem. 73 (1995) 629-634. doi:10.1139/v95-081.

[38] R.W. Thring, E. Chornet, J. Bouchard, P.F. Vidal, R.P. Overend, Evidence for the heterogeneity of glycol lignin, Ind. Eng. Chem. Res. 30 (1991) 232-240. doi:10.1021/ie00049a036.

[39] S.Y. Park, J.-Y. Kim, H.J. Youn, J.W. Choi, Fractionation of lignin macromolecules by sequential organic solvents systems and their characterization for further valuable applications, Int. J. Biol. Macromol. 106 (2018) 793-802. doi:10.1016/j.ijbiomac.2017.08.069.

[40] A. Sluiter, B. Hames, R. Ruiz, C. Scarlata, J. Sluiter, D. Templeton, D. Crocker, Determination of Structural Carbohydrates and Lignin in Biomass, NREL/TP-510-42618. Golden, CO, 2012.

[41] S. Constant, H.L.J. Wienk, A.E. Frissen, P. de Peinder, R. Boelens, D.S. van Es, R.J.H. Grisel, B.M. Weckhuysen, W.J.J. Huijgen, R.J.A. Gosselink, P.C.A. Bruijnincx, New insights into the structure and composition of technical lignins: a comparative characterisation study, Green Chem. 18 (2016) 2563-2910. doi:10.1039/C5GC03043A.

[42] D. Smink, S.R.A. Kersten, B. Schuur, Recovery of lignin from deep eutectic solvents by liquidliquid extraction, Sep. Purif. Technol. 235 (2020). doi:10.1016/j.seppur.2019.116127. 


\title{
Chapter 5
}

\author{
Process development for biomass \\ delignification using deep eutectic \\ solvents. Conceptual design supported \\ by experiments
}




\title{
Process development for biomass delignification using deep eutectic solvents.
}

Conceptual design supported by experiments

\begin{abstract}
Deep eutectic solvents (DES) have been proposed as solvents for biomass delignification. This paper describes a conceptual process design for the delignification of Eucalyptus globulus using a DES comprised of $30 \mathrm{wt} \%$ choline chloride and $70 \mathrm{wt} \%$ lactic acid. In this design, the lignin and hemicellulose by-products are recovered by liquid-liquid extraction (LLX) using 2-MTHF as solvent. Material and energy balances were made and the energy usage of the process was optimized with additional experiments. The amount of DES was reduced to the minimal amount required to fill the porous biomass ( $5 \mathrm{~kg}$ per $\mathrm{kg}$ wood), with minor influences on the yield and delignification. Direct recycling of lignin-in-DES mixtures without lignin removal by LLX to the delignification stage may save energy, but increased repolymerization increases the lignin's molar weight, which decreases its value and makes recovery by LLX more difficult. After optimization, the total energy usage of the proposed process is $8.4 \mathrm{GJ} / \mathrm{t}$ pulp, which is $24 \%$ lower than the kraft process. The main benefit of DES based delignification processes is the possible valorization of byproducts, such as lignin and furans from hemicellulose.
\end{abstract}




\section{Chapter 5}

\section{Introduction}

Deep eutectic solvents (DESs) are composite solvents that exhibit deep eutectic behavior upon mixing the constituents. Various authors proposed a definition for a DES [1-5], but no final definition or consensus has been achieved yet. Regardless of what a formal definition of DESs should be, these composite solvents that exhibit their low transition temperatures [6] due to hydrogen bonding, attracted wide attention in academia. Since these solvents can easily be prepared in numerous ways by combining a hydrogen bond donor and acceptor [7] and are often biocompatible, biodegradable [8] and can have a low toxicity [9], DESs have been used for various applications. Examples include $\mathrm{CO}_{2}$ capture [10-12], air pollutant removal [13], extractive distillation [14], metal extractions [15], desulfurization $[16,17]$ and biomass fractionation [18-21].

Lignocellulosic biomass is a renewable raw material source and can be converted into cellulose fibers and, among other byproducts, lignin by delignification technologies. The obtained cellulose pulp can be used for paper production, production of other materials, or can be converted to bio-ethanol or other platform chemicals [22-24]. Lignin is an aromatic biopolymer with advocated potential for the chemical industry and current research is focusing on lignin valorization $[25,26]$. Other byproducts, such as hemicellulose and extractables can be converted into furans and turpentine respectively $[27,28]$.

Most conventional cellulose fiber producing installations make use of the kraft process, in which lignocellulose is delignified using sodium hydroxide and sodium sulfide to form cellulose fibers suitable for papermaking. The lignin is depolymerized by a nucleophilic substitution reaction with the sulfide, meaning the lignin that is finally obtained is highly sulfurized. As a consequence, to be able to recycle the sodium sulfide, the lignin has to be combusted. Kraft mills may also produce lignin as byproduct, but the scale and applications are limited. Kraft lignin is mainly used for low-value applications, such as heat recovery [29].

Although kraft plants are highly integrated and energy effective plants [30], they still have an average heat usage around $11 \mathrm{GJ} / \mathrm{t}$ [31]. This heat is provided from the combustion of the extracted lignin and other parts of the tree that are unsuitable of papermaking, such as the bark. Most modern kraft mills have an energy surplus, which is most often used to provide power to the grid.

DESs have been reported for the delignification of various types of lignocellulose, including softwoods (spruce [32,33], pine [34-36]), hardwoods (beech [21,37], poplar [34,38-40], eucalyptus [18,41-43] and willow [44,45]), grasses (miscanthus [46]) and agricultural 


\section{Process development for biomass delignification using deep eutectic solvents.}

Conceptual design supported by experiments

byproducts (wheat straw [21,32,47,48], rice straw [27,49-52], corncob [53-55], corn stover $[44,56])$. Lignin that is produced using DESs often shows very little signs of condensation [34] and typically has a low molar weight $[34,57]$. Many studies have been performed on biomass delignification using DES and many DES, biomass types and processing conditions have been studied. However, to the best of our knowledge, no conceptual design has been made for biomass delignification using DES yet.

Especially DESs comprised of lactic acid and choline chloride were very often used for biomass delignification $[18,34-40,42,43,45,48,50,52,54,57]$. Although the optimal lactic acid to choline chloride ratios for delignification are between 10:1 and 50:1, [18] a DES comprised of $30 \mathrm{wt} \%$ choline chloride and $70 \mathrm{wt} \%$ lactic acid was used in this study since it is possible to regenerate lignin from this DES by LLX, which has potential for significant energy savings [58].

In this work, a conceptual design was made according to the method described by Douglas [59], which is easy to use and relevant for industrial applications [60]. Using this approach, a complex process design is divided into multiple, much simpler problems. Following the Douglas method, the input-output structure of the process was defined first, after which the separations were defined. Later, the mass and energy balances were made using rigorous calculations. Therefore, it is relatively easy to screen alternatives and thereby optimize the design. In this work, the process was optimized for energy usage.

\section{Methods and materials}

\subsection{Materials}

Air-dry E. globulus chips were donated by The Navigator Company. The commercially sized chips (typically $25-35 \times 10-25 \times 2.5-6 \mathrm{~mm}, \mathrm{~L} \times \mathrm{W} \times \mathrm{T}$ ) were milled to produce wood meal using a hammer mill and sieved (mesh $-25 /+70$ ) and contained 5.6 wt $\%$ moisture. The wood contained $21.6 \%$ lignin, $50.6 \%$ glucose, $14.0 \%$ xylose, and $1.1 \%$ galactose (oven dry basis), as determined by acid hydrolysis using the standard NREL method [61]. Lactic acid (>85\%), choline chloride (>98\%) and sulfuric acid (95-98\%) were purchased from Sigma-Aldrich. 2MTHF (emplura) was purchased from VWR. 


\section{Chapter 5}

\subsection{Experimental procedures}

\subsubsection{Biomass delignification experiments}

1 to $2 \mathrm{~g}$ wood meal (oven dry basis) was added together with $10 \mathrm{~g}$ DES to a Teflon-lined autoclave. This autoclave was inserted into a direct contact heater, which heated the autoclave to $130{ }^{\circ} \mathrm{C}$ in a couple of minutes. After $1 \mathrm{~h}$, the autoclave was taken out of the heater and gently cooled down to room temperature. The contents were washed using ethanol and filtered over a Whatman glass fiber filter before drying of the residue to a constant weight at $105^{\circ} \mathrm{C}$ in a convection oven. All experiments were performed in duplo. The yield was calculated according to equation 1.

yield $(\%)=\frac{\text { Solid residue }(g)}{\text { biomass }(g) *\left(1-\text { Water content in wood }\left(\frac{g}{g}\right)\right)} * 100$

The acid insoluble lignin in the solid residue was determined by acid hydrolysis according to the NREL method [61]. The degree of delignification was calculated according to equation 2

Delignification $(\%)=100-$ Yield $(\%) * \frac{\text { Lignin in residue }(\%)}{\text { Lignin } \text { in } \operatorname{wood}(\%)}$

\subsubsection{Lignin extraction experiments}

$3 \mathrm{~mL}$ lignin in DES mixture, $3 \mathrm{~mL}$ 2-MTHF and 0.5 to $3 \mathrm{~mL}$ water were added to a glass vial with a screw cap. The vials were placed in a Julabo SW22 shaking bath at $50{ }^{\circ} \mathrm{C}$ and shaken overnight at $200 \mathrm{rpm}$. The phases were settled under gentle shaking at $20 \mathrm{rpm}$ until they were fully separated. The lignin contents in both phases analyzed by GPC.

\subsubsection{Preparation of lignin in DES mixture}

$700 \mathrm{~g}$ lactic acid and $300 \mathrm{~g}$ choline chloride were added to a round bottomed flask (2L) with a condenser. The mixture was heated to $130{ }^{\circ} \mathrm{C}$ and $200 \mathrm{~g}$ (oven dry basis) commercially sized chips were added to the flask. The mixture was stirred gently for 3 or $8 \mathrm{~h}$ and the mixtures were filtered while hot over a $53 \mu \mathrm{m}$ steel mesh. The lignin content in the mixtures was determined by acid hydrolysis, for which $20 \mathrm{~mL}$ of the lignin-in-DES mixture was added to a Teflon-lined autoclave, together with $60 \mathrm{~mL}$ water. $3 \mathrm{~mL} 72 \%$ Sulfuric acid was added to the mixture using a pipette and the autoclave was inserted into a direct contact heater at $120^{\circ} \mathrm{C}$ and kept there for one hour. The mixture was cooled down to room temperature and filtered over a Whatman glass fiber filter. The residue was dried in a convection oven at $105^{\circ} \mathrm{C}$ and the acid insoluble lignin content was determined gravimetrically. 


\section{Process development for biomass delignification using deep eutectic solvents.}

Conceptual design supported by experiments

\subsection{Analysis}

\subsubsection{Acid hydrolysis}

The acid insoluble lignin content of the sample was determined by hydrolysis of the sample according to standardized NREL procedure [61]. $0.3 \mathrm{~g}$ Sample was added to a Teflon-lined autoclave, together with $3 \mathrm{~mL}$ sulfuric acid (72\%) and the mixture was kept at $30{ }^{\circ} \mathrm{C}$ for $1 \mathrm{~h}$ while stirring every $10 \mathrm{~min}$. After this, $84 \mathrm{~mL}$ water was added and the tube was kept at 120 ${ }^{\circ} \mathrm{C}$ for another hour. The solids were filtered and dried overnight at $105{ }^{\circ} \mathrm{C}$. The acid insoluble lignin content was calculated according to equation 3.

Acid insoluble lignin $(\%)=\frac{\text { Residue }(g)}{\text { sample }(g) *\left(1-\text { Water content }\left(\frac{g}{g}\right)\right)} * 100$

\subsubsection{GPC}

An Agilent 1200 series was used for the gel permeation chromatography (GPC) with a refractive index detector and a UV detector operating at $254 \mathrm{~nm}$ using $3 \mathrm{GPC}$ PLgel $3 \mu \mathrm{m}$ MIXED-E columns in series. The column was operated at $40{ }^{\circ} \mathrm{C}$ and a $95: 5$ (v:v) tetrahydrofuran and water mixture was the solvent at a flowrate of $1 \mathrm{~mL} / \mathrm{min}$. Molecular weight distributions were calibrated using polystyrene solutions having molecular weights ranging from 162 to $27,810 \mathrm{~g} / \mathrm{mol}$.

\subsubsection{HPLC}

The lactic acid content in het hydrolysis liquids was determined by high performance liquid chromatography (HPLC). An Agilent 1200 system was equipped with a Hi-Plex-H column operated at $60{ }^{\circ} \mathrm{C}$ and a refractive index detector at $55^{\circ} \mathrm{C} .5 \mathrm{mM}$ sulfuric acid in water was used as mobile phase with a flowrate of $0.6 \mathrm{~mL} / \mathrm{min}$.

\subsubsection{Karl-Fischer titration}

The water content of lignin in DES mixture was determined by Karl-Fischer titration using a Metrohm 787 KF Titrino. Hydranal composite 5 (5 mg water $/ \mathrm{mL}$ ) was titrated from a $20 \mathrm{~mL}$ burette in a 3:1 (v:v) mixture of methanol and dichloromethane. The sample was measured in duplo with a relative error $<2 \%$. 


\section{Chapter 5}

\subsubsection{Determination of ash content}

The ash content in the eucalyptus was determined according to the standard NREL procedure [62]. 1.5 to $2 \mathrm{~g}$ biomass was pre-dried in a convection oven at $105^{\circ} \mathrm{C}$ and added to a porcelain crucible which was pre-dried at $575^{\circ} \mathrm{C}$. This crucible was inserted into an oven at $575{ }^{\circ} \mathrm{C}$ to oxidize all organic material. The analysis was performed in duplo. The ash content was determined gravimetrically by equation 4 .

Ash content $(\%)=\frac{\text { Residue after oxidation }(g)}{\text { Dry biomass }(g)} * 100$

\section{Results and discussion}

\subsection{Conceptual process design and initial energy requirement estimation}

\subsubsection{Input-output structure}

First, the type of lignocellulosic biomass must be selected. In principle, every type of lignocellulosic biomass (hardwood, softwood, grasses, agricultural wastes) can be selected for the process. We selected $E$. globulus for further studies because this species is the most cultivated species in fastgrowing plantations [63] and because eucalyptus was also used in our previous studies $[18,58]$. However, the methodology applies to majority of the lignocellulosic biomass sources.

Next, the morphology of the feed must be selected. Obviously, the DES impregnation rate increases if the particles are smaller and therefore, the cooking will be faster and more homogeneous. Cutting wood chips inherently cuts cellulose fibers and therefore decreases the average fiber length, which compromises the fiber quality. Therefore, chip size is a tradeoff between these two variables and chips are generally 20 to $30 \mathrm{~mm}$ long. For other applications, such as cellulose fermentation to bio-ethanol, the fiber quality is irrelevant. In these cases, chip size will be a tradeoff between ease of impregnation and the energy costs involved in chipping. The chip size is very important for the design of the digester, but not for further processing of the pulp and DES recovery. Therefore, this is no factor in the rigorous calculations.

Feed impurities are important for any (chemical) process. In the case of lignocellulosic biomass, three major impurities are present: water, extractables and ash. Presence of water in the feed is not expected to pose any problems in the process. Addition of some water to 


\section{Process development for biomass delignification using deep eutectic solvents. Conceptual design supported by experiments}

DES will decrease the viscosity and is beneficial in the recovery process. However, little is known yet on the influence of water on the pulping process. Also, high water contents may result in significant evaporation at the pulping temperature, which may require the use of pressurized equipment or venting during pulping. Extractables are low molar weight compounds, such as fatty acids, sterols, terpenoids and waxes that can be extracted from biomass using neutral solvents. Considering the hydrophobic nature of these compounds, they will end up in the 2-MTHF during the lignin extraction. Extractables may be removed by steaming biomass prior to further processing. Ash present in the feed dissolves in the DES and will accumulate in the DES recycle loop. Since purging a fraction of the DES is very costly, it will be highly desirable to remove ash prior to DES processing, for instance by acid leaching [64]. Salts that do end up in the DES recycle will have to be removed by complicated separation techniques, such as electrodialysis. The ash content in the eucalyptus used for this study was only $0.38 \mathrm{wt} \%$, but can be much higher for other biomass sources. For example, straw can have an ash content of 6 to $8 \%$ [65]. For the rigorous calculations only the presence of water in the feed was included.

The outlet streams of this process must at least consist of a stream for the produced cellulose and lignin. Besides these products, some of the hemicelluloses will also break down during DES processing. During treatment with acid DESs, hemicellulose breaks down to sugar fractions, which further react to furans. Li et al. [28] and Hou et al. [27] studied the fractionation of rice straw using acid based DESs. Both authors $[27,28]$ could only recover less than half of the hemicellulose removed as either sugar or furanic compound, with the remainder referred to as 'Loss'. We expect these losses to be furanics and sugars that reacted further to form polymeric byproducts called 'humin'. Separation of sugars from DES is complicated. Both compounds are completely non-volatile, excluding separation by distillation. Furthermore, both compounds are highly polar, making affinity based separation very challenging. The only options appear to be a delicate membrane-based process based on the small difference in size of the molecules and ions in the system, another option is to let the sugars react further to furans. These furans may be separated by LLX using organic solvents, such as $2-M T H F[22,66,67]$. Small sugars produced in the cooking will for a major part already be converted into furans, and in the proposed process it seems likely that produced furans will also be extracted by 2-MTHF and thus leave the process together with the lignin. Little is known about the humins, but with its furanic structure, it seems possible that these by-products are also extracted by 2-MTHF and thus leave the process together with the lignin. Alternatively, humins may precipitate during the process on the reaction equipment, as in the commercial production of furfural from 


\section{Chapter 5}

hemicellulose rich agricultural wastes [68]. In the used lignin-in-DES mixtures, only $3 \%$ of the initial amount of xylose present in the biomass was found back by HPLC. For the rigorous calculations, we assumed that all hemicellulose that is removed from the biomass structure leaves to process as 'hemicellulose byproduct' (HBP) together with the lignin. This means that the input-output structure looks as described in Fig. 5.1.

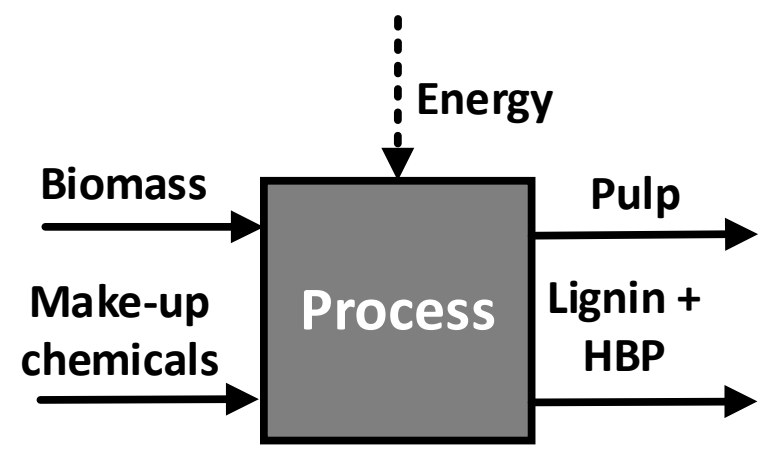

Fig. 5.1. The input-output structure of the conceptual process.

\subsubsection{Batch versus continuous}

In kraft pulping, continuous digesters have become standard. Although some batch digesters are still in operation, batch pulping has become out of date. In a typical continuous digester, wood chips are fed at the top of the reactor vessel and slowly sink through cooking liquor with various compositions. Compared to the current aqueous pulping liquors, DESs have a much higher density and viscosity [69]. The increased density of the DES increases the buoyant forces exerted on a wood chip and the increased viscosity increases the drag force on a wood chip. This will decrease the flow rate of chips through a continuous digester filled with DES and thus greatly complicates the design of such a digester. As a consequence, much data must be gathered to make a detailed design. More than half of all European pulp mills had a capacity exceeding $200 \mathrm{kt}$ per year in 2018 [70]. Although some older mills still operate semi-batch wise, this is highly unusual at this scale. Therefore, pulping must be executed continuously, just as other operations, such as solvent recovery and pulp washing.

\subsubsection{The separation system}

After the pulping reactor, a mixture of cellulose pulp, DES, lignin and hemicellulose byproducts must be separated. In this mixture, the lignin and hemicellulose by-products are dissolved in the DES. It is convenient to separate the solid pulp from the liquid DES first, for instance by pressing. During pressing, part of the liquid remains as stagnant liquid in the fibers in the porous pulp beds. Therefore, the liquid in the pulp must be displaced by 


\section{Process development for biomass delignification using deep eutectic solvents.}

Conceptual design supported by experiments

another liquid. Washing with water is very convenient since water is inexpensive, non-toxic and non-flammable. However, if water is used to displace the DES in the cellulose fibers, the water will mix with the DES, causing lignin to precipitate on the fibers, which is very undesirable. Therefore, the DES in the cellulose fibers must first be displaced by clean DES, before it can be displaced by water.

After the separation between the DES and pulp, the liquid mixture containing DES, water, lignin and hemicellulose by-products must be separated. In our previous paper we made a brief comparison between the regeneration of lignin from DES using cold water precipitation [71] and concluded that the low molar weight lignin fractions could not be recovered by cold water precipitation. Furthermore, LLX using 2-MTHF has the potential to save $95 \%$ energy compared to cold water precipitation [71]. Therefore, lignin is recovered from the DES using LLX. Water is removed later from the mixture, since it aids LLX of lignin from the DES. We assume that the hemicellulose-byproducts are also extracted by 2-MTHF (see section 3.1.1.). The 2-MTHF can be recovered by evaporation and the lignin and hemicellulose by-products remain in the evaporation residue, together with any DES that may have leached to the 2-MTHF during extraction. This DES can be washed from the products using water and the washing water is recycled back to the extraction stage.

At last, the DES must be separated from the water and any 2-MTHF that leached to the DES phase during extraction. Water and 2-MTHF may be separated from the DES by evaporation. After condensation, the water and 2-MTHF can be separated in a settler vessel because of the immiscibility between water and 2-MTHF. Altogether, the flowsheet as shown in Fig. 5.2 is obtained. 


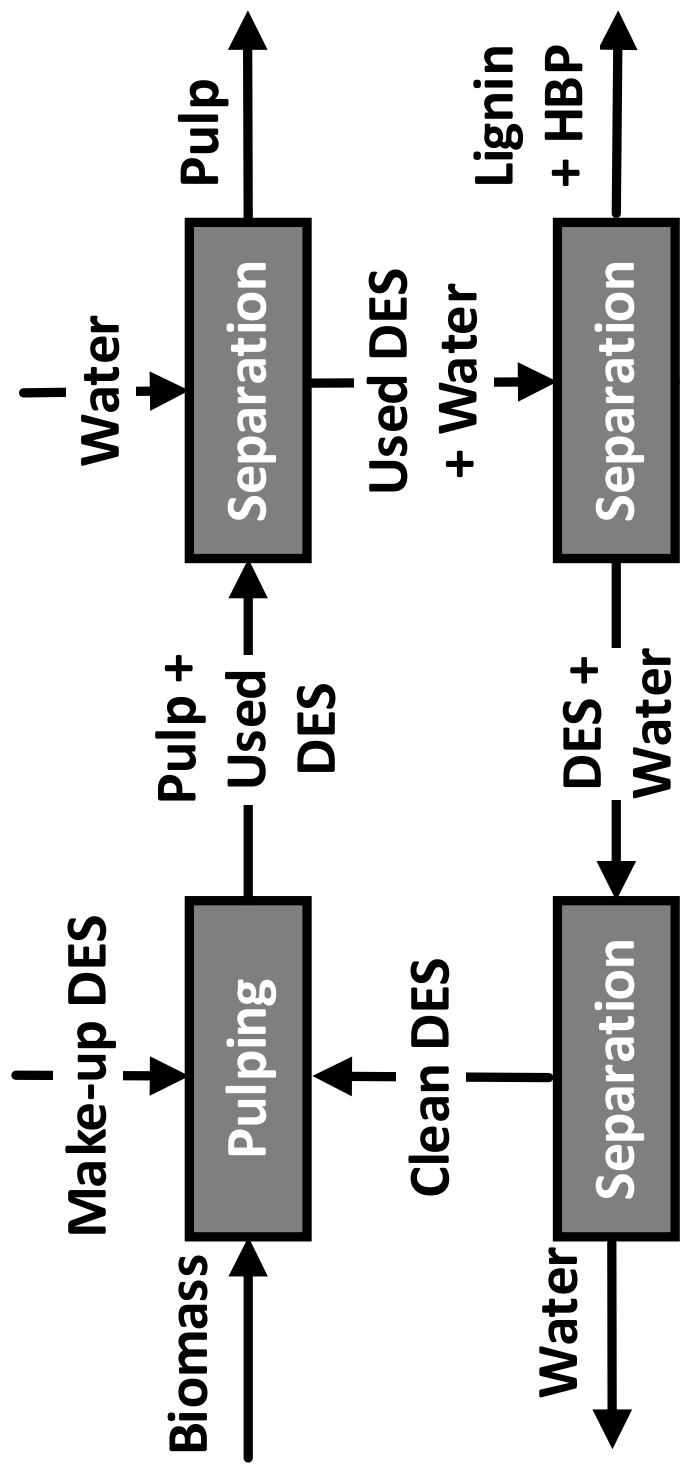

Fig. 5.2. Structure of the conceptual process. In the left figure, the process is shown by function and in the right figure, the process is shown by operations. After pulping, the pulp in used DES suspension (3) is pressed and washed to form a clean pulp suspension (6). All Used DES and water from the washing and pressing stages are combined in stream (7), which is mixed with water from the lignin wash (13) and the lignin and HBP present in this mix (8) are extracted using 2-MTHF (9 and 10). The clean DES recycle (16) is dried and the clean DES (18) is used again for pulping (2) and washing (4). 
Process development for biomass delignification using deep eutectic solvents.

Conceptual design supported by experiments

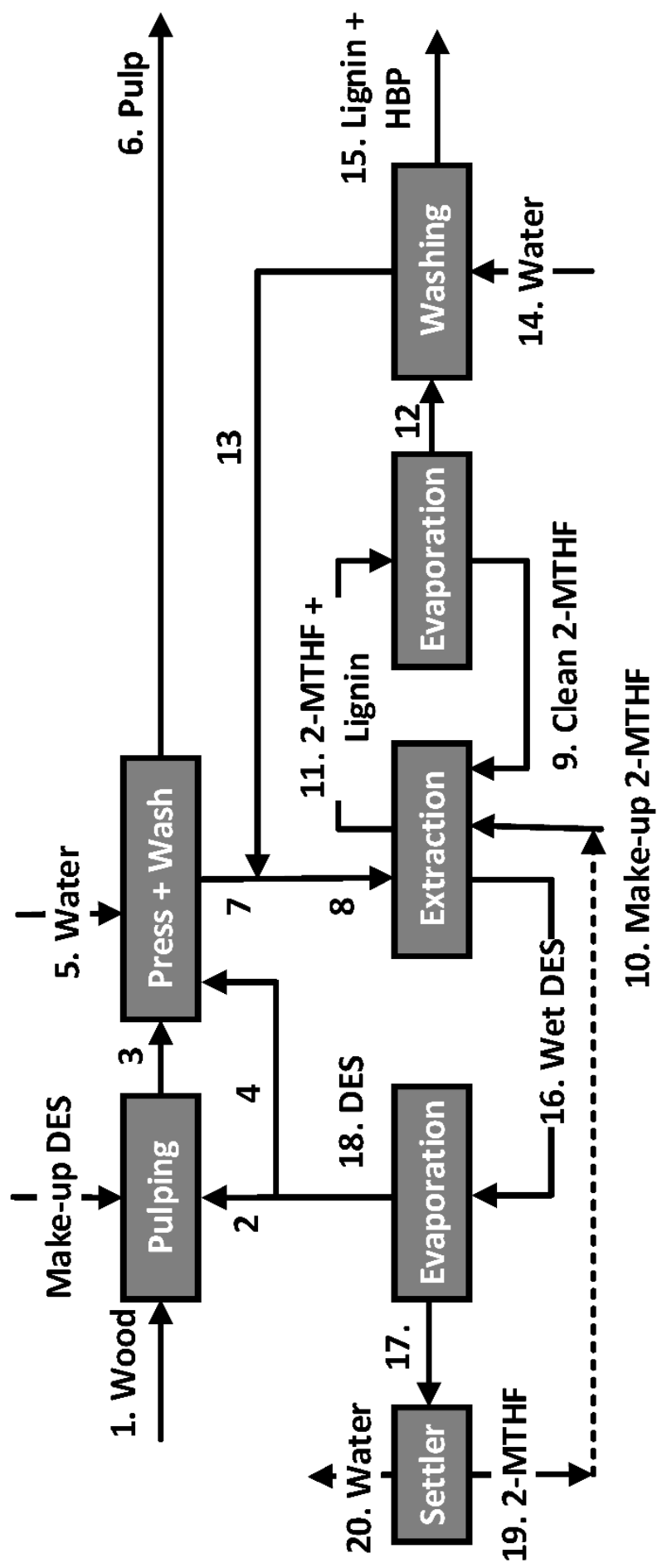




\section{Chapter 5}

\subsection{Mass balance}

In the conceptual process, biomass is fractionated into pulp, lignin and hemi-cellulose byproducts. Any other byproducts or losses are not taken into account in this process design. Therefore, the amount of biomass entering the process (stream 1, fig. 5.2) ( $\mathrm{M}_{\mathrm{B}, \mathrm{in}}$ ) is equal to the amounts of pulp (stream 6, fig. 5.2) ( $\mathrm{M}_{\mathrm{p}, \text { out }}$ ), lignin ( $\mathrm{ML}$, out) and hemicellulose byproducts (Мнвр,out) produced (stream 15, fig. 5.2), as shown in equation 5.

$$
M_{B, \text { in }}=M_{P, \text { out }}+M_{L, \text { out }}+M_{H B P, \text { out }}
$$

The amount of pulp produced is the sum of the amount of biomass entering the process, multiplied by the pulp yield ( experimentally at $57 \%$.

$$
M_{P, \text { out }}=M_{B, \text { in }} * y_{P}
$$

The amount of lignin produced is equal to the amount of lignin removed from the biomass. This is the amount of biomass entering the process, multiplied by the lignin fraction in the biomass $(\mathrm{x} L \mathrm{~B})$ and the degree of delignification $(\mathrm{y} \mathrm{L})$, as shown in equation 7 . These fractions were determined experimentally at respectively $21.6 \%$ and $94.1 \%$.

$M_{L, \text { out }}=M_{B, \text { in }} * x_{L, B} * y_{L}$

For convenience, the pulp production is set to $1000 \mathrm{~kg} / \mathrm{h}$ and therewith, the system of 3 equations can be used to solve the 3 unknowns ( $M_{B, i n}, M_{L, o u t}$ and $M_{H B P, o u t}$ ).

The amount of DES used for pulping in the digester (stream 2, fig. 5.2)(MDEs,pulping) is equal to the amount of biomass, multiplied by the DES to biomass ratio (DB), as shown in equation (8). Prior to optimizing the flow sheet, this ratio is set to 10 since this is a common ratio in literature [34].

$M_{D E S, \text { pulping }}=M_{B, \text { in }} * D B$

After pulping, the pulp is first washed using DES to remove lignin from the pulp. To the best of our knowledge, no data is available on pulp washing using DES yet. Therefore, data used on water washing is used to give an estimate on the amount of DES required for washing. It is common to use around $3 \mathrm{~kg}$ water per $\mathrm{kg}$ pulp in industry [72]. This washing factor (WF) is multiplied by the amount of pulp produced to calculate the amount of DES required for washing (MDEs,wash), as shown in equation (9).

$M_{D E S, \text { wash }}=M_{P, \text { out }} * W F_{P}$ 


\section{Process development for biomass delignification using deep eutectic solvents. Conceptual design supported by experiments}

Water is required to aid LLX of lignin from the DES. Therefore, the water fraction in the DES recycle stream (stream 16, fig. 5.2) (XW,DESrecycle) is defined as the amount of water in the

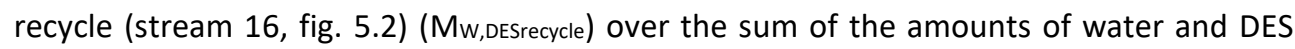
(from pulping and washing), as shown in equation (10). A water mass fraction of 0.5 is assumed, since this is sufficient for full lignin recovery using LLX [71].

$x_{W, D E S r e c y c l e}=\frac{M_{W, D E S r e c y c l e}}{M_{D E S, \text { Pulping }}+M_{D E S, \text { washing }}+M_{W, \text { DESrecycle }}}$

The amount of solvent required for the extraction stage (stream $9+10$, fig. 5.2) (MMTHF,extraction) is equal to the total mass of the DES and water in the recycle (stream 16, fig. 5.2), multiplied by the solvent to feed ratio (SF), as shown in equation (11). A ratio of 0.5 was used, since this is sufficient for full lignin recovery [71].

$M_{M T H F, \text { extraction }}=\left(M_{D E S, \text { pulping }}+M_{D E S, \text { washing }}+M_{W, D E S r e c y c l e}\right) * S F$

Since the extraction solvent and DES are partially miscible, some of the extraction solvent leaches to the DES recycle (from stream 9 to stream 16, fig. 5.2). This amount (MMTHF,leached) is determined by the solubility factor ( $\mathrm{X}_{\mathrm{MTHF}}$,leached $)$ of 2-MTHF in DES, as shown in equation (12). This factor was estimated at 0.1 from equilibrium data [58].

$M_{M T H F, \text { leached }}=x_{M T H F, \text { leached }} *\left(M_{D E S, \text { pulping }}+M_{D E S, \text { washing }}+M_{W, D E \text { Srecycle }}\right)$

Besides leaching of solvent to the DES recycle, some DES will also leach to the solvent (from stream 8 to stream 11). It must be noted that DESs are not pseudo-pure compounds, and especially during LLX, their composition changes since every DES constituent has a different leaching characteristics. In this case, lactic acid has a much higher solubility in 2-MTHF than choline chloride [58] and thus, relatively more lactic acid than choline chloride will leach to the 2-MTHF phase (from stream 8 to stream 11, fig. 5.2). However, after extraction any leached DES will end up in stream 12 of the process, where it is washed of the lignin and HBP and furthermore recycled directly back to the extraction stage via streams 13 and 8 (see fig. 5.2). Therefore, it is not expected that the composition of the leached DES will have any influence on the energy usage of the process and is therefore not taken into consideration. This amount (MDES,MTHFleach) is determined from the solubility factor of DES in 2-MTHF (XDES,MTHF), as shown in equation (13). This factor was estimated at 0.3 from equilibrium data [58].

$M_{D E S, M T H F l e a c h}=M_{M T H F, \text { extraction }} * x_{D E S, M T H F}$ 


\section{Chapter 5}

At last, the water balance is made. Some water is naturally present in this wood. Since it was decided not to pre-dry the wood, this amount has to be taken into account as well. The fraction of water naturally present in biomass $(\mathrm{xw}, \mathrm{B})$ is 0.5 [73]. This is defined as de amount of water in the biomass $\left(\mathrm{Mw}_{\mathrm{w}, \mathrm{B}}\right)$, divided by the amounts of water and biomass entering the process, as shown in equation (14).

$x_{W, B}=\frac{M_{W, B}}{M_{B, i n}+M_{W, B}}$

Since pulp is a porous material, some water will always remain in the pulp after washing (stream 6, fig. 5.2). If the process is integrated with for instance a papermaking plant, this amount does not need to be removed since cellulose pulp must be fed to a papermaking machine in an aqueous suspension. Alternatively, the water can be removed if the pulp is sold on the market. The water fraction in the pulp $(\mathrm{xw}, \mathrm{p})$ is defined by the amount of water in the pulp $\left(\mathrm{Mw}_{\mathrm{w}} \mathrm{P}\right)$, divided by the amount of pulp and water in the pulp, as shown in equation (15). The water fraction in pulp was set at 0.67 , since this amount can typically be achieved by pressing of the pulp [74].

$x_{W, P}=\frac{M_{W, P}}{M_{P, o u t}+M_{W, P}}$

After evaporation of 2-MTHF from the lignin and HBP, any DES that remains with the lignin and HBP (stream 12, fig. 5.2) must be removed from the lignin by washing with water. The amount of water required for lignin and HBP washing (stream 14, fig. 5.2) ( $\mathrm{Mw}$, Lwash) is determined by the amount of DES that must be washed from the lignin and HBP, multiplied by a washin factor $\left(W_{F_{L}}\right)$, as shown in equation (16). The washing factor is estimated at 2 , it is assumed that $2 \mathrm{~kg}$ water is required to wash $1 \mathrm{~kg}$ DES from the lignin and HBP.

$M_{W, L w a s h}=M_{D E S, M T H F} * W F_{L}$

In addition, the amount of water required for the washing of pulp must be determined. Industrially, $3 \mathrm{~kg}$ water is used to wash $1 \mathrm{~kg}$ pulp. After the pulp washing step, DES is sent to a LLX operation to remove lignin. In this step also water is needed. It is expected that for LLX additional water is needed. This additional amount can be added during LLX, but it is better to add it during pulp washing, because using more water for washing will ease the washing operation. This amount of water goes to the extraction stage together with the DES mixture (from stream 5 via streams 7 and 8, fig. 5.2). Therefore, the amount of water

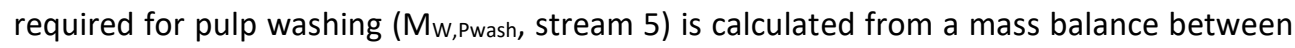
the water required in the DES recycle (stream 16), the water entering the recycle from the biomass (stream 1), lignin wash (stream 14) and the water that leaves the process in the pulp (stream 6). This is shown in equation (17). 
Process development for biomass delignification using deep eutectic solvents.

Conceptual design supported by experiments

$M_{W, P w a s h}=M_{W, D E S r e c y c l e}-M_{W, B}-M_{W, L w a s h}+M_{W, P}$

The amount of water used from pulp washing must always be higher or equal to the minimum amount of water required for pulp washing. This amount is $3 \mathrm{~kg}$ water per $\mathrm{kg}$ pulp and called the wash factor (WFP), shown in equation (18). In case the amount of water calculated by equation 17 is lower than the lower boundary stated in equation (18), the amount of water required for washing will be determined according to equation (18) and the water fraction in the DES recycle (calculated from equation 10) will increase.

$M_{W, P w a s h} \geq M_{P, \text { out }} * W F_{P}$ 
Table 5.1. Assumptions made for the mass balance of the conceptual process with their justifications.

\begin{tabular}{|c|c|c|c|c|}
\hline Symbol & Description & Value & Unit & Justification \\
\hline DB & DES to biomass ratio & 10 & $\mathrm{~kg} / \mathrm{kg}$ & $\begin{array}{l}\text { Common ratio used in } \\
\text { literature [34] }\end{array}$ \\
\hline$I_{B}$ & $\begin{array}{l}\text { Lignin fraction in } \\
\text { biomass }\end{array}$ & 0.216 & $\begin{array}{l}\mathrm{kg} \text { lignin/kg } \\
\text { biomass }\end{array}$ & $\begin{array}{l}\text { Measured by acid } \\
\text { hydrolysis, see [18] }\end{array}$ \\
\hline $\mathrm{MP}$, out & $\begin{array}{l}\text { Total cellulose } \\
\text { production }\end{array}$ & 1000 & $\mathrm{~kg} / \mathrm{h}$ & For convenience $^{a}$ \\
\hline SF & Solvent to feed ratio & 0.5 & $\mathrm{~kg} / \mathrm{kg}$ & Estimated from [58] \\
\hline$W F_{L}$ & Washing factor lignin & 2 & $\mathrm{~kg} / \mathrm{kg}$ DES & \\
\hline WFp & Washing factor pulp & 3 & $\mathrm{~kg} / \mathrm{kg}$ & $\begin{array}{l}\text { Estimated from water } \\
\text { washing data }^{b}\end{array}$ \\
\hline $\mathrm{X}_{\mathrm{DES}, \mathrm{MTHF}}$ & $\begin{array}{l}\text { Solubility of DES in 2- } \\
\text { MTHF }\end{array}$ & 0.3 & $\mathrm{~kg} / \mathrm{kg}$ & Estimated from [58] \\
\hline $\mathrm{X}_{\mathrm{MTHF}, \mathrm{DES} \text { recycle }}$ & $\begin{array}{l}\text { Solubility of 2-MTHF in } \\
\text { DES }\end{array}$ & 0.1 & $\mathrm{~kg} / \mathrm{kg}$ & Estimated from [58] \\
\hline$X_{W, B}$ & $\begin{array}{l}\text { Water fraction in } \\
\text { biomass }\end{array}$ & 0.5 & $\mathrm{~kg} / \mathrm{kg}$ & [73] \\
\hline $\mathrm{XW}$,DESrecycle & $\begin{array}{l}\text { Water fraction in DES } \\
\text { after LLX }\end{array}$ & 0.5 & $\mathrm{~kg} / \mathrm{kg}$ & Estimated from [71] \\
\hline$X_{W, P}$ & Water fraction in pulp & 0.67 & $\mathrm{~kg} / \mathrm{kg}$ & $\begin{array}{l}\text { Typically achievable by } \\
\text { pressing [74] }\end{array}$ \\
\hline $\mathrm{yL}$ & $\begin{array}{l}\text { Lignin removal from } \\
\text { biomass }\end{array}$ & 0.94 & $\begin{array}{l}\text { kg lignin in } \\
\text { biomass/kg } \\
\text { lignin removed }\end{array}$ & Measured in this work \\
\hline$y_{p}$ & $\begin{array}{l}\text { Solid yield after } \\
\text { delignification }\end{array}$ & 0.57 & $\mathrm{~kg} / \mathrm{kg}$ biomass & Measured in this work \\
\hline
\end{tabular}

a Normalized to $1 \mathrm{t} / \mathrm{h}$ for convenience. All numbers can be scaled linearly to any desired production capacity.

b Only data about water washings are available, which state that $2.5 \mathrm{~m}^{3}$ water [74] per $\mathrm{t}$ of pulp is required. Based on the density of DES, being higher than water, $3 \mathrm{~kg}$ DES per $\mathrm{kg}$ pulp was assumed to be the minimum for DES washing of pulp. 


\section{Process development for biomass delignification using deep eutectic solvents. Conceptual design supported by experiments}

\subsection{Energy balance}

During pulping, the mixture of DES and wood is kept at $130^{\circ} \mathrm{C}$. After pulping, the pulp is first washed using clean DES from the evaporation plant. The clean DES is not heated, nor cooled before the washing stage. After the clean DES wash, the pulp is washed using fresh water. The use of hot water is beneficial because it increases diffusion rates and decreases the viscosity of the liquid mixtures. It is assumed that this water enters the washing plant at 80 ${ }^{\circ} \mathrm{C}$ because at this temperature, no pressurized equipment is required and this temperature can easily be achieved using waste heat of the process. Either water from the evaporation plant may be used directly in the washing stage, or the heat in this stream may be used to pre-heat water for the washing stage. It is assumed that the suspension of cellulose fibers in water exits the washing plant at the inlet temperature of the washing water $\left(80^{\circ} \mathrm{C}\right)$ and that the rest of the liquids from the washing plant are mixed. Before LLX, this stream (stream 7, fig. 5.2) is cooled down to $75^{\circ} \mathrm{C}$. This is slightly lower than the boiling point of 2-MTHF (which is $80^{\circ} \mathrm{C}$ ), so that no pressurized equipment is required for LLX.

After LLX, water is removed from the DES recycle (stream 16, fig. 5.2.) by multi-effect flash evaporation. It is assumed that these multi-effect flash evaporators have the same characteristics as the multi-effect flash evaporators currently used in the kraft process. Typically, these evaporators use a 7 effect evaporation train and have a steam efficiency of 5.95 [75] (1 ton of steam is used to evaporate 5.95 ton of water). If it is assumed that the heat content of steam is $2.2 \mathrm{GJ} / \mathrm{t}$ [75], the heat duty of the water evaporation step can be calculated using equation 19.

$Q_{\text {water evaporation }}=2.2 * \frac{M_{W, D E \text { Srecycle }}}{\text { steam efficency }}$

In multi effect flash evaporation, the first stage or stages are heated using direct steam. The steam that evaporates from this liquid is used to heat the next stage, and so forth. The DES enters at the last effect and is thus heated further with each consecutive stage. It is assumed that the total heat increase is equal to the heat increase in a kraft evaporator, which is typically $40^{\circ} \mathrm{C}[76]$. This means that the dry DES exits the evaporation train at $75+40=115$ ${ }^{\circ} \mathrm{C}$. 
Chapter 5

Table 5.2. Mass balance of the conceptual process.

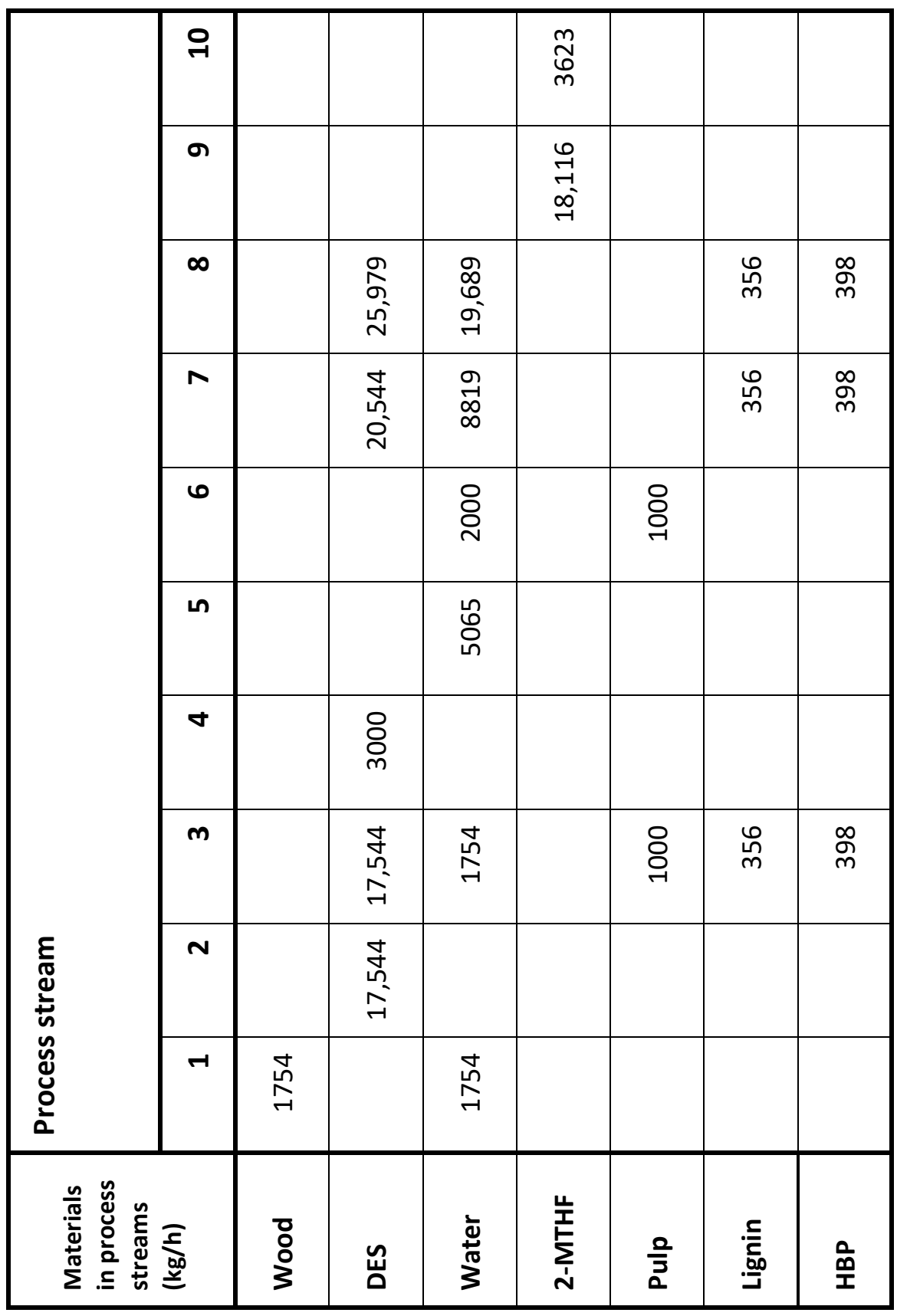


Process development for biomass delignification using deep eutectic solvents.

Conceptual design supported by experiments

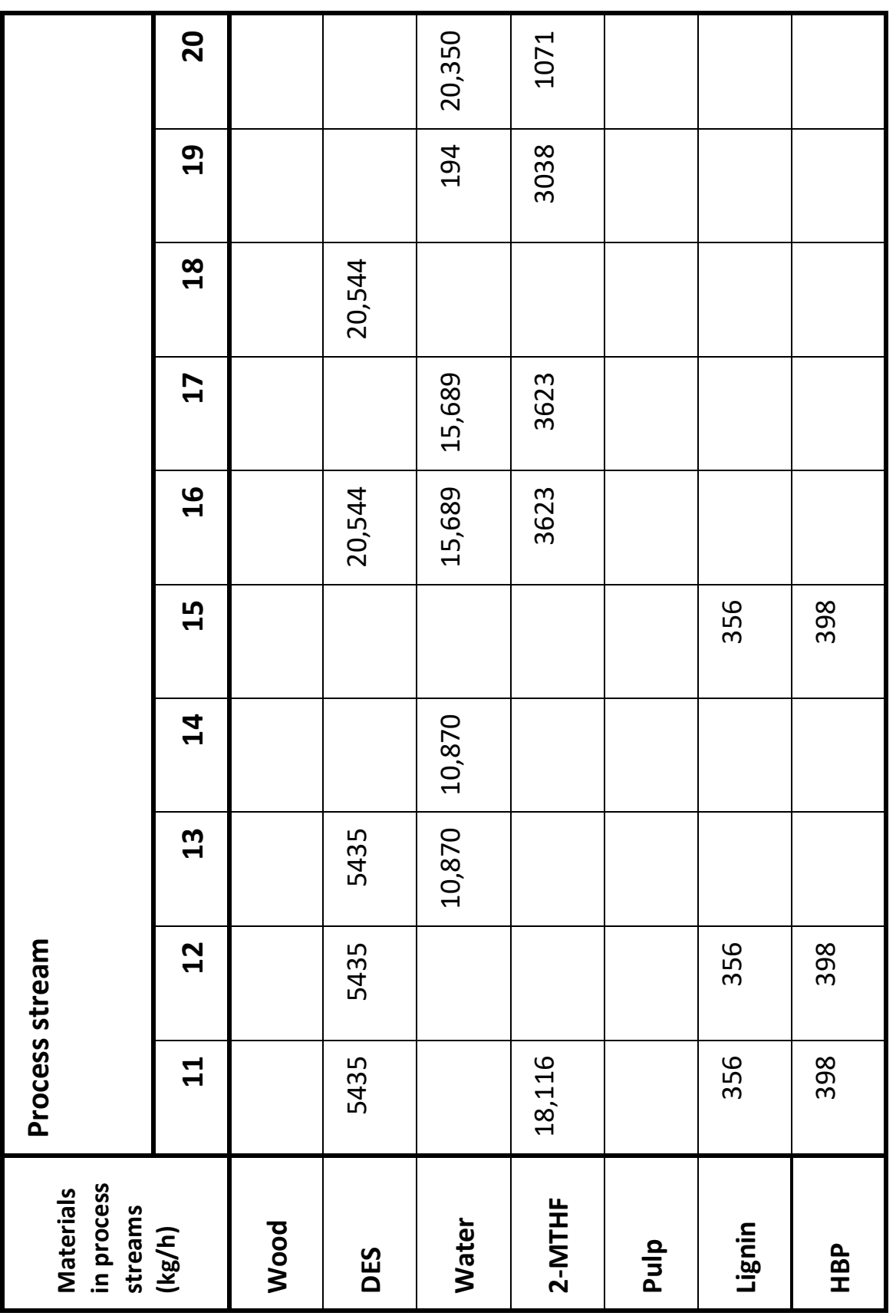




\section{Chapter 5}

After LLX, the 2-MTHF is also recovered using multi-effect flash evaporation. It is assumed that the setup of the multi stage flash evaporation is similar to the setup of the water evaporation. However, the heat of evaporation of 2-MTHF is only $0.40 \mathrm{MJ} / \mathrm{kg}$, which is much lower than the heat of evaporation of water, which is $2.2 \mathrm{MJ} / \mathrm{kg}$. This means that in the first stage, $1 \mathrm{~kg}$ steam is required to evaporate $2.2 / 0.4=5.5 \mathrm{~kg} 2-\mathrm{MTHF}$ and thus the heat duty is reduced by this factor. The 2-MTHF vapor from the first stage is than used to heat the next stage, and so forth. It is assumed that the same evaporation efficiency is achieved as for the evaporation of water from DES, thus the heat duty is reduced by the same efficiency factor of 5.95. The total heat to evaporate the 2-MTHF after LLX can be calculated according to equation (20).

$Q_{M T H F}$ evaporation $=2.2 * \frac{0.40}{2.2} * \frac{M_{M T H F, \text { extraction }}}{\text { Evaporation efficiency }}$

After the evaporation train, the DES is clean and ready to be used again in the pulping step. The DES and wood chips are added to a digester. For the energy calculations we assume that the wood chips enter the digester at room temperature. Both the DES and the chips (with water in them) must be heated to $130{ }^{\circ} \mathrm{C}$ in the digester. This heat can be calculated using the heat capacities of wood, water and DES, according to equation (21).

$Q_{\text {Digester }}=\left(C_{P, \text { wood }} * M_{B, \text { in }}+C_{P, \text { water }} * M_{W, B}\right) *\left(T_{\text {digester }}-T_{\text {room }}\right)$

$+C_{P, D E S} * M_{D E S, \text { pulping }} *\left(T_{\text {digester }}-T_{\text {evaporation,end }}\right)$

Little is known about the heats of reaction in DES delignification. To the best of our knowledge, only one study was performed on the heats of kraft delignification [75]. However, these results cannot be used to make an estimation for DES delignification since the delignification chemistry is completely different. Courchene et al. [75] found that the heat released during kraft pulping indicating an exothermic process, is due to the neutralization of acidic carbohydrate breakdown products with $\mathrm{NaOH}$, a reaction that does not occur in DES delignification. The question whether biomass conversion processes are endothermic or exothermic also plays in other fields, such as pyrolysis. In the pyrolysis process, many endothermic and exothermic reaction zones were observed. Overall, it is believed that pyrolysis of wood is slightly endothermic with a heat of reaction around 0.6 $\mathrm{MJ} / \mathrm{kg}$ [76], although it must also be noted that lignin breakdown reactions are more exothermic than cellulose breakdown reaction [77] (which remain mostly inert during pulping). Furthermore, the fraction of the polymers that reacts in the pulping is much smaller than in pyrolysis. Taken together, it appears justified to neglect the heat that is 


\section{Process development for biomass delignification using deep eutectic solvents. Conceptual design supported by experiments}

produced or required during DES pulping, but further research is necessary to find out whether this assumption is realistic.

At last, the pulp may be dried. For many cellulose applications, such as papermaking or enzymatic hydrolysis for the production of other chemicals, the cellulose is used in an aqueous slurry. When this plant is integrated with the pulping plant, drying of the pulp is unnecessary. In this study the heat of drying is taken into account, since we study a nonintegrated pulp mill. It is assumed that the heat required for pulp drying is the same as in a commercial pulp mill, which is $3 \mathrm{GJ} / \mathrm{t}$ [31]. In short, heat is required for the digester and to evaporate water and 2-MTHF and cooling of the DES is required before LLX. Furthermore, the produced pulp may be dried. Unfortunately, the heats for multi-effect flash evaporation and pulping must be provided at high temperatures $\left(>120^{\circ} \mathrm{C}\right)$ and thus, there are little opportunities for heat integration.

Table 5.3. Energy usage in the conceptual process before and after optimization.

\begin{tabular}{|l|r|r|}
\hline Operation & $\begin{array}{l}\text { Heat before } \\
\text { optimization (GJ/t) }\end{array}$ & \multicolumn{2}{l|}{$\begin{array}{l}\text { Heat after } \\
\text { optimization (GJ/t) }\end{array}$} \\
\hline Digester & 1.7 & 1.3 \\
\hline Water evaporation & 7.6 & 3.2 \\
\hline 2-MTHF evaporation & 1.4 & 0.7 \\
\hline Pulp drying & 3.0 & 3.0 \\
\hline Total & 13.7 & 8.2 \\
\hline
\end{tabular}

\subsection{Process improvement}

The amount of heat required for a non-integrated DES based pulping process was estimated at $13.7 \mathrm{GJ} / \mathrm{t}$ using rigorous calculations. To put this number into perspective; a typical kraft process uses $11.0 \mathrm{GJ} / \mathrm{t}$ in heat. In order to make a DES based pulping process competitive to the kraft, the energy usage should be lower than in the kraft process. Considering that many decades of optimization have taken place in the development of the kraft process, also optimization of the DES-based process should be done, and starting from the values 


\section{Chapter 5}

taken from laboratory observations, a first set of improvements is considered based on a combination of experiments and calculations.

\subsubsection{DES to biomass ratio}

The most obvious parameter to change in the process is the DB ratio. Using less DES will reduce the duty in the digester and require less water and 2-MTHF for extraction. However, a decreased DB ratio will increase the lignin concentration in the DES, which may decrease the delignification rate. Furthermore, there is a minimum DB ratio because biomass itself is a porous structure and biomass in a digester has a packing density. This typically results in a packing density around $230 \mathrm{~kg} / \mathrm{m}^{3}$ for hardwoods [74]. Assuming the density of wood is $1,500 \mathrm{~kg} / \mathrm{m}^{3}$ [74] and the density of the DES applied in this study is $1140 \mathrm{~kg} / \mathrm{m}^{3}$ [69], at least $4.2 \mathrm{~kg}$ DES is required to fill the empty spaces in the wood packing. For convenience, the DB ratio was reduced from $10: 1$ to $5: 1 \mathrm{~kg} / \mathrm{kg}$. It was found that delignification degree decreased from $94.1 \%$ to $87.0 \%$ and the yield increased from $57 \%$ to $59 \%$. Although the delignification degree decreased, it is still well above the fiber liberation point, which is at $80 \%$ delignification [78]. This is schematically shown in fig. 5.3 [78]. The total energy use in the process decreased to $9.3 \mathrm{GJ} / \mathrm{t}$ pulp.

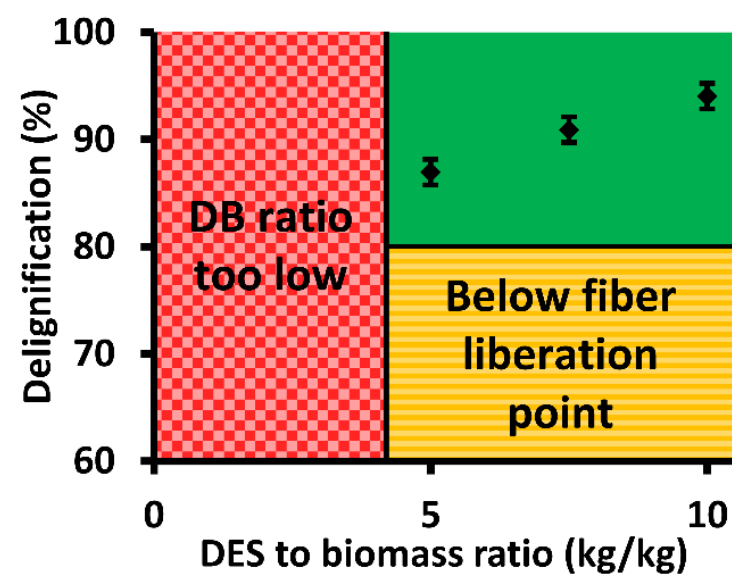

Fig. 5.3. Delignification of eucalyptus as function of the DB ratio. The three experimental delignifications of eucalyptus were obtained by treating the wood $1 \mathrm{~h}$ at $130{ }^{\circ} \mathrm{C}$. The region in which the DB ratio is too low to fill the porous biomass bed with DES is indicated in red blocks and the region below the fiber liberation point is indicated with orange stripes. 


\section{Process development for biomass delignification using deep eutectic solvents.}

Conceptual design supported by experiments

\subsubsection{Water addition}

Reducing the amount of water used in the LLX of lignin from the DES will decrease the energy requirement in the water evaporator. The water content in the DES must be between 25 and $50 \mathrm{wt} \%$ for full lignin recovery [58]. The lignin recoveries in one extraction stage were determined for 6 water contents in the raffinates between 20 and 55 wt\%. It was found that the single stage recovery did not improve much when the water content in the raffinate increased more than $40 \%$.

Water has two functions in the process, it is required for full extraction of the lignin from the DES, and it is required for the washing of the cellulose fibers and lignin. The water that is required for washing the cellulose and lignin is recycled to the extraction stage. When the minimum amounts of washing water are mixed with the DES, the water contents in the raffinate are between $38 \%$ and $43 \%$ for a $B D$ of $1: 10$ and $1: 5$ respectively. These values are shown in Fig. 5.4 as the dashed and dash-dot lines. It can be seen from the figure that the single stage recovery does not increase much further when more water is added than the water that is already present from the recycling of the water washings. Therefore, the amount of water required for the process is limited by the amount required for the washing stages, rather than the lignin recovery. At a DB ratio of 5:1 and $43 \%$ water in the raffinate, the total energy usage of the process drops to $8.2 \mathrm{GJ} / \mathrm{t}$ cellulose pulp. 


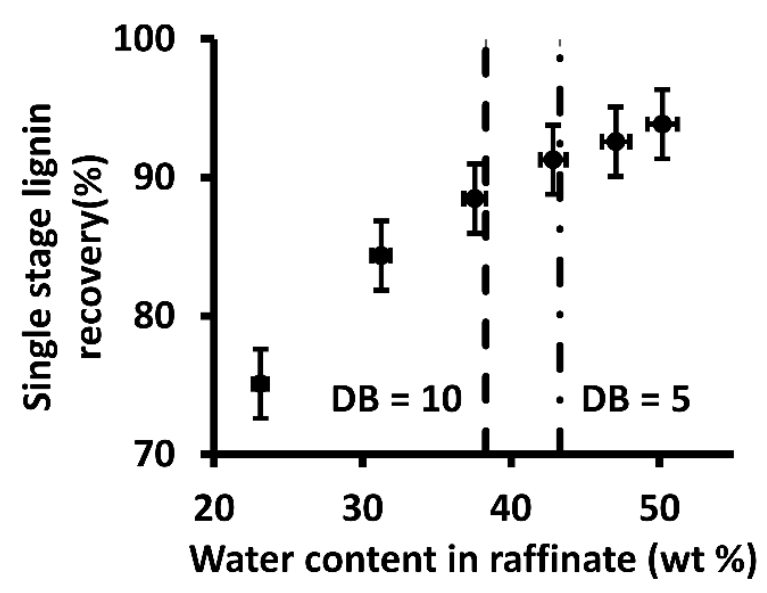

Fig. 5.4. Single stage lignin recovery from DES using 2-MTHF for various amounts of water in the DES raffinate at equilibrium. The water contents in the raffinate that are obtained in the proposed process by mixing the minimum amounts of water (see equation 18) are indicated by dashed lines for two DB ratios. These are the minimum amounts of water that can be reached from a process point of view.

\subsubsection{Recycling of washing DES}

The DES that is currently used for washing is sent directly to the LLX stage, where lignin and HBP are removed from it. The lignin contents in the eluent streams are however lower than the lignin contents in the DES that exits the digester. Thus, the lignin that exits the washing stream may be considered as not fully saturated. Therefore, it may be considered to send the eluent from DES washing with a low lignin content back directly to the pulping stage. If this DES is recycled back directly to the digester, the total energy usage can be further reduced from 8.2 to $7.1 \mathrm{GJ} / \mathrm{t}$. However, when more lignin is present in the digester, this may cause lignin and hemicellulose polymerization reactions, which may inhibit the delignification rate and increase the lignin molar weight. To investigate on the severeness of the repolymerization, delignification experiments were carried out with previously prepared lignin-in-DES mixtures.

From fig. 5.5 it can be seen that the delignification decreases with the initial lignin content. However, the delignification stays above $80 \%$, even when the initial lignin content exceeded 2.5 wt\%. The lignin molar weight distribution in these liquids was also investigated by GPC. First, the lignin molar weight distributions in the previously prepared lignin-in-DES mixture, 


\section{Process development for biomass delignification using deep eutectic solvents.}

Conceptual design supported by experiments

and in the DES that was obtained after the delignification experiment using clean DES were determined. When the lignin-in-DES mixture is used for a consecutive delignification experiment, the lignin that is added to the DES during the delignification experiment is added to the lignin that was already present in the mixture. If we assume that the lignin that was initially present in the lignin-in-DES mixture is inert during the delignification experiment, it would be expected that the lignin obtained by the delignification experiment using the lignin-in-DES mixture is the sum of the lignin in the initial lignin-in-DES mixture and the lignin obtained using the clean DES. We can then expect the molar weight of the lignin obtained from the delignification experiment using the lignin-in-DES mixture to be the weighted average of the lignin in the lignin-in-DES mixture and the lignin obtained by delignification using a clean DES. This expected molar weight distribution was compared to the distribution that was actually obtained in the delignification experiment using a ligninin-DES mixture, as shown in fig. 5.6. In this figure, it can clearly be seen that the obtained molar weight is much higher than the expected molar weight and thus, additional condensation reactions must have taken place with the lignin that was initially present in the mixture. This will not only make it harder to valorize the obtained lignin, but it will also make lignin recovery by LLX much harder. Therefore, recycling of washing DES without lignin recovery is not considered for the conceptual design.

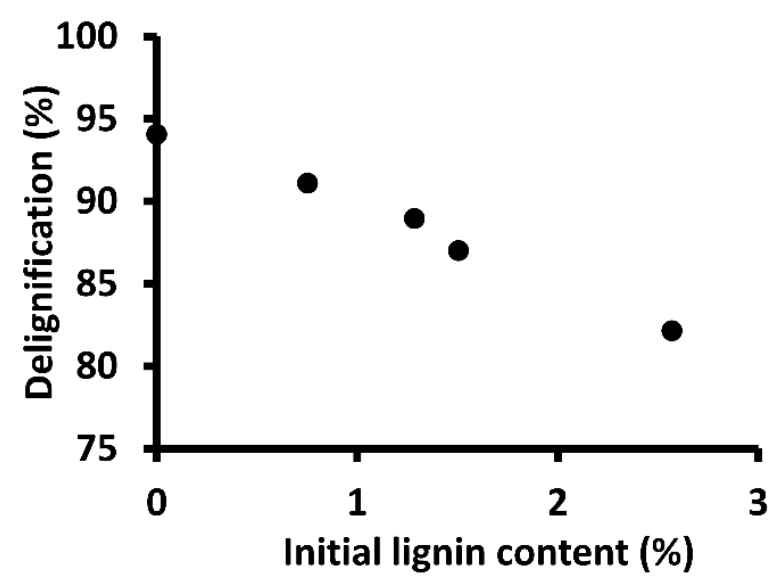

Fig. 5.5. Delignification of eucalyptus as function of the initial lignin content of the DES. Eucalyptus was treated $1 \mathrm{~h}$ at $130^{\circ} \mathrm{C}$. 


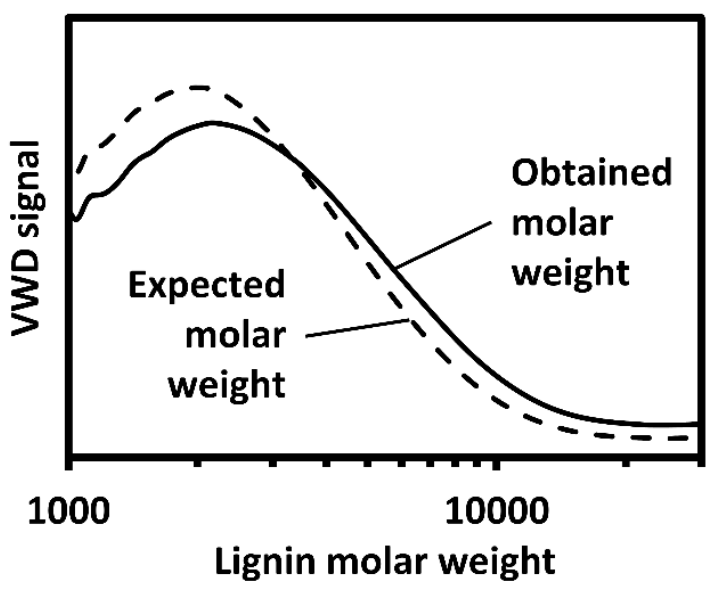

Fig. 5.6. Obtained and expected molar weight distributions for a delignification experiment using a lignin-in-DES mixture. The obtained graph is the GPC spectrum from the trial with $2.6 \mathrm{wt} \%$ initial lignin. The expected molar weight graph is the weighted average of the GPC spectrum of the lignin-in-DES mixture and the GPC spectrum obtained from the delignification experiment using clean DES.

\subsection{Solvent losses}

Lactic acid can form esters with hydroxyl groups in other molecules, just like any other carboxylic acid. This means that lactic acid may also form esters with hydroxy groups in lignin and cellulose. For example, Kajimoto et al [79]. produced cellulose fibers from Sugi pine using lactic acid and found that the produced fibers contained 6 to $9 \%$ lactic acid, which was polymerized to the cellulose fibers. The lactic acid fraction in the lignin and cellulose produced by DES was determined by acid hydrolysis. It was found that the cellulose contained 3.6 wt \% lactic acid, while the lignin contained 6.4 wt \% lactic acid. By mass balance this means a loss of $36 \mathrm{~kg}$ lactic acid in the pulp and $20 \mathrm{~kg}$ in the lignin per t cellulose produced, adding up to a total loss of $56 \mathrm{~kg}$ lactic acid per $\mathrm{t}$ cellulose pulp. Possibly, lactic acid can be removed from cellulose fibers by ozone bleaching [80].

More research is required to determine the losses by solvent degradation during DES processes. Rodriguez et al. [81] researched degradation by esterification between the lactic acid and choline chloride. However, these esterification reactions are equilibrium reactions. This means that the formed degradation product (the ester between lactic acid and choline chloride) reacts back to the initial DES, and especially by operating the pulping stage wet, the presence of water dramatically reduces the esterification of lactic acid. 


\section{Process development for biomass delignification using deep eutectic solvents. Conceptual design supported by experiments}

\section{Outlook}

The energy use in this process is mainly due to the evaporation of water used for washing the cellulose fibers. This means that there is relatively little room for an improvement in energy use by the optimization of pulping and regeneration conditions. Nevertheless, the heat duty of the proposed DES process is around $25 \%$ lower than the kraft process. Washing with other solvents, such as ethanol instead of water may further decrease the energy usage of the process since the heat of evaporation of ethanol is much lower than water. Another possible reduction of the heat duty can be obtained by reducing the evaporation of water, by (at least partially) dewater the DES using a membrane. Further research on this subject is necessary to accurately estimate the technical feasibility of such process and to estimate the possible savings in energy use.

Deep eutectic solvents offer may advantages over other delignification processes. The proposed DES is non-toxic, non-flammable and non-volatile, which means that operations with DES are inherently safe. However, this is not the case for 2-MTHF, which is used in the recovery. Although 2-MTHF a bio-based solvent and its use is justified by the significant energy savings, it is very volatile and flammable. It is desirable to find non-flammable alternatives to 2-MTHF.

It seems that all operations can be performed using readily available technology. Furthermore, no pressurized equipment is required since the proposed DES is non-volatile. This means that the process may have a very low capital expenditure. The biggest opportunity for DES based products is the valorization of by-products. Next to the produced cellulose, lignins may be produced al well. Furthermore, the process may be adjusted to produce valuable furanic products from the hemi-cellulose, such as (hydroxymethyl)furfural $[82,83]$. These chemical may be used as feedstock for chemical industry as a replacement of fossil resources, as schematically shown in fig. 5.7.

In the proposed process, DES losses are significant due to polymerization of lactic acid to lignin and cellulose. This means that the process either has high solvent losses, or expensive post-treatments to recover DES. Furthermore, some 2-MTHF leaches to the DES during LLX. This is evaporated from the DES together with the water and can be separated using a simple settler since 2-MTHF is immiscible with water. However, 2-MTHF and water do have a mutual solubility [85]. A solubility calculation using the data from Glass et al. [85] results in a loss of $456 \mathrm{~kg}$ 2-MTHF per $\mathrm{t}$ cellulose. This amount must also be recovered from the water, for instance by extraction using either a high boiling solvent, such as dodecane, or 


\section{Chapter 5}

solvent impregnated resins. In this case, the 2-MTHF can be recovered from the extractant by flash evaporation, meaning heat of evaporation of 2-MTHF must be added to the total heat duty. This amount is $0.456 * 0.4=0.18 \mathrm{GJ} / \mathrm{t}$ cellulose. Alternatively, membrane separations may be considered for this separation, but more work is required to find out whether a membrane separation is technically feasible. Membrane separations do not require additional heat, but will require some additional electric power [86]. The kraft process is currently favored over other biomass fractionation processes since the cellulose fibers produced by this process have good properties for papermaking. More research is required to see whether DESs can produce a similar fiber quality.

\section{Conclusions}

A conceptual process design was made for the delignification of lignocellulosic biomass using a deep eutectic solvent comprised of lactic acid and choline chloride. Mass and energy balances were made using rigourous calulations. Optimizing the amounts of water and DES used in the process reduced the estimated heat duty from 13.7 to $8.4 \mathrm{GJ} / \mathrm{t}$ cellulose, which is $24 \%$ lower than the kraft process. The amount of DES in the process could be reduced to the amount that is physically required to fill the porous biomass bed. The amount of water required for sufficient lignin recovery by LLX is already achieved when the water used for washing of the cellulose and lignin are recycled to the LLX stage. Recycling of lignin-in-DES mixtures directly back to the delignification stage may save a minor amount of energy, but will increase the molar weight of the lignin, which decreases its potential for valorization and makes recovery by LLX more difficult. Valorization of by-products, such as lignin and furanics from hemi-cellulose is key in DES based delignification processes. 
Process development for biomass delignification using deep eutectic solvents.

Conceptual design supported by experiments

\section{Current industrial situation}

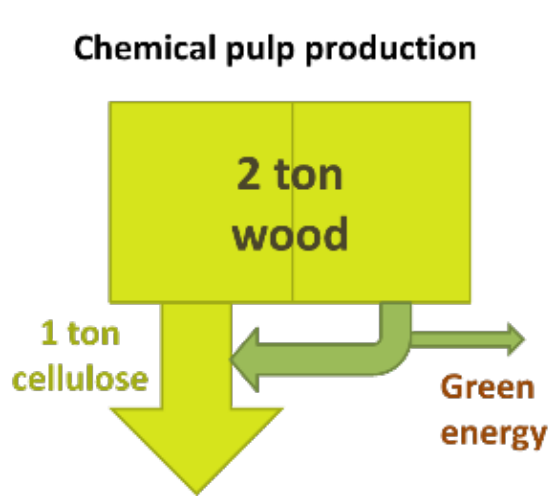

Fossil chemicals production

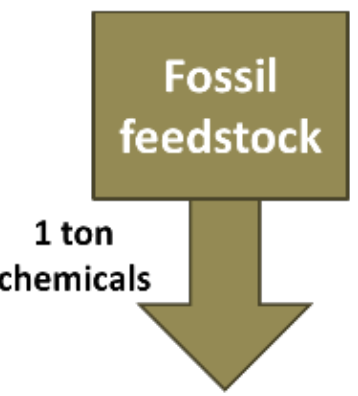

\section{Desired DES pulping processes}

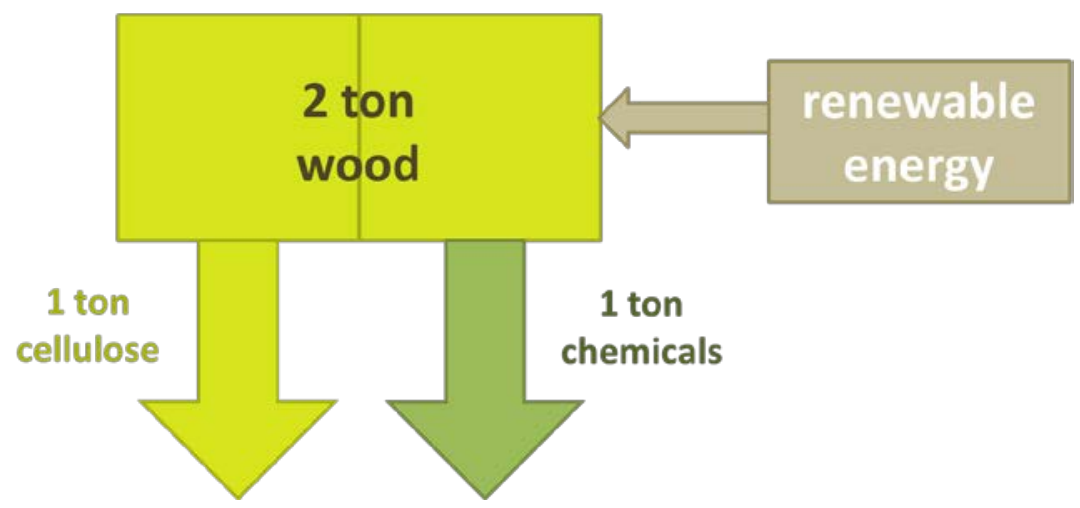

Fig. 5.7. Conceptual comparison of the feedstocks and products in the current industrial situation and the desired DES process. Picture was adapted from the ProviDES final report [84]. 


\section{Bibliography}

[1] B. Schuur, T. Brouwer, D. Smink, L.M.J. Sprakel, Green solvents for sustainable separation processes, Curr. Opin. Green Sustain. Chem. 18 (2019) 57-65. doi:10.1016/j.cogsc.2018.12.009.

[2] E.L. Smith, A.P. Abbott, K.S. Ryder, Deep Eutectic Solvents (DESs) and Their Applications, Chem. Rev. 114 (2014) 11060-11082. doi:10.1021/cr300162p.

[3] M.A.R. Martins, S.P. Pinho, J.A.P. Coutinho, Insights into the Nature of Eutectic and Deep Eutectic Mixtures, J. Solution Chem. 48 (2019) 962-982. doi:10.1007/s10953-018-0793-1.

[4] Q. Zhang, K. De Oliveira Vigier, S. Royer, F. Jérôme, Deep eutectic solvents: syntheses, properties and applications, Chem. Soc. Rev. 41 (2012) 7108-7146. doi:10.1039/C2CS35178A.

[5] A. Paiva, R. Craveiro, I. Aroso, M. Martins, R.L. Reis, A.R.C. Duarte, Natural Deep Eutectic Solvents - Solvents for the 21st Century, ACS Sustain. Chem. Eng. 2 (2014) 1063-1071. doi:10.1021/sc500096j.

[6] M. Francisco, A. van den Bruinhorst, M.C. Kroon, Low-Transition-Temperature Mixtures (LTTMs): A New Generation of Designer Solvents, Angew. Chemie Int. Ed. 52 (2013) 30743085. doi:10.1002/anie.201207548.

[7] F.J. V Gomez, M. Espino, M.A. Fernández, M.F. Silva, A Greener Approach to Prepare Natural Deep Eutectic Solvents, ChemistrySelect. 3 (2018) 6122-6125. doi:10.1002/slct.201800713.

[8] Q. Lu, W. Liu, L. Yang, Y. Zu, B. Zu, M. Zhu, Y. Zhang, X. Zhang, R. Zhang, Z. Sun, J. Huang, X. Zhang, W. Li, Investigation of the effects of different organosolv pulping methods on antioxidant capacity and extraction efficiency of lignin, Food Chem. 131 (2012) 313-317. doi:10.1016/j.foodchem.2011.07.116.

[9] I.P.E. Macário, F. Jesus, J.L. Pereira, S.P.M. Ventura, A.M.M. Gonçalves, J.A.P. Coutinho, F.J.M. Gonçalves, Unraveling the ecotoxicity of deep eutectic solvents using the mixture toxicity theory, Chemosphere. 212 (2018) 890-897.

doi:10.1016/j.chemosphere.2018.08.153.

[10] G. García, S. Aparicio, R. Ullah, M. Atilhan, Deep eutectic solvents: Physicochemical properties and gas separation applications, Energy and Fuels. 29 (2015) 2616-2644. doi:10.1021/ef5028873.

[11] N.R. Mirza, N.J. Nicholas, Y. Wu, K.A. Mumford, S.E. Kentish, G.W. Stevens, Experiments and Thermodynamic Modeling of the Solubility of Carbon Dioxide in Three Different Deep Eutectic Solvents (DESs), J. Chem. Eng. Data. 60 (2015) 3246-3252. doi:10.1021/acs.jced.5b00492.

[12] N. López-Salas, E.O. Jardim, A. Silvestre-Albero, M.C. Gutiérrez, M.L. Ferrer, F. RodríguezReinoso, J. Silvestre-Albero, F. Del Monte, Use of eutectic mixtures for preparation of monolithic carbons with CO2-adsorption and gas-separation capabilities, Langmuir. 30 (2014) 12220-12228. doi:10.1021/la5034146.

[13] L. Moura, T. Moufawad, M. Ferreira, H. Bricout, S. Tilloy, E. Monflier, M.F. Costa Gomes, D. Landy, S. Fourmentin, Deep eutectic solvents as green absorbents of volatile organic pollutants, Environ. Chem. Lett. 15 (2017) 747-753. doi:10.1007/s10311-017-0654-y.

[14] Q. Pan, X. Shang, J. Li, S. Ma, L. Li, L. Sun, Energy-efficient separation process and control scheme for extractive distillation of ethanol-water using deep eutectic solvent, Sep. Purif. Technol. 219 (2019) 113-126. doi:10.1016/j.seppur.2019.03.022.

[15] A. Söldner, J. Zach, B. König, Deep eutectic solvents as extraction media for metal salts and oxides exemplarily shown for phosphates from incinerated sewage sludge ash, Green 


\section{Process development for biomass delignification using deep eutectic solvents. Conceptual design supported by experiments}

Chem. 21 (2019) 321-328. doi:10.1039/c8gc02702a.

[16] F. Lima, J. Gouvenaux, L.C. Branco, A.J.D. Silvestre, I.M. Marrucho, Towards a sulfur clean fuel: Deep extraction of thiophene and dibenzothiophene using polyethylene glycol-based deep eutectic solvents, Fuel. 234 (2018) 414-421. doi:10.1016/j.fuel.2018.07.043.

[17] F. Lima, M. Dave, A.J.D. Silvestre, L.C. Branco, I.M. Marrucho, Concurrent Desulfurization and Denitrogenation of Fuels Using Deep Eutectic Solvents, ACS Sustain. Chem. Eng. 7 (2019) 11341-11349. doi:10.1021/acssuschemeng.9b00877.

[18] D. Smink, A. Juan, B. Schuur, S.R.A. Kersten, Understanding the Role of Choline Chloride in Deep Eutectic Solvents Used for Biomass Delignification, Ind. Eng. Chem. Res. 58 (2019) 16348-16357. doi:10.1021/acs.iecr.9b03588.

[19] D.J.G.P. Van Osch, L.J.B.M. Kollau, A. Van Den Bruinhorst, S. Asikainen, M.A.A. Rocha, M.C. Kroon, lonic liquids and deep eutectic solvents for lignocellulosic biomass fractionation, Phys. Chem. Chem. Phys. 19 (2017) 2636-2665. doi:10.1039/c6cp07499e.

[20] A. Mišan, J. Nađpal, A. Stupar, M. Pojić, A. Mandić, R. Verpoorte, Y.H. Choi, The perspectives of natural deep eutectic solvents in agri-food sector, Crit. Rev. Food Sci. Nutr. (2019) 1-29. doi:10.1080/10408398.2019.1650717.

[21] M. Jablonský, A. Haz, V. Majova, Assessing the opportunities for applying deep eutectic solvents for fractionation of beech wood and wheat straw, Cellulose. 26 (2019) 7675-7684. doi:10.1007/s10570-019-02629-0.

[22] A.A. Rosatella, S.P. Simeonov, R.F.M. Frade, C.A.M. Afonso, 5-Hydroxymethylfurfural (HMF) as a building block platform: Biological properties, synthesis and synthetic applications, Green Chem. 13 (2011) 754-793. doi:10.1039/C0GC00401D.

[23] S.N. Naik, V. V Goud, P.K. Rout, A.K. Dalai, Production of first and second generation biofuels: A comprehensive review, Renew. Sustain. Energy Rev. 14 (2010) 578-597. doi:10.1016/j.rser.2009.10.003.

[24] M. Dusselier, P. Van Wouwe, A. Dewaele, E. Makshina, B.F. Sels, Lactic acid as a platform chemical in the biobased economy: The role of chemocatalysis, Energy Environ. Sci. 6 (2013) 1415-1442. doi:10.1039/C3EE00069A.

[25] R. Rinaldi, R. Jastrzebski, M.T. Clough, J. Ralph, M. Kennema, P.C.A. Bruijnincx, B.M. Weckhuysen, Paving the Way for Lignin Valorisation: Recent Advances in Bioengineering, Biorefining and Catalysis, Angew. Chemie Int. Ed. 55 (2016) 8164-8215. doi:10.1002/anie.201510351.

[26] N.J. Westwood, I. Panovic, C.S. Lancefield, Chemical Modification of Lignin for Renewable Polymers or Chemicals, in: Z. Fang, J. Smith Richard L. (Eds.), Prod. Biofuels Chem. from Lignin, Springer, Singapore, 2016: pp. 183-216. doi:10.1007/978-981-10-1965-4_7.

[27] X.-D. Hou, K.-P. Lin, A.-L. Li, L.-M. Yang, M.-H. Fu, Effect of constituents molar ratios of deep eutectic solvents on rice straw fractionation efficiency and the micro-mechanism investigation, Ind. Crops Prod. 120 (2018) 322-329. doi:10.1016/j.indcrop.2018.04.076.

[28] A.L. Li, X.D. Hou, K.P. Lin, X. Zhang, M.H. Fu, Rice straw pretreatment using deep eutectic solvents with different constituents molar ratios: Biomass fractionation, polysaccharides enzymatic digestion and solvent reuse, J. Biosci. Bioeng. 126 (2018) 346-354.

doi:10.1016/j.jbiosc.2018.03.011.

[29] $H$. Chen, 3 - Lignocellulose biorefinery feedstock engineering, in: H. Chen (Ed.), Lignocellul. Biorefinery Eng. Princ. Appl., Woodhead Publishing, Sawston, Cambridge, 2015: pp. 37-86. doi:10.1016/B978-0-08-100135-6.00003-X.

[30] A.W. Rudie, P.W. Hart, Catalysis-a potential alternative to kraft pulping, Tappi J. 13 (2014) 13-20.

[31] M. Suhr, G. Klein, I. Kourti, S.R. Miguel Rodrigo Gonzalo, Germán Giner Santonja, L.D. 


\section{Chapter 5}

Sancho, Best Available Techniques (BAT) Reference Document for the Production of Pulp, Paper and Board, European IPPC Bureau, Seville, Spain, 2015.

[32] R. Wahlström, J. Hiltunen, M. Pitaluga De Souza Nascente Sirkka, S. Vuoti, K. Kruus, Comparison of three deep eutectic solvents and 1-ethyl-3-methylimidazolium acetate in the pretreatment of lignocellulose: Effect on enzyme stability, lignocellulose digestibility and one-pot hydrolysis, RSC Adv. 6 (2016) 68100-68110. doi:10.1039/c6ra11719h.

[33] T. Schäfer, M. Eisenlauer, U. Teipel, Extraction of Spruce Lignin with a Deep Eutectic Solvent in Dependence of the Particle Size , Chemie-Ingenieur-Technik. 90 (2018) 507-512. doi:10.1002/cite.201700104.

[34] C. Alvarez-Vasco, R. Ma, M. Quintero, M. Guo, S. Geleynse, K.K. Ramasamy, M. Wolcott, X. Zhang, Unique low-molecular-weight lignin with high purity extracted from wood by deep eutectic solvents (DES): a source of lignin for valorization., Green Chem. 18 (2016) 51335141. doi:10.1039/c6gc01007e.

[35] P. Li, Q. Zhang, X. Zhang, X. Zhang, X. Pan, F. Xu, Subcellular dissolution of xylan and lignin for enhancing enzymatic hydrolysis of microwave assisted deep eutectic solvent pretreated Pinus bungeana Zucc, Bioresour. Technol. 288 (2019) 121475. doi:10.1016/j.biortech.2019.121475.

[36] P.D. Muley, J.K. Mobley, X. Tong, B. Novak, J. Stevens, D. Moldovan, J. Shi, D. Boldor, Rapid microwave-assisted biomass delignification and lignin depolymerization in deep eutectic solvents, Energy Convers. Manag. 196 (2019) 1080-1088. doi:10.1016/j.enconman.2019.06.070.

[37] J.L.K. Mamilla, U. Novak, M. Grilc, B. Likozar, Natural deep eutectic solvents (DES) for fractionation of waste lignocellulosic biomass and its cascade conversion to value-added bio-based chemicals, Biomass and Bioenergy. 120 (2019) 417-425. doi:10.1016/j.biombioe.2018.12.002.

[38] L. Li, L. Yu, Z. Wu, Y. Hu, Delignification of poplar wood with lactic acid-based deep eutectic solvents, Wood Res. 64 (2019) 499-514. https://www.scopus.com/inward/record.uri?eid=2-s2.085071913520\&partnerID $=40 \& m d 5=6 e e 4 f 14656$ e842d00dab11550585159e.

[39] D. Tian, R.P. Chandra, J.-S. Lee, C. Lu, J.N. Saddler, A comparison of various lignin-extraction methods to enhance the accessibility and ease of enzymatic hydrolysis of the cellulosic component of steam-pretreated poplar, Biotechnol. Biofuels. 10 (2017) 157. doi:10.1186/s13068-017-0846-5.

[40] D. Tian, Y. Guo, J. Hu, G. Yang, J. Zhang, L. Luo, Y. Xiao, S. Deng, O. Deng, W. Zhou, F. Shen, Acidic deep eutectic solvents pretreatment for selective lignocellulosic biomass fractionation with enhanced cellulose reactivity, Int. J. Biol. Macromol. 142 (2019) 288-297. doi:10.1016/j.ijbiomac.2019.09.100.

[41] X. Liang, Y. Fu, J. Chang, Effective separation, recovery and recycling of deep eutectic solvent after biomass fractionation with membrane-based methodology, Sep. Purif. Technol. 210 (2019) 409-416. doi:10.1016/j.seppur.2018.08.021.

[42] X.-J. Shen, J.-L. Wen, Q.-Q. Mei, X. Chen, D. Sun, T.-Q. Yuan, R.-C. Sun, Facile fractionation of lignocelluloses by biomass-derived deep eutectic solvent (DES) pretreatment for cellulose enzymatic hydrolysis and lignin valorization, Green Chem. 21 (2019) 275-283. doi:10.1039/c8gc03064b.

[43] J. Chang, J. Liu, S.J. Guo, X.F.Y. Wang, Investigation into selective separation of lignin in novel deep eutectic solvent, J. South China Univ. Technol. 44 (2016) 14-20. doi:10.3969/j.issn.1000-565X.2016.06.003.

[44] Y. Song, R.P. Chandra, X. Zhang, T. Tan, J.N. Saddler, Comparing a deep eutectic solvent (DES) to a hydrotrope for their ability to enhance the fractionation and enzymatic hydrolysis 


\section{Process development for biomass delignification using deep eutectic solvents. Conceptual design supported by experiments}

of willow and corn stover, Sustain. Energy Fuels. 3 (2019) 1329-1337. doi:10.1039/c8se00617b.

[45] T. Li, G. Lyu, Y. Liu, R. Lou, L.A. Lucia, G. Yang, J. Chen, H.A.M. Saeed, Deep eutectic solvents (DESs) for the isolation of willow lignin (salix matsudana cv. zhuliu), Int. J. Mol. Sci. 18 (2017) 2266. doi:10.3390/ijms18112266.

[46] Z. Guo, Q. Zhang, T. You, Z. Ji, X. Zhang, Y. Qin, F. Xu, Heteropoly acids enhanced neutral deep eutectic solvent pretreatment for enzymatic hydrolysis and ethanol fermentation of Miscanthus x giganteus under mild conditions, Bioresour. Technol. 293 (2019) 122036. doi:10.1016/j.biortech.2019.122036.

[47] Z. Zhao, X. Chen, M.F. Ali, A.A. Abdeltawab, S.M. Yakout, G. Yu, Pretreatment of wheat straw using basic ethanolamine-based deep eutectic solvents for improving enzymatic hydrolysis, Bioresour. Technol. 263 (2018) 325-333. doi:10.1016/j.biortech.2018.05.016.

[48] M. Jablonský, A. Škulcová, L. Kamenská, M. Vrška, J. Šíma, Deep Eutectic Solvents: Fractionation of Wheat Straw, BioResources. 10 (2015) 8039-8047. doi:10.15376/biores.10.4.8039-8047.

[49] P. Domínguez de María, Recent trends in (ligno)cellulose dissolution using neoteric solvents: Switchable, distillable and bio-based ionic liquids, J. Chem. Technol. Biotechnol. 89 (2014) 11-18. doi:10.1002/jctb.4201.

[50] X.-D. Hou, A.-L. Li, K.-P. Lin, Y.-Y. Wang, Z.-Y. Kuang, S.-L. Cao, Insight into the structurefunction relationships of deep eutectic solvents during rice straw pretreatment, Bioresour. Technol. 249 (2018) 261-267. doi:10.1016/j.biortech.2017.10.019.

[51] W.-L. Lim, A.A.N. Gunny, F.H. Kasim, I.M. AlNashef, D. Arbain, Alkaline deep eutectic solvent: a novel green solvent for lignocellulose pulping, Cellulose. 26 (2019) 4085-4098. doi:10.1007/s10570-019-02346-8.

[52] A.K. Kumar, B.S. Parikh, M. Pravakar, Natural deep eutectic solvent mediated pretreatment of rice straw: bioanalytical characterization of lignin extract and enzymatic hydrolysis of pretreated biomass residue., Environ. Sci. Pollut. Res. 23 (2016) 9265-9275. doi:10.1007/s11356-015-4780-4.

[53] Z. Guo, Q. Zhang, T. You, X. Zhang, F. Xu, Y. Wu, Short-time deep eutectic solvent pretreatment for enhanced enzymatic saccharification and lignin valorization, Green Chem. 21 (2019) 3099-3108. doi:10.1039/c9gc00704k.

[54] C.W. Zhang, S.Q. Xia, P.S. Ma, Facile pretreatment of lignocellulosic biomass using deep eutectic solvents, Bioresour. Technol. 219 (2016) 1-5. doi:10.1016/j.biortech.2016.07.026.

[55] A. Procentese, E. Johnson, V. Orr, A. Garruto Campanile, J.A. Wood, A. Marzocchella, L. Rehmann, Deep eutectic solvent pretreatment and subsequent saccharification of corncob, Bioresour. Technol. 192 (2015) 31-36. doi:10.1016/j.biortech.2015.05.053.

[56] F. Xu, J. Sun, M. Wehrs, K.H. Kim, S.S. Rau, A.M. Chan, B.A. Simmons, A. Mukhopadhyay, S. Singh, Biocompatible Choline-Based Deep Eutectic Solvents Enable One-Pot Production of Cellulosic Ethanol, ACS Sustain. Chem. Eng. 6 (2018) 8914-8919. doi:10.1021/acssuschemeng.8b01271.

[57] G. Lyu, T. Li, X. Ji, G. Yang, Y. Liu, L.A. Lucia, J. Chen, Characterization of lignin extracted from willow by deep eutectic solvent treatments, Polymers (Basel). 10 (2018) 869. doi:10.3390/polym10080869.

[58] D. Smink, S.R.A. Kersten, B. Schuur, Recovery of lignin from deep eutectic solvents by liquidliquid extraction, Sep. Purif. Technol. 235 (2020) 116127. doi:10.1016/j.seppur.2019.116127.

[59] J.M. Douglas, Conceptual Design of Chemical Processes, McGraw-Hill, New York, 1988.

[60] G.J. Harmsen, Industrial best practices of conceptual process design, Chem. Eng. Process. 


\section{Chapter 5}

Process Intensif. 43 (2004) 671-675. doi:10.1016/j.cep.2003.02.003.

[61] A. Sluiter, B. Hames, R. Ruiz, C. Scarlata, J. Sluiter, D. Templeton, D. Crocker, Determination of Structural Carbohydrates and Lignin in Biomass, NREL/TP; 510-42618. Golden, CO, 2012.

[62] A. Sluiter, B. Hames, R. Ruiz, C. Scarlata, J. Sluiter, D. Templeton, Determination of ash in biomass, laboratory analytical procedure (LAP), Golden, CO, 2008.

[63] J.R. Dillen, S. Dillén, M.F. Hamza, Pulp and Paper: Wood Sources, in: Ref. Modul. Mater. Sci. Mater. Eng., Elsevier, 2016. doi:10.1016/B978-0-12-803581-8.09802-7.

[64] S.R.G. Oudenhoven, A.G.J. van der Ham, H. van den Berg, R.J.M. Westerhof, S.R.A. Kersten, Using pyrolytic acid leaching as a pretreatment step in a biomass fast pyrolysis plant: Process design and economic evaluation, Biomass and Bioenergy. 95 (2016) 388-404. doi:10.1016/j.biombioe.2016.07.003.

[65] S.R.G. Oudenhoven, R.J.M. Westerhof, S.R.A. Kersten, Fast pyrolysis of organic acid leached wood, straw, hay and bagasse: Improved oil and sugar yields, J. Anal. Appl. Pyrolysis. 116 (2015) 253-262. doi:10.1016/j.jaap.2015.09.003.

[66] I.P. Mikheenko, J. Gomez-Bolivar, M.L. Merroun, L.E. Macaskie, S. Sharma, M. Walker, R.A. Hand, B.M. Grail, D.B. Johnson, R.L. Orozco, Upconversion of Cellulosic Waste Into a Potential "Drop in Fuel" via Novel Catalyst Generated Using Desulfovibrio desulfuricans and a Consortium of Acidophilic Sulfidogens, Front. Microbiol. 10 (2019) 970. doi:10.3389/fmicb.2019.00970.

[67] S. Dutta, S. De, B. Saha, M.I. Alam, Advances in conversion of hemicellulosic biomass to furfural and upgrading to biofuels, Catal. Sci. Technol. 2 (2012) 2025-2036. doi:10.1039/C2CY20235B.

[68] H.E. Hoydonckx, W.M. Van Rhijn, W. Van Rhijn, D.E. De Vos, P.A. Jacobs, Furfural and Derivatives, in: Ullmann's Encycl. Ind. Chem., Wiley, Weinheim, 2007. doi:10.1002/14356007.a12_119.pub2.

[69] M. Francisco, A. van den Bruinhorst, L.F. Zubeir, C.J. Peters, M.C. Kroon, A new low transition temperature mixture (LTTM) formed by choline chloride+lactic acid: Characterization as solvent for CO2 capture, Fluid Phase Equilib. 340 (2013) 77-84. doi:10.1016/j.fluid.2012.12.001.

[70] CEPI, Key Statistics, European pulp and paper industry, Confederation of European Paper Industries, Brussels, 2018.

[71] D. Smink, S.R.A. Kersten, B. Schuur, Comparing multistage liquid-liquid extraction with cold water precipitation for improvement of lignin recovery from deep eutectic solvents, Submitt. Publ. (2020).

[72] M. Ek, G. Gellerstedt, G. Henriksson, Wood chemistry and wood biotechnology, De Gruyter, Berlin, 2009. doi:10.1515/9783110213409.

[73] H.E. Bown, J.-P. Lasserre, An air-drying model for piled logs of Eucalyptus globulus and Eucalyptus nitens in Chile, New Zeal. J. For. Sci. 45 (2015) 1-9. doi:10.1186/s40490-0150047-6.

[74] M. Ek, G. Gellerstedt, G. Henriksson, Pulping Chemistry and Technology, De Gruyter, Berlin, 2009. doi:10.1515/9783110213423.

[75] C. Courchene, T. McDonough, P. Hart, E. Malcom, B. Carter, Determining The Heat Of Reaction Of Kraft Pulping, Tappi J. 4 (2005) 9-13.

[76] S. Sinha, A. Jhalani, R. M R, A. Ray, Modeling of pyrolysis in wood: A review, J. Sol. Energy Soc. India. 10 (2000) 41-62.

[77] A.F. Roberts, The heat of reaction during the pyrolysis of wood, Combust. Flame. 17 (1971) 79-86. doi:10.1016/S0010-2180(71)80141-4.

[78] E. Brännvall, The Limits of Delignification in Kraft Cooking, BioResources. 12 (2017) 20812107. doi:10.15376/biores.12.1.2081-2107. 


\section{Process development for biomass delignification using deep eutectic solvents.}

Conceptual design supported by experiments

[79] T. Kajimoto, Y. Tachibana, Y. Maeda, S. Kubota, T. Hata, Y. Imamura, Characterization of the Pulp-Like Fibers Separated from Sugi with L-Lactic Acid, Mokuzai Gakkaishi. 54 (2008) 319326. doi:10.2488/jwrs.54.319.

[80] N. Neumann, K. Balser, Acetocell - an innovative process for pulping, totally free from sulfur and chlorine., Das Pap. 47 (1993) 16-24.

[81] N. Rodriguez Rodriguez, A. van den Bruinhorst, L.J.B.M. Kollau, M.C. Kroon, K. Binnemans, Degradation of Deep-Eutectic Solvents Based on Choline Chloride and Carboxylic Acids, ACS Sustain. Chem. Eng. 7 (2019) 11521-11528. doi:10.1021/acssuschemeng.9b01378.

[82] S. Hu, Z. Zhang, Y. Zhou, B. Han, H. Fan, W. Li, J. Song, Y. Xie, Conversion of fructose to 5hydroxymethylfurfural using ionic liquids prepared from renewable materials, Green Chem. 10 (2008) 1280-1283. doi:10.1039/b810392e.

[83] L.-X. Zhang, H. Yu, H.-B. Yu, Z. Chen, L. Yang, Conversion of xylose and xylan into furfural in biorenewable choline chloride-oxalic acid deep eutectic solvent with the addition of metal chloride, Chinese Chem. Lett. 25 (2014) 1132-1136. doi:10.1016/j.cclet.2014.03.029.

[84] ProviDES Final report, Deep Eutectic Solvents in the paper industry, Institute for Sustainable Process Technology, Amersfoort, 2018. www.providespaper.eu.

[85] M. Glass, M. Aigner, J. Viell, A. Jupke, A. Mitsos, Liquid-liquid equilibrium of 2methyltetrahydrofuran/water over wide temperature range: Measurements and rigorous regression, Fluid Phase Equilib. 433 (2016) 212-225. doi:10.1016/j.fluid.2016.11.004.

[86] W. Kujawski, Pervaporative Removal of Organics from Water Using Hydrophobic Membranes. Binary Mixtures, Sep. Sci. Technol. 35 (2000) 89-108. doi:10.1081/SS100100145. 


\section{Chapter 6}

Conclusions and outlook 
This thesis describes research and design for a conceptual process for the delignification of biomass using a deep eutectic solvent (DES) comprised of choline chloride and lactic acid. In chapter 2, the delignification mechanism of the DES was studied. Although it was clear that the lignin is cleaved by an acid hydrolysis mechanism, the influence of choline chloride on delignification was unclear. The influence of choline chloride on the lignin solubility, cleaving reactions and mass transfer were investigated and it was found that the choline anion increased the lignin cleavage reaction rate and thereby the delignification rate. These findings are a spur for further solvent development or optimization for biomass delignification. Since the chloride anion is the active part of choline chloride, other salts such as sodium chloride may be used for delignification processes just as well, but choline chloride offers great advantages in the DES recovery. This was studied in chapter $\mathbf{3}$, where an alternative lignin recovery method to cold water precipitation was proposed, involving liquid-liquid extraction using an organic solvent. Six solvents were screened for this purpose and 2-methyltetrahydrofuran (2-MTHF) was selected as the most suitable one. It was found that choline chloride is required for two phase formation. At equilibrium, at least $30 \%$ choline chloride must be present in the DES to form two phases and addition of more choline chloride reduces the mutual solubility of 2-MTHF and lactic acid. It is expected that this method saves significant amounts of heat compared to the current benchmark. In chapter 4, the recovery of lignin from DES using LLX was further studied and compared with cold water precipitation. It was found that LLX was more suitable for the removal of lignin fractions with a low molar weight, while cold water precipitation was more suitable for the recovery of lignin fractions with a high molar weight. For industrial applications, a combination of both approaches is desired. Also, the lignin composition was investigated of the various fractions that were extracted by $2-\mathrm{MTHF}$ and fractions that remained in the DES and it was found that the fractions remaining in de DES had a highly condensed nature. In chapter 5, all previous findings were combined to design an conceptual process for the delignification of eucalyptus globulus using a DES comprised of choline chloride and lactic acid. Mass and energy balances were made and the heat consumption of the process was optimized using additional experiments. It was found that the DES to biomass ratio could be reduced to 5 , the minimum required to fill the porous structure of the wood. After the optimization, the predicted final process used $8.4 \mathrm{GJ}$ heat per ton pulp produced, which is a $24 \%$ reduction compared to the Kraft process. A further reduction to $7.1 \mathrm{GJ} / \mathrm{t}$ is possible if lignin-in-DES mixtures from the washing plant are recycled back to the delignification stage without any purification. This is not considered, since it increases the molar weight of the produced lignin, which makes recovery more difficult and decreases the value of the produced lignin. Furthermore, the DES based process offers great opportunities for the valorization of byproducts, such as lignin or furans from hemicellulose. 


\section{Chapter 6}

This thesis provided initial studies on a conceptual design for the delignification of eucalyptus using a mixture of choline chloride and lactic acid. The results from these studies were highly encouraging and show great potential for industrial application. However, a couple of issues need to be addressed before industrial implementation of this process. The quality of the produced cellulose fibers was not addressed in this thesis. It is key to produce cellulose that is suitable for papermaking, since the value of cellulose for papermaking is much higher than cellulose for other purposes, such as fermentation to bio-ethanol. Furthermore, lactic acid formed esters with the hydroxyl groups present in the cellulose and lignin, which will cause signification solvent losses. Also, the studied DES seems corrosive to metals, as some corrosion was observed on the metal laboratory equipment. However, since the entire process is operated at atmospheric pressure and at relatively mild temperature, it seems viable to investigate alternative construction materials, such as high performance plastics.

In this thesis, only one DES was studied, which used acetic hydrolysis reactions, catalyzed by a halide salt, to cleave the lignin. However, there are more types of DES and therewith more mechanisms in which biomass can be delignified, such as hydrolysis using alkaline DESs. Also, DESs can be used as solvents for various catalysts, such as metallic catalysts, which may also improve delignification. More research is also required on the role of the halide ion, which was used in these studies. Although it is clear that it increases the delignification rate, the effects on carbohydrate degradation are not known yet. Since both lignin cleavage and carbohydrate breakdown are important for the quality of the cellulose pulp, further studies must be conducted to see whether the addition of chloride increases the selectivity of delignification over carbohydrate breakdown.

Although only one DES was studied in this thesis, one great advantage of a DES is its tunable character. The constituents of a DES can be altered, just as the ratio between the constituents. For instance, a 1:250 molar ratio of choline chloride to lactic acid was already effective for biomass delignification, while at least $30 \%$ is required at equilibrium to form a two phase system with 2-MTHF, allowing efficient lignin recovery. This character contributed to the huge popularity of DES, but has one drawback. A proliferation of mixtures that are entitled as DES, will hollow the value of the term DES.

The proposed DES process has a great potential to produced byproducts from cellulose production, which may be used as feedstocks for the chemical industry as replacements for fossil feedstocks. However, it must be pointed out that the pulp industry only produces $272 \mathrm{Mt}$ of byproducts per year, whereas the total fossil material feedstock for the chemical industry is $760 \mathrm{Mt} / \mathrm{y}$. This means that a 


\section{Conclusions and outlook}

significant part of the material demands can be replaced by byproducts from the pulp and paper industry, but other sustainable resources are required as well to fully replace fossil resources. 


\section{List of abbreviations}

\begin{tabular}{|c|c|}
\hline Abbreviation & Description \\
\hline 2-MTHF & 2-methyl tetrahydrofuran \\
\hline $\mathrm{BHT}$ & Butylated hydroxytoluene \\
\hline $\mathrm{ChCl}$ & Choline Chloride \\
\hline CPME & Cyclopentyl methyl ether \\
\hline DB & DES to biomass ratio \\
\hline DES & Deep Eutectic Solvent \\
\hline DSC & Differential Scanning Calorimetry \\
\hline FT-IR & Fourier-transform Infrared Spectroscopy \\
\hline GPC & Gel Permeation Chromatography \\
\hline GVL & Y-valerolactone \\
\hline HBP & Hemicellulose byproduct \\
\hline HPLC & High Pressure Liquid Chromatography \\
\hline HSQC & Heteronuclear single quantum coherence spectroscopy \\
\hline LA & Lactic Acid \\
\hline$I_{B}$ & Lignin fraction in biomass \\
\hline LCC & Lignin Carbohydrate Complexes \\
\hline LLX & Liquid-liquid extraction \\
\hline$M_{P, \text { out }}$ & Total cellulose production \\
\hline MWL & Milled Wood Lignin \\
\hline SEM & Scanning electron microscopy \\
\hline SF & Solvent to feed ratio \\
\hline VWD & Variable Wave Detector \\
\hline WFL & Washing factor lignin \\
\hline WFp & Washing factor pulp \\
\hline $\mathrm{X}_{\mathrm{DES}, \mathrm{MTHF}}$ & Solubility of DES in 2-MTHF \\
\hline XMTHF,DESrecycle & Solubility of 2-MTHF in DES \\
\hline $\mathrm{XW}, \mathrm{B}$ & Water fraction in biomass \\
\hline $\mathrm{XW}, \mathrm{DES}$ recycle & Water fraction in DES after LLX \\
\hline$X_{W, P}$ & Water fraction in pulp \\
\hline $\mathrm{YL}$ & Lignin removal from biomass \\
\hline$y_{p}$ & Solid yield after delignification \\
\hline
\end{tabular}




\section{Publications}

Boelo Schuur, Thomas Brouwer, Dion Smink, Lisette M.J. Sprakel, Green solvents for sustainable separation processes, Current Opinion in Green and Sustainable Chemistry, 18, 2019, DOI: 10.1016/j.cogsc.2018.12.009

Dion Smink, Alberto Juan, Sascha R.A. Kersten, Boelo Schuur, Understanding the Role of Choline Chloride in Deep Eutectic Solvents Used for Biomass Delignification, Industrial and Engineering Chemistry Research, 58 (36), 2019, DOI: 1021/acs.iecr.9b03588

Dion Smink, Sascha R.A. Kersten, Boelo Schuur, Recovery of lignin from deep eutectic solvents by liquid-liquid extraction, Separation and Purification Technology, 235, 2020, 116127, DOI: 10.1016/j.seppur.2019.116127.

Dion Smink, Sascha R.A. Kersten, Boelo Schuur, Comparing multistage liquid-liquid extraction with cold water precipitation for improvement of lignin recovery from deep eutectic solvents, submitted for publication

Dion Smink, Sascha R.A. Kersten, Boelo Schuur, Process development for biomass delignification using deep eutectic solvents. Conceptual design supported by experiments, submitted for publication

\section{Conference presentations}

Biomass fractionation processes with deep eutectic solvents, NPS15, Enschede, 31 May 2018

Insights in Biomass Fractionation with Deep Eutectic Solvents, EWLP 2018, Aveiro, 29 June 2018

Pulping with deep eutectic solvents. Solvent regeneration methods for industrial application, Paper and Beyond 2018, Brussels, 16 October 2018

Recovery of lignin from deep eutectic solvents by liquid-liquid extraction, IL-SEPT, Sitges, 11 September 2019 


\section{Acknowledgements}

First of all, I would like to thank my promotor, Boelo, for giving me the opportunity to perform my research at SPT. I really liked to work with you for your enthusiasm, kindness and your many innovative ideas. I would also like to thank my second promotor, Sascha. I appreciated your comprehensive knowledge and the many discussions we've had.

I also want to thank my other committee members for their time and efforts to read and judge my thesis, prof. dr. ir. E. Zondervan, prof. dr. ir. W. de Jong, prof. dr. ir. J. Huskens and prof. dr. H.J.M. Bouwmeester. In particular, I would like to thank prof. dr. A.J.D. Silvestre. Armando, I liked the many discussions with you and your work in the ProviDES project. Also, I would like to thank you for showing me around in Aveiro during EWLP 2018.

I would like to thank the many people and organizations involved in the ProviDES project, not only for their financial and in-kind contributions, but also for the fruitful discussions and help with analysis. There have been too many people and organizations involved to mention all of them, but I would like to mention a couple. Annita and Agata, thanks for taking the lead in this project and thanks for your great involvement. I would like to thank Heiner Grussenmeyer and Math Jennekens for their commitment to the project and hope that both of you will enjoy your retirement. Kari and Matti, thank you for showing me around in your factories in Lappeenranta and Frans thank you for showing me around at the Parenco factory. Furthermore, I would like to thank Stora Enso, Sappi and The Navigator Company for their help in analysis, fruitful discussions and supply of raw materials.

I would also like to thank all the people I worked together with in SPT. First of all thanks to the supporting staff. Benno, Erna, Johan, Karst and Ronald, my work would not have been possible without your help with the experiments and analysis. Yvonne, thank your for your support and helping me though the horror finita system. Furthermore, I would like to thank my colleague PhD and PDEng students and post-docs. Angelo, thanks for all the chocolate from Switzerland. Lionel and Vincent, thanks for being my paranymph. Lisette, thanks for the many cakes and cookies you baked, I've had way too many. Marek, thanks for being a great supervisor during my MSc assignment and bringing lots of Tatratea. Pushkar, thanks for inviting me to your wedding in India. I really enjoyed the trip. I also appreciate the many discussions on lignin, your help with the GPC and your help in the application of your model in chapter 2. Thomas, I liked our trip to Sitges, it was a great time. Stijn, thanks for your help at the start of my PhD project. Urmi, you are a very kind person and I liked our trip to Brussels. Also thanks to Alan, Cindy, Chiel, Daan, Enas, Ehsan, Evelyn, Juraj, Rick, Maria, Martin, Martijn, Mahsa, Michel, Muthia, Natalia, Özge, Qian, Sandra, Sam, Stevia, Tim, 
Tomas, Shahab, Surika, Tim, Xiaohua, Yordi and Varsha. Thanks to you there was never a quiet day in the office. Roel, I liked to discuss your alternative views on the world and our shared support for De Graafschap. At last, I also want to thank all other professors in our group. Louis, thank you for great involvement in education and your advices on process design. Jean-Paul, thanks for the fruitful discussions about the work in chapter 2. I also want to thank Henk, Pilar, Tony, Wim and Wim for their contributions to the group.

I also want to thank the students I worked with. Kuno, your work was a solid basis for the work in chapter 3. Jonne, your work gave great insights in the stability of sugars in DES. Maarten and Shannon, you did great work on the often complicated analytical methods. Bas, your work gave good insights in the role of particle size on delignification. Ross, thanks for your work on in-situ lignin removal and thanks for one of the best goodbye parties in a long time.

Furthermore, I would like to thank the people in D.R.V. Hippocampus. I've had a great time during (and after) the lessons and enjoyed the many other activities. In particular, I would like thank Gijs, Friso, Marjolijn and Vera. Thanks to you I've had a great time in the board of 2017-2018.

I can't go without mentioning the great time I've had with the 'Jochies'. David, Dennis, Edo, Finn, Han, Jan-Niklas, Lionel, Raoul, and Rolf, thanks for all great nights at the 'TBS', the Tuesdays at the Vestingbar, the many games and other activities and of course our great trip to Argentina. You've all been great friends.

At last, I want to thank my family. Theo, Sandra and Carmen, thanks for your support throughout my life.

Of course, I can't go without thanking the love of my life. Vahideh, I've been loving you from the moment we met. Thanks for all your love and support, especially in the last few months of my PhD. 